\title{
Jarmo Piirainen
}

Neuromuscular Function and

Balance Control in Young and

Elderly Subjects

Effects of Explosive Strength Training

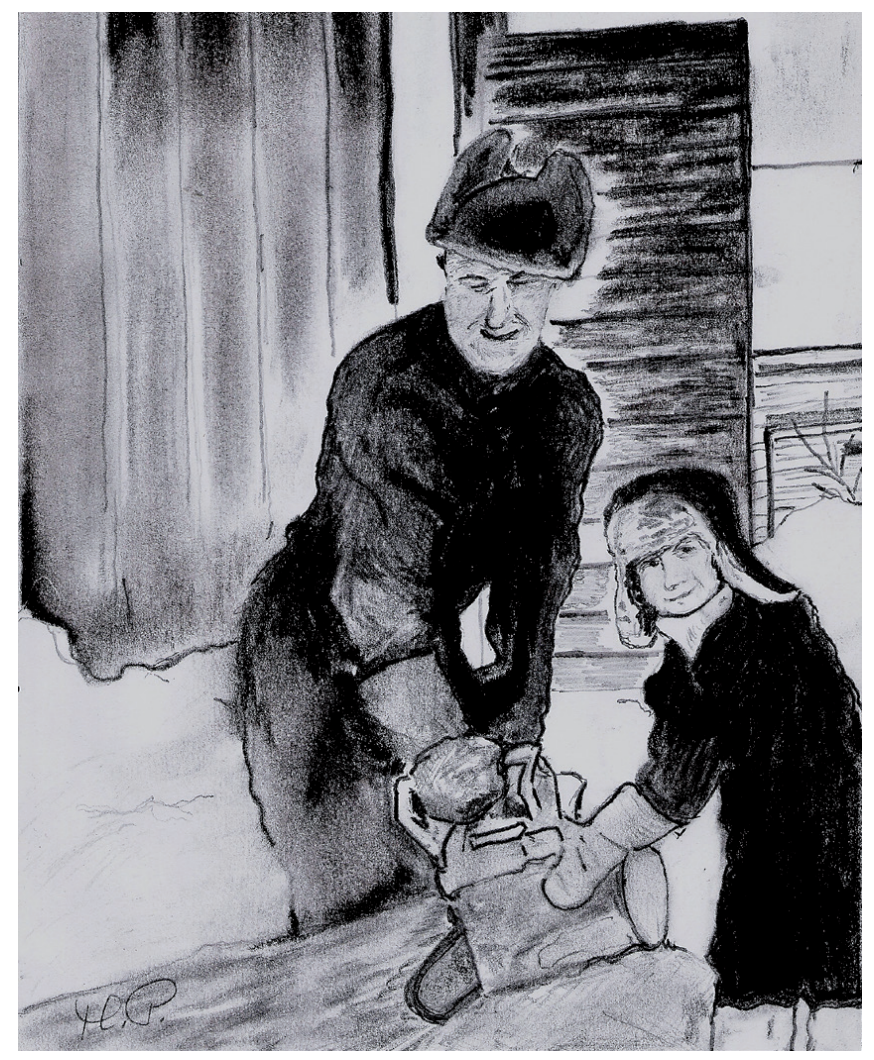




\title{
Jarmo Piirainen
}

\section{Neuromuscular Function and Balance Control in Young and Elderly Subjects}

\author{
Effects of Explosive Strength Training
}

Esitetään Jyväskylän yliopiston liikuntatieteellisen tiedekunnan suostumuksella julkisesti tarkastettavaksi Sokos Hotelli Vuokatin auditoriossa kesäkuun 7. päivänä 2014 kello 13.

Academic dissertation to be publicly discussed, by permission of the Faculty of Sport and Health Sciences of the University of Jyväskylä, in auditorium of Sokos Hotel Vuokatti, on June 7, 2014 at one o'clock pm.

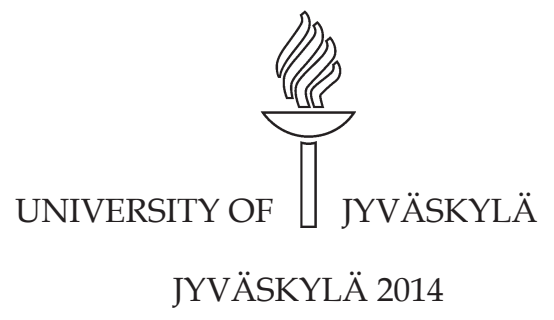




\section{Neuromuscular Function and Balance Control in Young and Elderly Subjects}

Effects of Explosive Strength Training 


\section{Jarmo Piirainen}

\section{Neuromuscular Function and Balance Control in Young and Elderly Subjects}

Effects of Explosive Strength Training

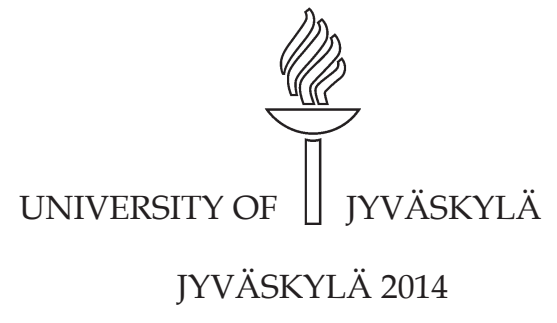




\section{Editors}

Taija Juutinen

The Department of Sport Sciences: Department of Biology of Physical Activity,

University of Jyväskylä

Pekka Olsbo, Timo Hautala

Publishing Unit, University Library of Jyväskylä

Cover picture by Marko Pääkkönen

URN:ISBN:978-951-39-5703-2

ISBN 978-951-39-5703-2 (PDF)

ISBN ISBN 978-951-39-5702-5 (nid.)

ISSN 0356-1070

Copyright @ 2014, by University of Jyväskylä

Jyväskylä University Printing House, Jyväskylä 2014 


\author{
ABSTRACT \\ Piirainen, Jarmo \\ Neuromuscular function and balance control in young and elderly subjects; Effects \\ of explosive strength training \\ Jyväskylä: University of Jyväskylä, 2014, 89 p. \\ (Studies in Sport, Physical Education and Health \\ ISSN 0356-1070; 204) \\ ISBN 978-951-39-5702-5 (nid.) \\ ISBN 978-951-39-5703-2 (PDF)
}

The aims of the present doctoral thesis were to examine the connections between neuromuscular function and balance control in young and elderly men, to examine the effects of different types of explosive strength training on neuromuscular function and dynamic balance control, and to develop a new method of measuring dynamic balance control. A total of 22 elderly ( $E, 60-72$ years) and 18 young $(Y, 20-$ 32 years) male subjects participated in the study. The study consisted of a crosssectional design (protocol I, $n=22$ in $E, n=10$ in $Y$; protocol II, $n=10$ in $E, n=9$ in $Y$ ) and an intervention design (12-week explosive strength training program) that included only elderly individuals (pneumatic, PNE n=11, plyometric, PLY n=9). Torque production was measured from quadriceps and plantar flexors in isometric conditions. Dynamic balance was measured during vertical (Protocol I) and horizontal (Protocol II) perturbations at different speeds. Static balance was also measured. H-reflexes were measured during standing rest, drop jumps and balance perturbations, where stretch reflexes were also analyzed. Age-related differences were more evident in knee extensor muscles than in plantar flexors. Elderly individuals showed weaker balance control in the anterior-posterior direction during vertical perturbations but not in static conditions. In addition, during horizontal perturbations, the elderly showed weaker balance control than young during anterior perturbations. Regarding stretch reflex responses, the reflex latency seems to be a more important factor related to balance control than stretch reflex amplitude. No age-related differences were observed in H-reflexes during standing rest, however, during fast balance perturbations the elderly showed significantly lower responses during both anterior and posterior perturbations. During the intervention, PNE trained using pneumatic strength training devices and PLY used a sledge ergometer device. In PNE, training adaptations were evident in the form of increased neural drive, whereas in PLY, adaptations were more evident in reflex responses. Surprisingly, both training regimens caused quite similar improvements in dynamic balance control. In a conclusion, it can be suggest that balance control should be measured in dynamic conditions using horizontal perturbations. Because both training regimens improved dynamic balance control, it seems that explosive strength training is generally beneficial for improving balance control in the elderly.

Keywords: Ageing, Dynamic Balance, H-reflex, Stretch reflex, Force production 
Jarmo Piirainen

Department of Biology of Physical Activity

Sports Technology unit, Snowpolis

University of Jyväskylä

88610 Vuokatti

Finland

E-mail: jarmo.piirainen@jyu.fi

Supervisors

Professor Vesa Linnamo, Ph.D.

Department of Biology of Physical Activity

University of Jyväskylä

Finland

Professor Janne Avela, Ph.D.

Department of Biology of Physical Activity University of Jyväskylä

Finland

Docent Neil Cronin, Ph.D.

Department of Biology of Physical Activity University of Jyväskylä

Finland

Reviewers

Professor Erika Zemková, Ph.D.

Department of Sports Kinantropology

University of Bratislava

Slovakia

Professor Andrew Cresswell, Ph.D.

School of Human Movement Studies

University of Queensland

Australia

Opponent

Professor Markus Gruber, Ph.D.

Department of Sports Science

University of Konstanz

Germany 


\section{ACKNOWLEDGEMENTS}

This thesis was carried out in Department of Biology of Physical Activity, Sports Technology Unit, Vuokatti, during the years 2006-2014. I wish to express my gratitude to all the people who have supported and helped me over the years in my thesis.

First I would like to thank my main supervisor Prof. Vesa Linnamo, Head of the Sports Technology Unit, for his excellent support over the years. Your door has always been open and I have always had your help and support whenever I have needed it. You have also given me the freedom to do my work in the best way for me to do it, which has helped me a lot during these years. I would also like to thank you that I have had the privilege of working as a lecturer in Vuokatti, although it has also caused some delay in my Ph.D. thesis schedule.

I also want to thank my other supervisors, Prof. Janne Avela and Doc. Neil J. Cronin, for their professional support and guidance. We did not meet so often due to the distance between Jyväskylä and Vuokatti, but the quality of our meetings was always high, which typically consisted of a large amount of discussion about the manuscripts and study designs. Despite the distance between Jyväskylä and Vuokatti, I have always had your support and help whenever I have needed it. I would also thank Doc. Cronin and Dr. Simon Walker for language review in my original articles. I would also like to express my gratitude to Prof. Erika Zemková and Prof. Andrew Cresswell for their excellent and valuable comments and criticism on the thesis and also editor Prof. Taija Juutinen for her contributions to the final version of the thesis.

I wish to express my appreciation and gratitude to the former Rector of the University of Jyväskylä, Aino Sallinen and Prof. Emer. Paavo Komi as well as Prof. Avela and Mr Toivo Takala from University of Jyväskylä and Mr Antti Leppävuori and Mr Pekka Vähäsöyrinki from Vuokatti for their contribution in bringing the Department of Biology of Physical Activity to Vuokatti. Without their actions and commitment to launch the Sports Technology Program in Vuokatti, I would probably not have been able to study in the masters program and later as a Ph.D. student. I would like to thank Mr Anssi Lipsonen, from Hur Labs Oy and Mr Mats Manderbacka, Mr Ralf Rönnqvist and Mr Hannu Rauhala from Hur Oy for their co-operation, especially during the first years of this thesis. I wish also to thank the staff of the Vuokatti Sports Institute and especially vice-rector Jyri Pelkonen for an excellent co-operation with University of Jyväskylä over the past 10 years that the Sports Technology Unit has been in Vuokatti.

I would like to thank also our main department staff from Jyväskylä, the head of our department Prof. Keijo Häkkinen and especially Ms. Minna Herpola and Mrs. Katja Pylkkänen for their support in administrative issues. I would also like thank my friend and colleague Dr. Ritva Taipale for great discussions and support especially during the last year of this thesis. In Vuokatti, we have a small but unique unit and I can sincerely say that it is best community where I 
have ever worked. We have had some great moments not only during every day work but also during congress trips and other social events. I wish to thank all of our staff, and especially my friend, Ms. Niina Sippola for the friendship and support that she gave me in data collection and analyses along with Mr. Harri Yrttiaho, Mr. Mika Koivusilta, Mr. Pauli Mikkonen, Ms Anni Hakkarainen, Mr. Olli Ohtonen and Mr. Petri Kekkonen. We had long days during the measurements but we also had a great atmosphere to work in with a lot of good memories. I wish to express my gratitude also to our laboratory engineers, Mr. Veli Kolehmainen ja Mr. Teemu Heikkinen who have designed and constructed the balance measurement systems. To succeed, you always need great people around you and I can say that I have been very lucky and privileged to work with all of you over the past eight years.

I wish also like to express my gratitude to my brother Jari and his family and my parents, Eine and Kauko who have always gave their unconditional support for my decisions. You have also helped me, Paula, and our sons over the years, usually in small every day issues, but when looking at the big picture, your help has been priceless for me and my family. Finally I would like to thank my wife Paula and my two great sons, Valtteri and Veeti. This thesis and my work in general has taken a lot of time from you, even though we still have had a great moments during this eight year period, when both sons were born. We have also managed to get our own home and the opportunity to live in region where we have been always happy. I cannot express my gratitude for your love and support during this 8-year period and I feel that as much as I have worked on this thesis, part of it belongs to you as well.

Kuhmo, 4.5.2014

Jarmo Piirainen 


\section{LIST OF ORIGINAL ARTICLES}

I Piirainen, J.M., Avela, J., Sippola, N., Linnamo, V. 2010. Age dependency of neuromuscular function and dynamic balance control. European Journal of Sport Science 10 (1), 69-79.

II

Piirainen, J.M., Linnamo, V., Sippola, N., Avela, J. 2012. Neuromuscular function during drop jump in young and elderly males. Journal of Electromyography and Kinesiology 22 (6), 852-858.

III

Piirainen, J.M., Cronin, N.J., Avela, J., Linnamo, V. 2014. Effects of plyometric and pneumatic explosive strength training on neuromuscular function and dynamic balance control in 60-70 year old males. Journal of Electromyography and Kinesiology 24 (2), 246-252.

Piirainen, J.M., Linnamo, V., Cronin, N.J., Avela, J. 2013. Agerelated neuromuscular functions and dynamic balance control during slow and fast dynamic balance perturbations. Journal of Neurophysiology 110 (11), 2557-2562. 


\section{ABBREVIATIONS}

$1 \mathrm{RM} \quad$ one repetition maximum

Apeakmax Anterior perturbation maximal peak displacement

Arec500 peak displacement 0-500 ms after the perturbation

BGA background muscle activity

BW body weight

$\mathrm{Ca}^{2+} \quad$ calcium ions

COP centre-of-pressure

DJ drop jump

EMG electromyography

EPSP excitatory post synaptic potential

H-reflex Hoffmann-reflex

$\mathrm{K}^{+} \quad$ Potassium ions

KE knee extension

LLR long-latency reflex

MLR medium-latency reflex

MU motor unit

MVC maximal voluntary contraction

$\mathrm{N}^{+} \quad$ Sodium ions

PAD IN primary afferent depolarization interneuron

PF plantar flexion

PLY plyometric

PNE pneumatic

PSI presynaptic inhibition

RMS root mean square

ROM range of motion

SLR short-latency reflex

SSC stretch-shortening cycle

TDST maximal torque after a double stimulation pulse

TDTW maximal passive twitch torque

TMS transcranial magnetic stimulation

TMVC maximal voluntary contraction torque 


\title{
CONTENTS
}

\author{
ABSTRACT \\ ACKNOWLEDGEMENTS \\ LIST OF ORIGINAL ARTICLES \\ ABBREVIATIONS \\ CONTENTS
}

2 REVIEW OF THE LITERATURE ................................................................ 13

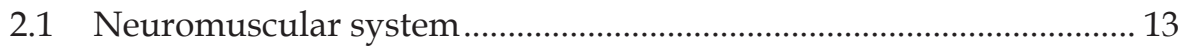

2.1.1 Supraspinal processing......................................................... 13

2.1.2 Spinal processing................................................................. 14

2.1.3 Skeletal muscle and motor unit.............................................. 17

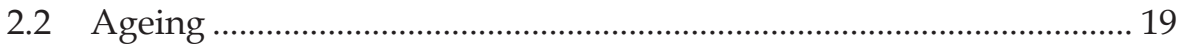

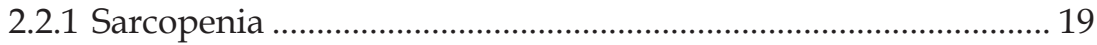

2.2.2 Age-related effects on motor unit properties ........................... 19

2.2.3 Motor control ............................................................................. 20

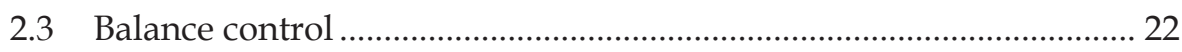

2.3.1 Static and dynamic balance control ........................................... 22

2.3.2 Sensory pathways contributing to balance control ................... 23

2.3.3 Effects of ageing on balance control during perturbations ....... 23

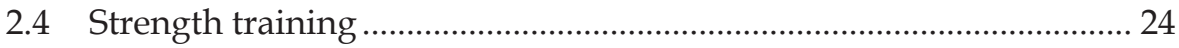

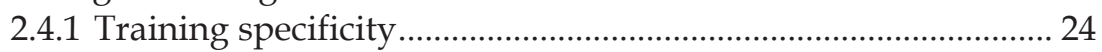

2.4.2 Power training ......................................................................... 25

2.4.3 Strength training in the elderly ............................................... 26

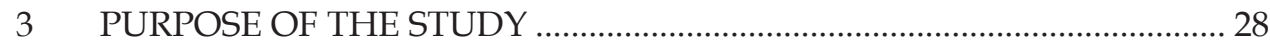

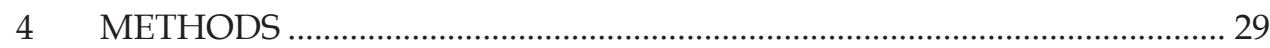

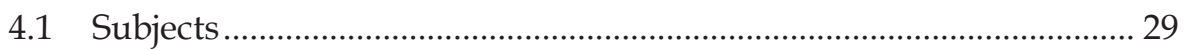

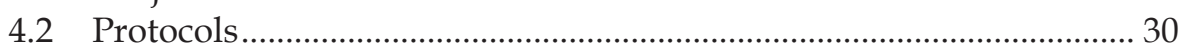

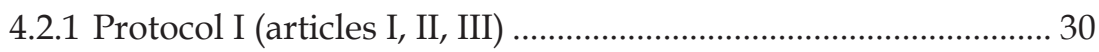

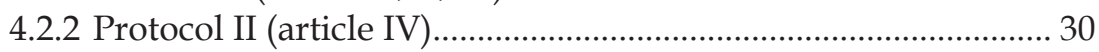

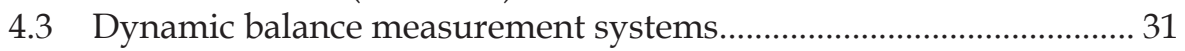

4.3.1 Prototype I, Vertical perturbations (articles I, II, III) ................. 31

4.3.2 Prototype II, Horizontal perturbations (article IV) ................... 32

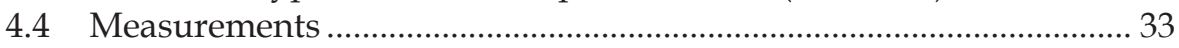

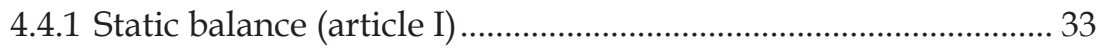

4.4.2 Vertical dynamic balance (articles I, III) .................................. 34

4.4.3 Horizontal dynamic balance (article IV) ................................... 34

4.4.4 Electromyography (EMG) (articles I, II, III and IV) .................. 35

4.4.5 Torque production (articles I, III, IV) ....................................... 35 
4.4.6 Activation level and neural drive (article I) ................................ 35

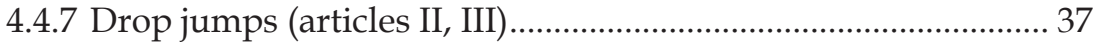

4.4.8 H-reflex (articles I, II, III and IV) ................................................. 38

4.4.9 Stretch reflex (article IV) ................................................................. 40

4.4.10 Explosive training (article III)..................................................... 41

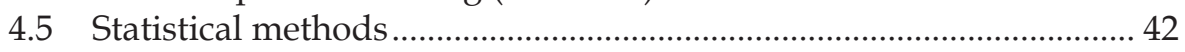

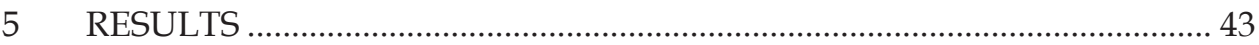

5.1 Cross-sectional study: Age-related differences ..................................... 43

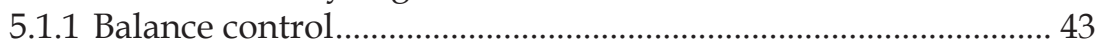

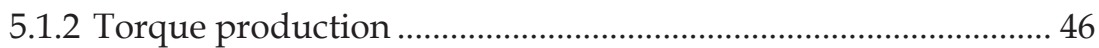

5.1.3 Activation level and V-wave response.......................................... 47

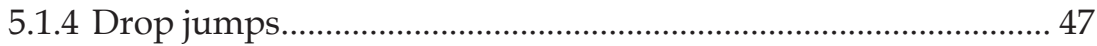

5.1.5 H-reflex (Standing rest) .................................................................. 48

5.1.6 Stretch reflex..................................................................................... 50

5.2 Intervention study: Effects of power training on neuromuscular function and dynamic balance control ................................................. 52

5.2.1 Dynamic balance control.............................................................. 52

5.2.2 Isometric torque production ...................................................... 52

5.2.3 Jump performance and H-reflex ................................................... 54

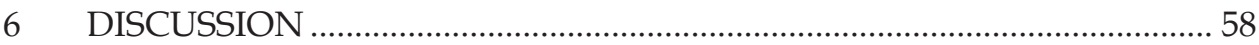

6.1 Age-related differences .................................................................... 59

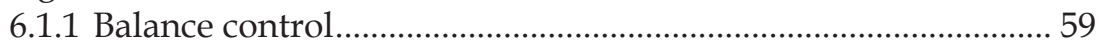

6.1.2 Torque production and drop jumps .............................................. 59

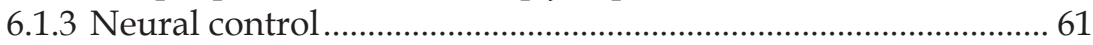

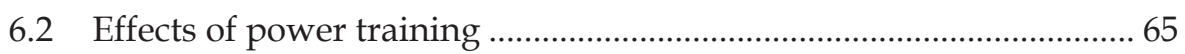

6.3 Practical applications and limitations of the study................................. 67

$7 \quad$ PRIMARY FINDINGS AND CONCLUSIONS ............................................. 70

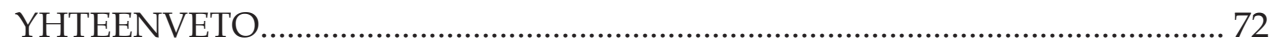

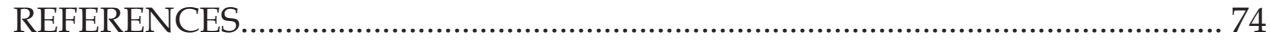




\section{INTRODUCTION}

Falling accidents have grown to be one of the major causes of injury in older people. $30 \%$ of over 65 year old individuals will fall at least once a year, and fractures caused by falling accidents are one of the major reasons for hospital treatment (Blake et al. 1988; Kannus et al. 2000). Typical injuries include hip fractures (Kannus et al. 2000), and it has been suggested that fall-induced injuries are a more common cause of fractures than osteoporosis (Kannus and Parkkari 2006), highlighting the importance of the prevention of falls. The reasons for the increasing number of fractures are still somewhat unknown, but it has been suggested that declines in muscle strength and neural control lead to poorer balance control, and are thus major contributors to this phenomenon (Izquierdo et al. 1999a; Kannus 1999; Scaglioni et al. 2003; Vandervoort 2002).

Balance control is a complex phenomenon that is associated with several human functions. It has been proposed that posture maintenance requires sensory information to detect orientation and motion, selection of an appropriate response, and activation of the muscles that can overcome balance disturbances (Enoka 2001). Balance is typically measured using static balance tests, which are easy and safe, and usually have good repeatability. However, it has been demonstrated that static balance tests do not necessarily reveal balance disorders or age-related differences as clearly as dynamic balance measurements (Baloh et al. 1994). In addition, control of the neuromuscular system is taskdependent and may therefore lead to differences between static and dynamic conditions.

It is well known that even older individuals can improve their strength and power by strength training. Explosive strength training can increase neural activity, peak power and maximal isometric and dynamic strength in older individuals (de Vos et al. 2005; Häkkinen et al. 2001). Explosive strength training may also be beneficial for improving neuromuscular properties and balance control in older people (Orr et al. 2006). Despite the large volume of training studies and their effects on balance control, the adaptation mechanisms between different explosive training types in elderly individuals are not clear at present. The purpose of the present doctoral thesis was to examine the connec- 
tions between neuromuscular function and dynamic balance control in young and elderly people. Special emphasis was directed to the effects of ageing and explosive strength training. In addition, an appropriate system for dynamic balance measurements was developed during the study. 


\section{REVIEW OF THE LITERATURE}

\subsection{Neuromuscular system}

Interaction between the central and peripheral nervous systems and skeletal muscle-tendon units produces muscle activity, which leads to force production and thus movement. All voluntary movements originate from the central nervous system via corticospinal tracts. Movement is coordinated by the somatosensory system along with the central nervous system and spinal cord. In the following sections, the basic principles of neuromuscular function are reviewed.

\subsubsection{Supraspinal processing}

Supraspinal structures play a key role in any voluntary action. The cerebral cortex represents the main center of incoming sensory and motor outputs. The primary somatosensory cortex, basal ganglia and cerebellum receive information from proprioceptors (Dykes et al. 1980; Ghez et al. 1991; Iwamura et al. 1980). The primary functions of the cerebellum are fine control of movements and balance control. In addition to somatosensory inputs, the cerebellum receives information from the cerebral cortex and vestibular organs (Amaral 2000). After processing of the information, the primary motor cortex sends the final command to the muscles via corticospinal pathways (Devanne et al. 1997). This pathway, together with corticobulbar pathways, forms pyramidal tracts that play an essential role in motor control (Jankowska and Edgley 2006).

It is possible that some muscles cannot be fully activated from the motor cortex during maximal voluntary force production. The activation level of a muscle can be measured using the twitch interpolation method, which was first described by Merton (Merton 1954). In this measurement, supramaximal electrical stimulation is given to the target muscle during maximal voluntary contraction. Supramaximality of the stimulus is determined by increasing the stimulus intensity until the twitch torque or M-wave reaches a plateau. Increasing the stimulation intensity $25-50 \%$ above the maximal level then ensures supra- 
maximal stimulation intensity. If a muscle is fully activated, no additional force can be seen after the supramaximal stimulation. Another method that has been used to assess central activity is the V-wave method (Upton et al. 1971). Whereas activation level can be measured by stimulating the muscle or nerve, $\mathrm{V}$-wave measurement always involves stimulation of the nerve that innervates the target muscle. In the V-wave measurement, supramaximal electrical stimulation is given and a V-wave response can be observed in EMG activity at the same latency as an H-reflex response. Thus, the V-wave response has been called an electrophysiological variation of the H-reflex (Aagaard et al. 2002). Previously it has been shown that strength training increases V-wave responses (Aagaard et al. 2002), suggesting enhanced motor output from higher centers.

\subsubsection{Spinal processing}

Spinal level coordination plays a very important role in motor control. There are several pathways that may have excitatory or inhibitory effects on alphamotoneuron pool excitability at the spinal level. The monosynaptic stretch reflex response (short latency reflex, SLR or M1) originating mainly from primary muscle spindles is probably the simplest example of these pathways. When a muscle is stretched rapidly, an unsynchronized burst is elicited from muscle spindles. This signal travels mainly through the fast conducting Ia-afferent pathways into the alpha-motoneuron pool via motor axons into the target muscle (Burke and Pierrot-Deseilligny 2005; Fellows et al. 1993). The latency of the soleus muscle SLR response is approximately 30-50 ms (Avela and Komi 1998). There are major differences in reflex responses between different muscles. In soleus muscle, large SLR responses can be seen, probably caused by a high number of low-threshold units (Burke and Pierrot-Deseilligny 2005), whereas in tibialis anterior, short latency responses can be seen only at very high stretching velocities (Nakazawa et al. 2003).

After the SLR response, a medium latency response (MLR or M2) may follow. It is a more complicated response than the SLR, and may originate from secondary muscle spindles via the group II afferent pathway in the spinal cord and via motor axons to the target muscle (Grey et al. 2001; Schieppati and Nardone 1997). Conduction velocity of the group II afferents is lower than group Ia-afferents, and therefore the soleus MLR response occurs typically 50$70 \mathrm{~ms}$ after muscle stretch (Burke and Pierrot-Deseilligny 2005; Petersen et al. 1998). Whereas the SLR is a monosynaptic excitatory response, the MLR is an oligosynaptic response. It has been suggested that Ib-afferents from golgi tendon organs may also contribute to MLR responses (Dietz 1998). Golgi tendon organs are located in muscle-tendon junctions, but are activated during muscle contraction rather than during muscle stretch (Burke and Pierrot-Deseilligny 2005). Nardone et al. (1990) showed that MLR responses are modulated during different postural tasks by changing the postural set. A third stretch reflex component is the long latency response (LLR or M3), which occurs typically 85-100 ms after stretch (Obata et al. 2010; Petersen et al. 1998). This response is probably the most complicated of the three responses, and it has been suggested to 
primarily originate from supraspinal structures (Shemmell et al. 2010). All three components are presented in figure 1. It should be noted that all three components are not always present, depending on the muscle, pre-activation and stretch velocity. Muscle spindles are innervated by gamma-motoneurons (Swash and Fox 1972), and increased gamma-drive leads to increased spindle stiffness and thus sensitivity to stretch (Burke and Pierrot-Deseilligny 2005), enabling spindles to still detect length changes in active conditions.

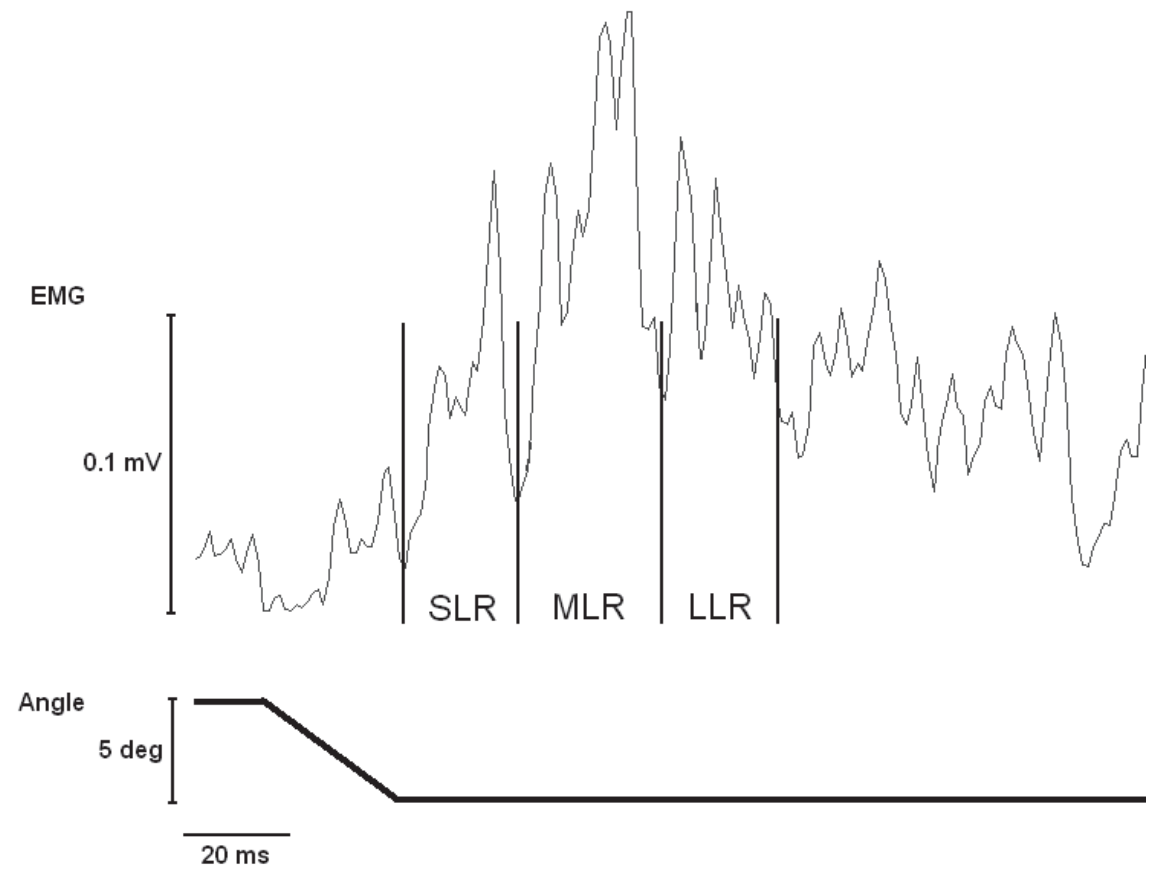

FIGURE 1 Short- (SLR), medium- (MLR) and long- (LLR) latency components caused by a rapid plantar flexion stretch (Modified from Petersen et al. 1998).

Synaptic transmission efficiency between Ia-afferents and alpha-motoneurons (figure 2) is usually measured using the H-reflex (Hoffmann-reflex) method, which was first described by Paul Hoffmann in early $20^{\text {th }}$ century. The H-reflex response has also been used as an indicator of alpha-motoneuron pool excitability, however, it is strongly influenced by presynaptic inhibition (Stein 1995). The H-reflex response travels through the same monosynaptic pathway (figure 2) as the short latency stretch reflex (Schieppati 1987). However, these two methods and their responses cannot be compared. Major differences between these methods include the fact that the H-reflex is an artificial response, which bypasses muscle spindles and is a shorter duration synchronized pulse (Palmieri et al. 2004; Schieppati 1987). In addition, it has been shown that the Hreflex mainly measures excitability of the slow-twitch fibers (Buchthal and Schmalbruch 1970; Nardone and Schieppati 1988). H-reflexes have most commonly been measured from soleus muscle, because it has a high number of 
slow-twitch fibers. H-reflexes have also been measured from quadriceps (Larsen and Voigt 2006), tibialis anterior (Crone et al. 1987), flexor carpi radialis (Cavallari and Lalli 1998) and biceps brachii muscles (Harris-Love et al. 2007).

Several mechanisms are involved in the modulation of alpha-motoneuron pool excitability. Presynaptic inhibition (PSI) has been shown to modulate transmission from Ia-afferents to alpha-motoneurons before the synapse, leading to changes in excitatory post synaptic potentials (EPSP) (Eccles et al. 1961; Eccles et al. 1962; Stein 1995). There are two interneurons, first order primary afferent depolarization interneurons (PAD) and last order GABA-ergic PAD, which lead to excitatory or inhibitory potentials, depending on the primary task. All afferent inputs may affect PSI, but PSI is also modulated via corticospinal pathways (Stein 1995; Zehr 2002). Reciprocal inhibition, which is a disynaptic response, acts between the agonist and antagonist muscles. When an agonist muscle is activated, the antagonist muscle is inhibited through the inhibitory interneuron (Day et al. 1984) projecting motoneurons. This allows the agonist muscle to produce force as efficiently as possible. However, when a joint needs stabilization (e.g. during balance control), co-contraction of the agonist and antagonist muscles may occur. In those cases, transmission from reciprocal pathways seems to be reduced (Nielsen and Kagamihara 1992). One possible source of this reduction might be recurrent inhibition, which originates from Renshawcells (Renshaw 1946) in collateral branches of the motor axons. Recurrent inhibition produces decreased excitability of the motoneurons, and is the only source of inhibition that is activated by the motoneuron itself (Hultborn and PierrotDeseilligny 1979; Katz and Pierrot-Deseilligny 1999). The mechanisms described above affect alpha-motoneuron pool excitability and H-reflex responses. However, it seems that PSI has the strongest influence on H-reflex responses, and its effects should always be considered when analyzing excitability of the alphamotoneuron pool (Zehr 2002). H-reflexes are very sensitive to environmental changes, such as changes in voluntary muscle activity (Angulo-Kinzler et al. 1998), postural position (Koceja et al. 1995) or sway during static postural conditions (Tokuno et al. 2008). 


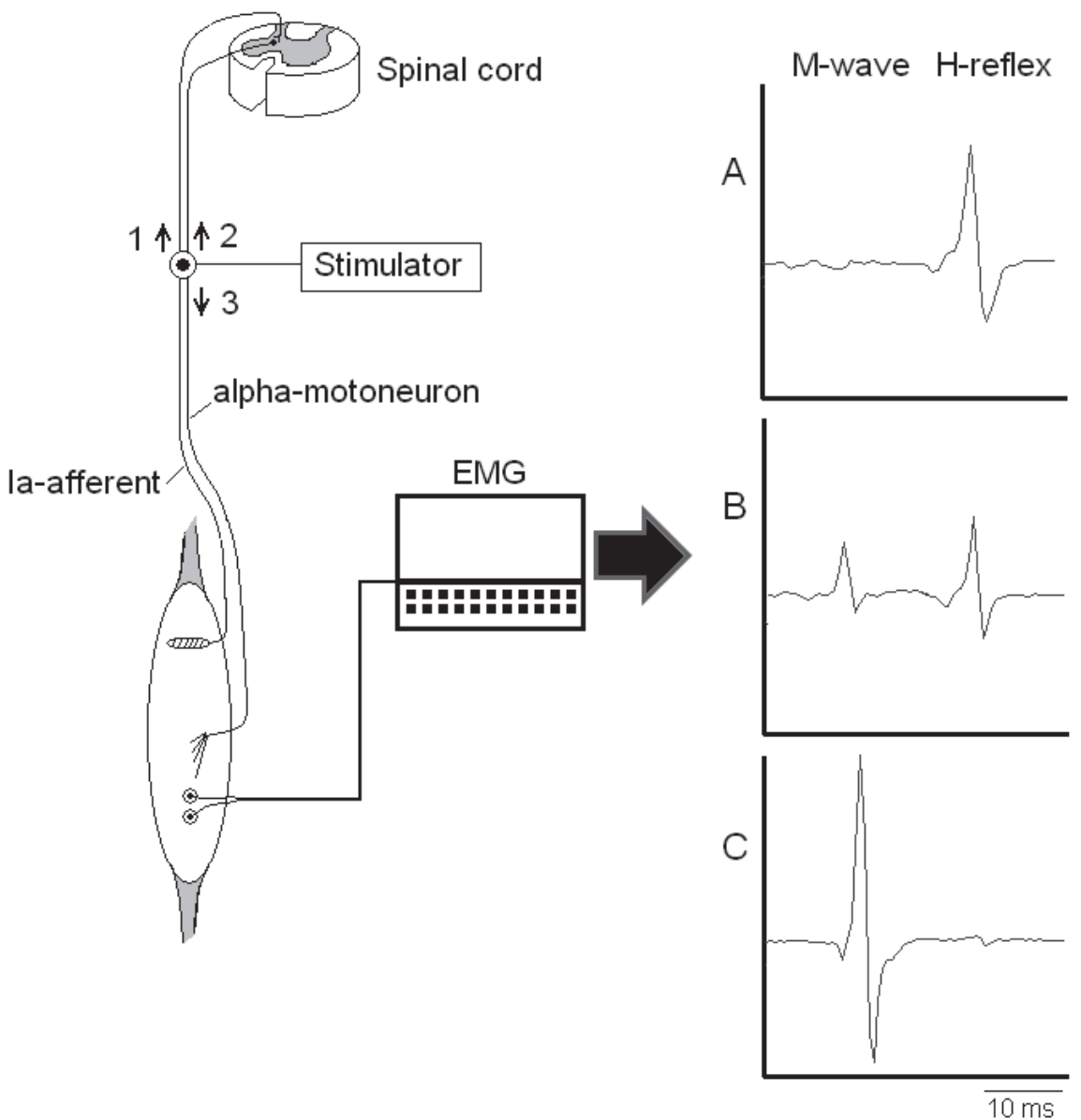

FIGURE 2 H-reflex pathway: Using low stimulation intensities, action potentials (H-reflex) are elicited from Ia-afferents (1) and travel through the alpha-motoneuron pool in the spinal cord to produce excitatory post-synaptic potentials. An H-reflex response can be seen in the EMG trace at a latency of approximately 30-40 ms (soleus) after stimulation (A). Increasing stimulation intensity produces action potentials (M-wave) in alpha-motoneurons (3), visible in the EMG trace at a latency of 5-10 ms. When an M-wave is elicited, antidromic action potentials (2) propagate towards the spinal cord and collide with reflex potentials, reducing the amplitude of the H-reflex (B). At very high stimulation intensities, the Mwave reaches a plateau and antidromic action potentials totally abolish the $\mathrm{H}$ reflex (C). (modified from Aagaard et al. 2002, Zehr 2002).

\subsubsection{Skeletal muscle and motor unit}

Movement occurs when one or more muscles are activated. Usually a muscle spans one or multiple joints. Muscle fibers are divided into three sub-levels, endomysium, perimysium and epimysium (Light and Champion 1984). The endomysium covers single muscle fibers whereas the perimysium collects fiber stacks into fascicles and the epimysium covers the entire muscle. This network 
is connected to bones via tendons. Skeletal muscle fibers consist of a series of contractile units, sarcomeres, within which the basic contractile elements are thick and thin contractile proteins (Enoka 2001).

Motor units (MU) are basic functional units of muscles and by activating muscle fibers via MUs, muscles produce force. A single MU consists of a motor neuron, axon and all muscle fibers that the neuron innervates (Enoka 2001). Innervation ratio varies between muscles from only a few to several hundred muscle fibers per motoneuron (Burke and Tsairis 1973; McComas et al. 1993; Solomonow 1984). If the ratio is low (small motor units), the muscle can produce relatively low force levels and vice versa (Salomonow 1984). However, in small motor units, force levels are more stable than in large ones. MUs are divided into slow and fast motor units based on their contractile properties (Burke 1967; Burke et al. 1973). In addition, fast units are further divided into two different categories, fast low fatigue (type IIa) and fast high fatigue (type $\mathrm{IIb})$. Slow MU (type I) fatigue resistance is high, but force production and contraction velocity are low compared to type II motor units, which can produce higher twitch tension in a shorter time (Burke 1967). Type IIb twitch tension is higher than type IIa, but there are no major differences in twitch contraction time between type IIa and type IIb MUs (English and Wolf 1982). Distribution of the different MU types varies between muscles. Soleus is a typical example of a slow muscle, consisting of about $70 \%$ slow type MUs (Edgerton et al. 1975). On the other hand, in vastus lateralis, which is part of the quadriceps muscle group, the distribution of fast and slow units is more equal (Linnamo et al. 2000; Staron et al. 2000).

Henneman and colleagues showed in the 1960`s that MUs are usually recruited in order from slow MUs to fast fatiguing units (Henneman et al. 1965). In addition, MUs are derecruited in reverse order from fast to slow (De Luca and Mambrito 1987). Thus, when an increase in force is needed, additional MUs are recruited to produce higher forces. It seems that all MUs are already activated at submaximal force levels, but this varies between muscles from 50-95\% (De Luca et al. 1982; Milner-Brown et al. 1973; Oya et al. 2009). However, it should be noted that recruitment thresholds of the MUs in a given muscle may vary between muscle contraction types (Linnamo et al. 2003). The final increment in force levels is produced mainly by increasing discharge rate of the active MUs (De Luca et al. 1982). In most cases, muscles are recruited according to the size principle, although there may be some cases where slow MUs are inhibited, allowing more efficient recruitment of fast units (Nardone et al. 1989). In some cases, the same MUs can fire twice with a very short interval (Christie and Kamen 2006). This phenomenon is called doublet firing and it can occur at any force level of muscle contraction. In addition, it has been suggested that doublets occur in MUs that have a higher maximal firing rate (Van Cutsem et al. 1998). 


\subsection{Ageing}

\subsubsection{Sarcopenia}

Functions of the neuromuscular system such as maximal neural activation and muscle performance are known to decrease with ageing, particularly after the 6th decade (Häkkinen and Häkkinen 1995; Häkkinen et al. 1995; Narici et al. 1991). This phenomenon is called sarcopenia. The main reasons for decreased strength properties with advancing age are loss of motor units and muscle atrophy, altered enzyme activity levels and muscle contractility, and changes in the endocrine and nervous systems (Vandervoort 2002). In addition, decreased physical activity level and poor nutrition, together with possible diseases, may enhance the decrement of strength properties.

\subsubsection{Age-related effects on motor unit properties}

Loss of muscle mass leads to decreased cross-sectional area of the muscle, which is directly related to decreased force production properties (Häkkinen and Häkkinen 1991). Between the genders, young men generally have a higher proportion of skeletal muscle mass, but the relative reduction in muscle mass is also higher during ageing in men (Gallagher et al. 1997). During the ageing process, loss of MUs, especially fast MUs, leads to MU rearrangement, whereby surviving MUs innervate some of the muscle fibers left from the lost units (Doherty et al. 1993b; Narici and Maffulli 2010; Vandervoort 2002). This leads to an increase in size of single MUs and a decreased total number of MUs. In addition to the loss of MUs, atrophy of surviving MUs also occurs, especially in fast MUs (Lexell et al. 1988). These changes have been observed in quadriceps (Häkkinen and Häkkinen 1991) and plantar flexors (Hasson et al. 2011), which are all antigravity muscles (Shah et al. 2006). In addition to the decreased number of MUs, activation of the MUs may also change during ageing. Connelly and colleagues (Connelly et al. 1999) showed that elderly individuals had lower mean MU firing rates at all force levels during isometric dorsiflexion. They also showed that lower firing rates were associated with longer twitch contraction duration. Similarly, Kallio et al. (Kallio et al. 2012) showed lower MU firing rates during isometric plantar flexion, as well as larger force fluctuations in the elderly. However, it seems that ageing does not affect MU synchronization (Kamen and Roy 2000; Semmler et al. 2000). A decrease in the number of MUs and an increase in the size of individual units may also lead to weaker fine motor control (Roos et al. 1997) and decreased force production capacity (Roos et al. 1999).

At the muscle level, the effects of degeneration are not only observed structurally but also in the contractile properties of the muscle. Hicks et al. (1992) showed significantly lower M-wave responses in the elderly. They suggested that this was caused at least partly by decreased $\mathrm{Na}+-\mathrm{K}+$ transport, which may have decreased resting membrane potential and decreased the am- 
plitude of the response. Inside the muscle, efficient $\mathrm{Ca} 2+$ release from the sarcoplasmic reticulum plays an important role in muscle contraction, and this has been shown to decline in elderly humans (Delbono et al. 1995). In addition, Höök et al. (2001) observed age-related differences in the speed of myosindriven actin filaments. All of these mechanisms may contribute to the decreased effectiveness of the excitation-contraction coupling process, and thus weaker muscle contractile properties.

\subsubsection{Motor control}

Age-related changes in muscle and nervous system properties lead inevitably to changes in motor control. Comparing muscle contraction types, ageing seems to affect isometric and concentric contractions, with very little effect on eccentric contractions (Klass et al. 2005). It is well known that in isometric and concentric conditions, age-related declines in force and power are caused by decreased muscle mass and loss of the fastest MUs (Häkkinen et al. 1998; Morse et al. 2004). Within the central components, age-related changes are less clear. Vandervoort and McComas (1986) found no significant differences in activation level of the plantar flexor muscles between young and old individuals. However, age-related differences were observed in the knee extensor muscles (Stackhouse et al. 2001; Stevens et al. 2003), which may indicate that changes in activation level are muscle group-dependent. In eccentric contractions, the smaller age-related changes may be caused by increased stiffness of the muscletendon complex (Ochala et al. 2004), although the full mechanisms are not known.

In spite of these findings, it may be more important to understand mechanisms of multi-joint tasks, especially those in which the stretch-shortening cycle (SSC) occurs such as walking and running, as these tasks are repeated on a daily basis. In SSC, utilization of the stretch reflex response, eccentric phase force production and elasticity are dependent on efficient muscle pre-activation (Komi 2000). After the eccentric phase (stretch), concentric muscle action (shortening) follows, leading to higher positive work compared to pure concentric action (Aura \& Komi, 1986a). Bosco \& Komi (1980) showed that ageing leads to decreased performance in SSC type actions. Hoffren et al. (Hoffren et al. 2007) have shown that age-related decreases in SSC performance during drop jumps are caused by decreased agonist EMG activity, increased co-activation in the braking phase and decreased utilization of tendinous tissue elasticity. These findings indicate different neural patterns and mechanical behavior between young and elderly individuals during drop jumps, and may contribute to decreased force and power production during ageing (Edwen et al. 2013; Runge et al. 2004).

In addition to the well-known age-related adaptations of muscle size and structure, as well as possible changes in central activation, reflex parameters may also change. SLR size has been shown to be similar between young and elderly subjects (Kawashima et al. 2004; Nardone et al. 1995) in soleus muscle. However, the conduction velocity (Nardone et al. 1995) of the SLR may de- 
crease during ageing, which could cause delayed feedback. Several studies have also shown longer reflex latencies in elderly subjects (Kawashima et al. 2004; Klass et al. 2011; Obata et al. 2010). There are several mechanisms that may contribute to decreased stretch reflex properties during ageing. It may be that ageing leads to increased stiffness of muscle fibers (Vandervoort 2002), which in turn decreases range of motion (ROM) (Gajdosik et al. 1999). Reduced ROM may lead to weaker sensitivity of the muscle spindles, and thus reduced properties of the stretch reflex response. Similar to structural changes, it has been speculated that neural innervation from gamma-motoneurons may also decrease, which reduces spindle discharge (Mynark and Koceja 2001). However, at present, there is no clear evidence to confirm that this age-related phenomenon exists.

The parameters of the SLR are quite well known, but the two other stretch reflex components (medium (MLR) and long latency reflex (LLR)) and their age-related changes are less studied. It has been suggested that MLR responses are quite similar between different age groups, but the LLR component seems to be higher with increasing age (Klass et al. 2011, Kawashima et al. 2004). One reason for an increased LLR may be an increased contribution of supraspinal activity (Taube et al. 2006), which may in turn compensate for the longer reflex latency (Nardone et al. 1995). However, Nardone et al. (1995) found no connection between LLR latency and amplitude, suggesting that the longer latency alone cannot explain the larger LLR response. It has been shown that intracortical inhibitory processes decrease during ageing (Peinemann et al. 2001), which may contribute to increased LLR responses in the elderly (Obata et al. 2010).

$\mathrm{H}$-reflexes are very sensitive to environmental changes such as alterations in body position (Koceja et al. 1995) or muscle activation level (Kallio et al. 2010), which makes measurements in dynamic conditions more challenging. In resting conditions, age-related differences are less clear. Some studies have reported no significant age-related differences in H-reflex responses (relative to Mmax) in resting conditions (Angulo-Kinzler et al. 1998; Scaglioni et al. 2003), whereas other studies have observed differences (Kido et al. 2004; Scaglioni et al. 2002). Despite the large number of studies that have investigated H-reflexes in resting conditions, dynamic situations are more functionally relevant and should be studied. Some studies have shown that the amplitude and especially modulation of the H-reflex during dynamic tasks or different postural positions may differ between age groups (Chalmers and Knutzen 2002; Koceja et al. 1995; Tsuruike et al. 2012). Koceja et al. (1995) and Angulo Kinzler et al. (1998) showed that in young subjects, H-reflexes decreased when subjects moved from supine to standing. However, this was not observed in the elderly, and the authors concluded that young and elderly subjects have a different ability to modulate H-reflexes in different postural conditions. Conversely, some studies have observed no age-related differences in H-reflex amplitudes during force production tasks (Kallio et al. 2010; Leonard et al. 1997), however, H-reflex modulation seems to be significantly delayed in older adults (Burke and Kamen 1996; Leonard et al. 1997). 
During walking, Chalmers \& Knutzen (2000) showed that the modulation of the H-reflex was similar in young and elderly subjects, although the amplitude of the H-reflex was significantly lower in the elderly during the stance phase. These results indicate that there are some age-related changes in H-reflex responses, but that the changes are highly task-dependent. It is generally agreed that PSI from descending pathways has a very strong influence on H-reflex modulation (Stein 1995). It has been suggested that age-related changes in $\mathrm{H}$ reflex responses are caused by changes in the modulation of PSI (Baudry et al. 2010; Butchart et al. 1993). Other mechanisms that may affect H-reflex responses during ageing include increased co-contraction (Benjuya et al. 2004) of agonistantagonist muscles, which is mainly modulated via disynaptic reciprocal inhibition (Hortobagyi and Devita 2006). However, Chalmers \& Knutzen (2000) showed that reciprocal inhibition or speed of movement had minor effects on H-reflex modulation during walking. On the other hand, changes in Renshaw cell activity (Chalmers and Knutzen 2000) or availability of serotonin (Capaday 1997) may also influence age-related H-reflex responses. However, it should be noted that H-reflexes are highly task and condition-dependent, so conclusions should be interpreted with caution.

\subsection{Balance control}

\subsubsection{Static and dynamic balance control}

Static balance tests are more common than dynamic tests, probably because they are usually very simple and safe to perform, and often have good repeatability (Bauer et al. 2008). During static balance tests, changes in the centre-ofpressure (COP) are used as an indicator of body sway during quiet standing (Zemková 2011; Zemková and Hamar 2008). It has been suggested that the muscles around the ankle joint are the main modulators of balance in static conditions (Winter et al. 2001). However, good static balance control does not necessarily indicate good balance control in dynamic situations. When balance control is challenged to a larger extent, knee and hip muscles are also activated (Kim and Robinson 2005) and neural control may be a lot more complicated than in static conditions. When balance perturbations are induced in static postural conditions, even small static sway or perturbation direction may influence the perturbation response (Tokuno et al. 2006). Depending on the task complexity, a fast and efficient response is often needed to achieve appropriate balance control. Therefore, it has been suggested that good balance control requires effective sensory information to detect orientation and motion, selection of an appropriate response to maintain balance and efficient activation of the muscles that respond to a balance disturbance (Enoka, 2001). 


\subsubsection{Sensory pathways contributing to balance control}

Three different sensory pathways (somatosensory, visual and vestibular inputs) are highly related to efficient balance control (Fitzpatrick et al. 1992; Woollacott and Shumway-Cook 1990). The somatosensory system can be divided into proprioceptors and cutaneous sensors (muscle spindles, joint receptors, golgi tendon organs), which provide information about muscle length and joint position that is important for dynamic balance control. Visual feedback gives information about the surrounding environment (Franklin et al. 2007) while the vestibular system is sensitive to changes in motion and orientation of the head (Horak et al. 1994). As all of these sensory systems are sensitive to environmental changes, they should all be taken into account in balance testing. For example, (Grace Gaerlan et al. 2012) showed that in young individuals, the visual system may be the predominant sensory system for maintaining balance during static conditions. However, during balance perturbations where rapid reactions and force production are needed, the somatosensory system may be more crucial. Horak et al. (1990) showed that weaker somatosensory feedback led to greater use of the hip strategy during a perturbation. In addition, loss of vestibular information seemed to be connected to decreased effectiveness of the hip strategy, suggesting that both of these sensory systems play an important role in balance control during perturbations. However, it is also noteworthy that Zemková and Hamar (2010) did not observe changes in balance control after acute enhancement of visual feedback.

\subsubsection{Effects of ageing on balance control during perturbations}

Balance control is highly task-dependent (Muehlbauer et al. 2012), and thus balance control and the control strategy may be completely different between different conditions. During sudden perturbations, efficient activity of the neuromuscular system is crucial to prevent falling and maintain balance. It has been suggested that three different strategies are generally used in perturbation based balance control. The ankle strategy is used during weak perturbations (figure 3), while the hip and step strategy are used during medium and large perturbations, respectively (Granacher et al. 2011). Individuals who are able to recover balance with a single step exhibit higher muscle activity in lower limb muscles compared to multiple steppers, showing that neural deficiencies can decrease balance control and alter the control strategy (Carty et al. 2012; Cronin et al. 2013). Moreover, this phenomenon is more evident in females than males (Carty et al. 2012). Thus, with poor balance control, the step strategy may already be used during slow perturbations to prevent large centre of mass displacements. It has been shown that in the elderly, the onset of muscle activity may occur later during perturbations (Lin and Woollacott 2002; Tokuno et al. 2010), however, differences may be clearer during anterior perturbations (Tang and Woollacott 1998). The latter authors also showed that muscle activation during the perturbation was lower in the elderly, and that slower responses and 
lower muscle activation together contributed to poor balance control rather than slower responses alone. In addition, co-activation of the agonist/antagonist pairs may be higher during the perturbation in the elderly, leading to reduced response effectiveness during perturbations (Tang and Woollacott 1998). In addition to high force, reaction time plays an essential role during sudden perturbations, and may also affect balance control strategy (Sturnieks et al. 2012). Granacher et al. (2006) showed lower force production properties and perturbation based reflex activity in the elderly, but found no correlation between the variables. These studies indicate that efficient force production is a key factor to prevent falling accidents during sudden perturbations. However, the role of the reflex system is less clear at present.

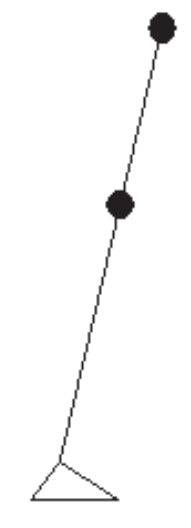

Ankle

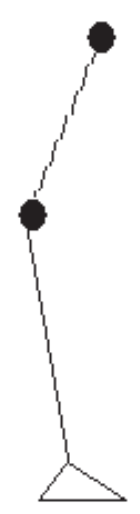

Hip

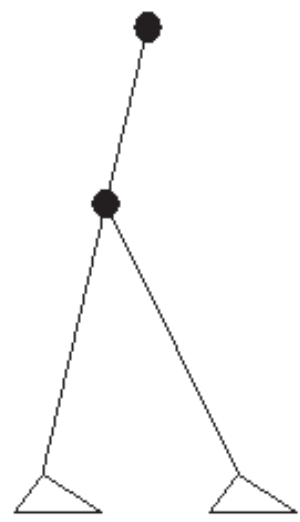

Step

FIGURE 3 Different control strategies during balance perturbations (modified from Granacher et al. 2011).

\subsection{Strength training}

\subsubsection{Training specificity}

Strength training is typically divided into three different categories. Neural strength training is performed using high training loads (90-100 \% of 1RM), with a low number of repetitions (1-3) per set and moderate rest periods (2-3 $\mathrm{min}$ ) between sets. This training regimen can lead to increased neural activity with minor muscle hypertrophy (Häkkinen 2002). In hypertrophy strength training, the training load is decreased (60-70 \% 1RM) compared to neural strength training, and the number of repetitions is increased (8-10). Typical rest periods (1-2 $\mathrm{min}$ ) between the sets are also shorter than in neural strength training (Ahtiainen et al. 2005; Piirainen et al. 2011). Power or explosive strength training is the third subcategory of the training types. The main goal of this 
training is to perform each repetition as fast as possible. Therefore, the load is typically only $30-60 \%$ of 1 RM with long rest periods (3-5 min) between sets. Long rest periods have been used to ensure full energetic and ionic recovery (de Salles et al. 2009; Sargeant 2007).

Typical changes in neural activity during strength training include increased firing frequency of the agonist motor units (Kamen and Knight 2004), decreased co-activation of the antagonist muscles (Häkkinen et al. 1998), enhanced coordination (Carroll et al. 2001) and increased activation of the synergistic muscles (Cronin et al. 2002; Sale 2003). In addition, an increased number of doublets may occur in motor units, especially after power training (Van Cutsem et al. 1998). However, the effect of strength training on enhanced synchronization of the motor units seems to be minor (Kidgell et al. 2006). On the other hand, hypertrophy type training can lead to increased uptake of amino acids and increased protein synthesis, as well as increased muscle hypertrophy (Häkkinen 2002). The amount of hypertrophy is also related to serum testosterone level, which is typically lower in women than in men (Weiss et al. 1983). Thus, each training type has different effects on the neuromuscular system. As this thesis examined the effects of different types of power training on balance control, the effects of these training modes are summarized in the following section.

\subsubsection{Power training}

In several power training studies, jumping (plyometric) training has been used to improve power production (Chimera et al. 2004; Häkkinen et al. 1985; Kyröläinen et al. 2005). In plyometric exercise, where both eccentric and concentric muscle actions occur, the effects of training on balance control may be more substantial than after pure concentric exercise. Plyometric exercise utilizes the stretch shortening cycle (SSC), which plays an essential role in most human movements. Chimera et al. (2004) did not find any changes in knee extensor or flexor muscle activation after plyometric training. Similarly, Kyröläinen et al. (2005) showed no changes in lower limb EMG activation or activation patterns after plyometric training. In plantar flexor muscles, Kubo et al. (2007) showed a significant increment in EMG activity, but only in the concentric phase of drop jumps. However, it has been shown that several months of power training including numerous jumping trials and minor extra loads may also increase neural activity of the knee extensor muscles, along with increased force production properties (Häkkinen et al. 1985), especially during the early phase of force production. Although the latter study did not observe changes in muscle fiber type distribution, the size of the type II fibers did increase. Similarly, Häkkinen et al. (2001) showed increased neural activation and increased size of both type I and type II fibers during combined heavy and explosive resistance training.

In terms of reflex responses, Voigt et al. (1998) showed increased Hreflexes during hopping after plyometric training, but no changes in stretch reflex responses. They suggested that the increased H-reflex response was due to more automatic control strategies during jumping with less voluntary activa- 
tion. They rationalized that when less voluntary activation is needed, PSI also decreases, leading to an increased H-reflex response. Therefore, it may be that plyometric training enhances spinal level activation during movement, leading to more efficient motor control without any major increments in voluntary muscle activity. On the other hand, Maffiuletti et al. (2001) showed that long term power trained individuals had a significantly lower Hmax/Mmax-ratio in resting conditions compared to endurance trained individuals. The authors suggested that this was caused by a lower number of slow twitch motor units in the power trained group. Despite the lower Hmax/Mmax-ratio and a trend towards a lower Hmax, peak torque produced by Hmax was significantly higher in the power trained group, suggesting that power training also increases force levels of the slow twitch units. Similarly, Koceja \& Kamen (1988) showed that sprinters produced higher force in tendon tap reflex measurements compared to endurance trained individuals. In addition, reflex latencies seemed to be shorter in sprinters, suggesting higher conduction velocities. However, Häkkinen and Komi (1986) showed that power training leads to decreased patella tendon reflex EMG amplitudes, while no changes were observed in reflex latencies or electromechanical delay. They suggested that a possible reason for the decreased amplitudes was decreased sensitivity of the muscle spindles, although possible morphological changes of the intrafusal chain fibers (which may have enhanced inhibitory activity from group II pathways) or the role of the Golgi tendon organs cannot be excluded.

Free weights, weight stack devices or pneumatic devices are often used in strength training. Pneumatic devices are based on air pressure, which may reduce the variability in required muscle force during the entire range of motion, thus leading to more efficient muscle contraction during the exercise and higher strength gains (Fleck and Kraemer 2004). The variability between training protocols is large and therefore it is difficult to compare these studies and the observed adaptations. In general, it seems that enhanced neural drive and thus increased force production properties, along with a possible increase in fiber size, are the most likely adaptations after explosive/power training. In terms of reflex responses, H-reflexes seem to be lower in power-trained individuals, while minor changes may also occur in stretch reflex amplitudes or latencies.

\subsubsection{Strength training in the elderly}

The effects of different types of strength training on the elderly have been studied widely over the past few decades (Caserotti et al. 2008; Häkkinen et al. 1998; Häkkinen et al. 2001; Suetta et al. 2004; Tracy et al. 2004). Hypertrophy type strength training enhances muscle fiber size (Mero et al. 2013), but the increments in the elderly may still be smaller than in younger individuals (Larsson 1982), which may indicate that muscle fiber atrophy is not the main reason for decreased force properties in the elderly. On the other hand, Martel et al. (2006) showed increased muscle fiber size in both slow and fast twitch fibers in the young, whereas in the elderly increments in fiber size were only observed in fast twitch fibers. These results indicate that similar hypertrophy responses can 
be seen between young and elderly individuals after hypertrophy strength training, although some minor differences may be observed in adaptations between fiber types. Previously, Topp et al. (1993) and Wolfson et al. (1996) have shown that three months of hypertrophy type strength training may improve balance control. On the other hand, Latham et al. (Latham et al. 2004) have suggested that the benefits of progressive resistance training for balance control in the elderly may not be so clear.

Despite possible improvements in muscle size, increased neural activation is needed to improve muscle strength and especially power (Häkkinen et al. 1998, Häkkinen et al. 2001). In very old subjects, Harridge et al. (1999) showed that the activation level of quadriceps muscle was only $80 \%$, indicating insufficient voluntary muscle activity. In the same study, 12 weeks of strength training increased muscle size and maximal voluntary force, but no significant improvements were found in activation level. However, a clear relationship was observed between changes in muscle activation and changes in maximal muscle force after the training period. On the other hand, Scaglioni et al. (2002) showed increased plantar flexor activation level after 16 weeks of strength training. Contrary to the positive adaptations in voluntary drive and muscle characteristics, reflex parameters seem to be unaltered after strength training (Granacher et al. 2006; Scaglioni et al. 2002).

High intensity strength training is important for elderly subjects to improve their maximal strength properties (Fiatarone et al. 1990), which also improves power properties (Miszko et al. 2003). However, it is unlikely that maximal strength is needed to correct balance control, especially during sudden perturbations where a rapid response is needed. Therefore, high velocity training or power training may enhance rapid motor control more effectively (Granacher et al. 2012). Previously it has been shown that power training leads to improved performance in the elderly (Henwood et al. 2008; Miszko et al. 2003), and may even be more efficient than traditional strength training (Miszko et al. 2003). In high velocity resistance training, typical neural adaptations include increased activation of the agonist muscle (Häkkinen et al. 1998; Van Cutsem et al. 1998) and a possible decrease in co-activation of the antagonist muscle in the elderly (Häkkinen et al. 1998). Similarly, Holsgaard-Larsen et al. (2011) showed increased rectus femoris activation after explosive strength training, although co-activation remained unaltered. In addition, a minor enhancement in muscle size may also occur (Häkkinen et al. 1998), but the main adaptation seems to be related to more efficient voluntary activation, especially in the early phase of force production. This seems to also be related to improved balance properties and functional capacity in older individuals (Holsgaard-Larsen et al. 2011; Izquierdo et al. 1999a). Previous studies have shown improvements in strength and power due to pneumatic power training (de Vos et al. 2005; Orr et al. 2006), as well as improved dynamic balance control (Orr et al. 2006) in elderly people. 


\section{PURPOSE OF THE STUDY}

With advancing age the probability of falling injuries increases. Decreased activity of the muscles and nervous system are most likely related to weaker balance control. The purpose of the present doctoral thesis was to examine the agerelated connections between neuromuscular function and balance control in young and elderly people. Special emphasis was directed to the effects of different types of explosive strength training on dynamic balance control in elderly individuals. In addition, a suitable technique to measure balance control in dynamic conditions was developed.

Specific aims of the thesis were:

1. Cross-sectional study: To examine connections between reflex activity, force production capacity and dynamic balance control in young and elderly men. Based on previous literature, it was hypothesized that timing and strength of reflex responses and/or rapid force production would be related to dynamic balance control.

2. Intervention study: To determine whether neuromuscular properties and balance control can be improved in the elderly by different types of explosive strength training; pneumatic vs. plyometric type training. It was hypothesized that plyometric training may enhance reflex characteristics, whereas pneumatic training may lead to more efficient muscle activation. Both training regimens were expected to improve dynamic balance control. 


\section{METHODS}

\subsection{Subjects}

A total of 22 elderly (E, 60-72 years) and 18 young ( $Y$, 20-32 years) male subjects participated in the investigation. The study consisted of two separate designs, a cross-sectional study $(\mathrm{E}, \mathrm{n}=22, \mathrm{Y}, \mathrm{n}=10$, original articles I and II; $\mathrm{E}, \mathrm{n}=10, \mathrm{Y}, \mathrm{n}=9$, original article IV) and an intervention study (Plyometric (PLY), n=9; Pneumatic (PNE), n=11, original article III). Two different measurement protocols were used in this investigation, protocol I (original articles I, II, III) and II (original article IV). Some of the subjects participated in both studies. Table 1 shows the physical characteristics of all subjects who participated in the different experiments.

TABLE 1 Physical characteristics of the study subjects (mean \pm SD).

\begin{tabular}{lllll}
\hline Arcticles I \& II & Age (yrs) & Height $(\mathrm{cm})$ & Body mass (kg) & Fat (\%) \\
\hline Young (N=10) & $27,1( \pm 2,8)$ & $179( \pm 8)$ & $77,1( \pm 12,6)$ & $16,8( \pm 4,9)$ \\
Elderly (N=20) & $64,2( \pm 2,7)$ & $176( \pm 6)$ & $80,2( \pm 9,1)$ & $22,0( \pm 5,4)$ \\
\hline Article III & & & & \\
\hline Plyometric (N=9) & $63,4( \pm 2,3)$ & $176( \pm 7)$ & $83,9( \pm 9,7)$ & $22,8( \pm 5,4)$ \\
Pneumatic (N=11) & $65,0( \pm 2,9)$ & $176( \pm 6)$ & $77,1( \pm 7,8)$ & $21,3( \pm 5,8)$ \\
\hline Article IV & & & & \\
\hline Young (N=9) & $27,0( \pm 3,1)$ & $181( \pm 5)$ & $80,5( \pm 9,6)$ & $17,0( \pm 3,4)$ \\
Elderly (N=10) & $67,6( \pm 2,9)$ & $173( \pm 6)$ & $75,2( \pm 7,8)$ & $19,3( \pm 7,3)$
\end{tabular}


All subjects in both studies were physically active in their daily lives but did not participate in any systematic training programs. Subjects provided written informed consent and were aware of the protocol and possible risks of the study. They also had an opportunity to abort the study at any time. Subject anonymity was maintained at all times. The study was conducted according to the declaration of Helsinki and was approved by the Ethics Committee of the University of Jyväskylä.

\subsection{Protocols}

\subsubsection{Protocol I (articles I, II, III)}

To minimize learning effects, subjects took part in a three day pre-study period, where they were familiarized with the test equipment and measurements. In protocol I, body composition was measured using an InBody-720 bioimpedance measurement device (Biospace Co. Ltd., Seoul, Korea). EMG electrodes were then attached, followed by a 10 minute cycling warm up $(80 \mathrm{~W})$. At the beginning of the actual measurements, static and dynamic balance (vertical) were measured using prototype I. Maximal drop jumps were measured in a sledge ergometer (Aura and Komi 1986b) from the optimal dropping height. Electromyography (EMG) was measured from five muscles and H-reflexes were measured from the soleus muscle during drop jumps with an intensity that corresponded to $20 \pm 5 \%$ of the maximal M-wave amplitude. Maximal H-reflex, maximal M-wave, and the H-reflex excitability curve were measured from the soleus muscle during standing rest. V-wave responses were measured from soleus muscle during maximal isometric plantar flexion. EMG was measured from five muscles during maximal isometric plantar flexion, knee extension and flexion. In addition, activation level was measured from the quadriceps using the twitch interpolation method. Maximal EMG values were used for EMG data normalization. The chronological order of all tests was: (1) warm-up, (2) static and dynamic balance (2) maximal drop jump test, (3) standing H-reflex (Hmax/Mmax), (4) H-reflex during drop jumps (5), V-wave measurement, (6) maximal isometric plantar flexion, knee extension and knee flexion along with maximal EMG measurement, (7) activation level measurement. Total testing time was approximately $1.5-2 \mathrm{~h}$.

\subsubsection{Protocol II (article IV)}

Similarly to protocol I, subjects first attended a short pre-study session (1 day) where they were familiarized with the test equipment and measurements. On the actual measurement day, after preparations and a 10 minute cycling warmup $(80 \mathrm{~W})$, maximal isometric plantar flexion torque production was measured. The H-reflex excitability curve was then measured from the soleus muscle during standing rest, and latencies and peak-to-peak amplitudes of the maximal $\mathrm{H}$ - 
reflex and maximal M-wave were measured. Dynamic balance (horizontal) was measured using prototype II. During dynamic balance perturbations, EMG activity was measured from soleus (SOL), medial gastrocnemius (MG) and tibialis anterior (TIB). Soleus H-reflexes were also measured 10ms, $30 \mathrm{~ms}$ and $90 \mathrm{~ms}$ after each perturbation type (anterior and posterior, Fast and Slow) at an intensity corresponding to $20 \pm 4 \%$ of the maximal M-wave amplitude. In addition, SLR, MLR and LLR were analysed from SOL, and MLR and LLR from TIB after Fast posterior and anterior perturbations, respectively. SLR responses were not detectable from TIB, probably because stretch velocity was too low. Total test session duration was approximately 2-2.5 hours.

\subsection{Dynamic balance measurement systems}

\subsubsection{Prototype I, Vertical perturbations (articles I, II, III)}

The first prototype included the frame of the system, pneumatic and control parts (Figure 4) and a safety frame. The system's frame is a $600 \times 600 \mathrm{~mm}$ plate. The valves (Rexroth, E/P pressure regulator series ED05, Bosch Rexroth; Germany) are placed in the middle section. Supporting plates are placed in the corners, which provide appropriate stiffness to the system. Cylinders (Pimatic, P2520-40/16-125, Polarteknik PMC Oy Ab; Vantaa, Finland) are placed in each corner, one centimetre inside each edge. The area of each cylinder is $40 \mathrm{~mm}^{2}$ and the cylinder displacement is $125 \mathrm{~mm}$, which gives the plate a 12 degree dropping capacity in maximal drops. A $3 \mathrm{~mm}$ thick plate is placed over the cylinders. This plate is the bottom plate from a BT4 balance platform. The system is controlled via National Instrument cards Ni cDaq-9172 and Ni 9263 (National Instruments Co.; Austin, USA), and the guiding software was built for Labview 7.1 (National Instruments Co.; Austin, USA). During the measurements, one edge of the plate was dropped at a time. A drop of $125 \mathrm{~mm}$ was performed during a $180 \mathrm{~ms}$ period. In this measurement, the edge returned to the starting position one second after dropping. 


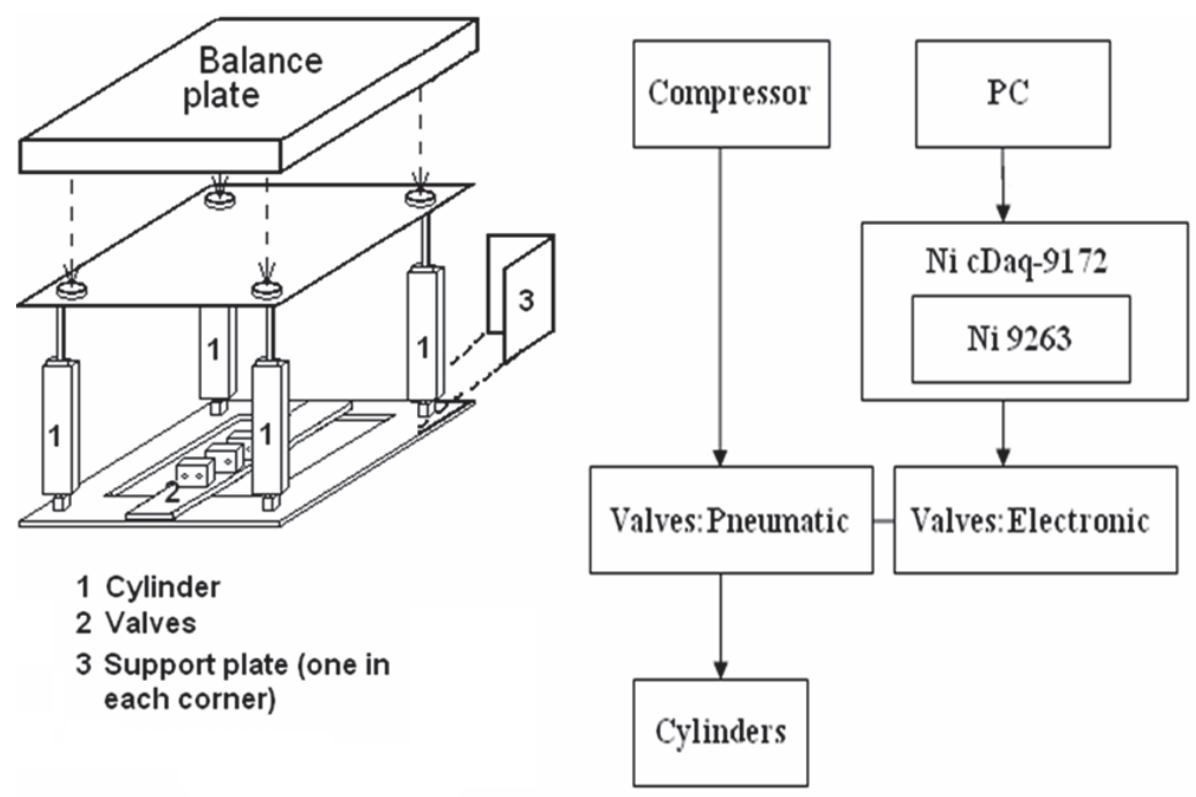

FIGURE 4 Vertical dynamic balance measurement system and flow chart.

\subsubsection{Prototype II, Horizontal perturbations (article IV)}

In prototype II (figure 5), horizontal perturbations were used to simulate a more natural situation. Dynamic balance was measured using the same commercial force plate (BT4 balance platform, HurLabs Oy, Tampere, Finland), which was placed over a perturbation device (University of Jyväskylä, Finland). The perturbation device consists of two steel frames (bottom $910 \times 910 \mathrm{~mm}$, middle 910 x $610 \mathrm{~mm}$ ), constructed from four $60 \times 30 \mathrm{~mm}$ steel tubes. A steel plate is placed over the middle frame, upon which sits the force plate. Wheels are placed under the middle frame and the upper steel plate enabling sideways movement of the middle plate and antero-posterior movement of the upper steel plate. Two electromechanical cylinders (EMC, Bosch Rexroth, Germany) produce movement of the frames with a maximal amplitude of $300 \mathrm{~mm}$, maximal force of $4000 \mathrm{~N}$ and maximal velocity of $70 \mathrm{~cm} / \mathrm{s}$. The cylinders are connected to three-phase motors (MSK030B, Bosch Rexroth, Germany) and frequency encoders (HCS02, Bosch Rexroth, Germany), which are controlled via an NI 4-channel analogue card (NI 9263, National Instruments, USA) and NI 8-channel digital card (NI 9472, National Instruments, USA). Both cards are connected to a USB card (NI cDAQ9172, National Instruments, USA), which is connected to the computer. Perturbation parameters (acceleration, velocity, amplitude) are determined and perturbations delivered manually using Labview (National Instruments, USA) and IndraWorks software (Bosch Rexroth, Germany). 


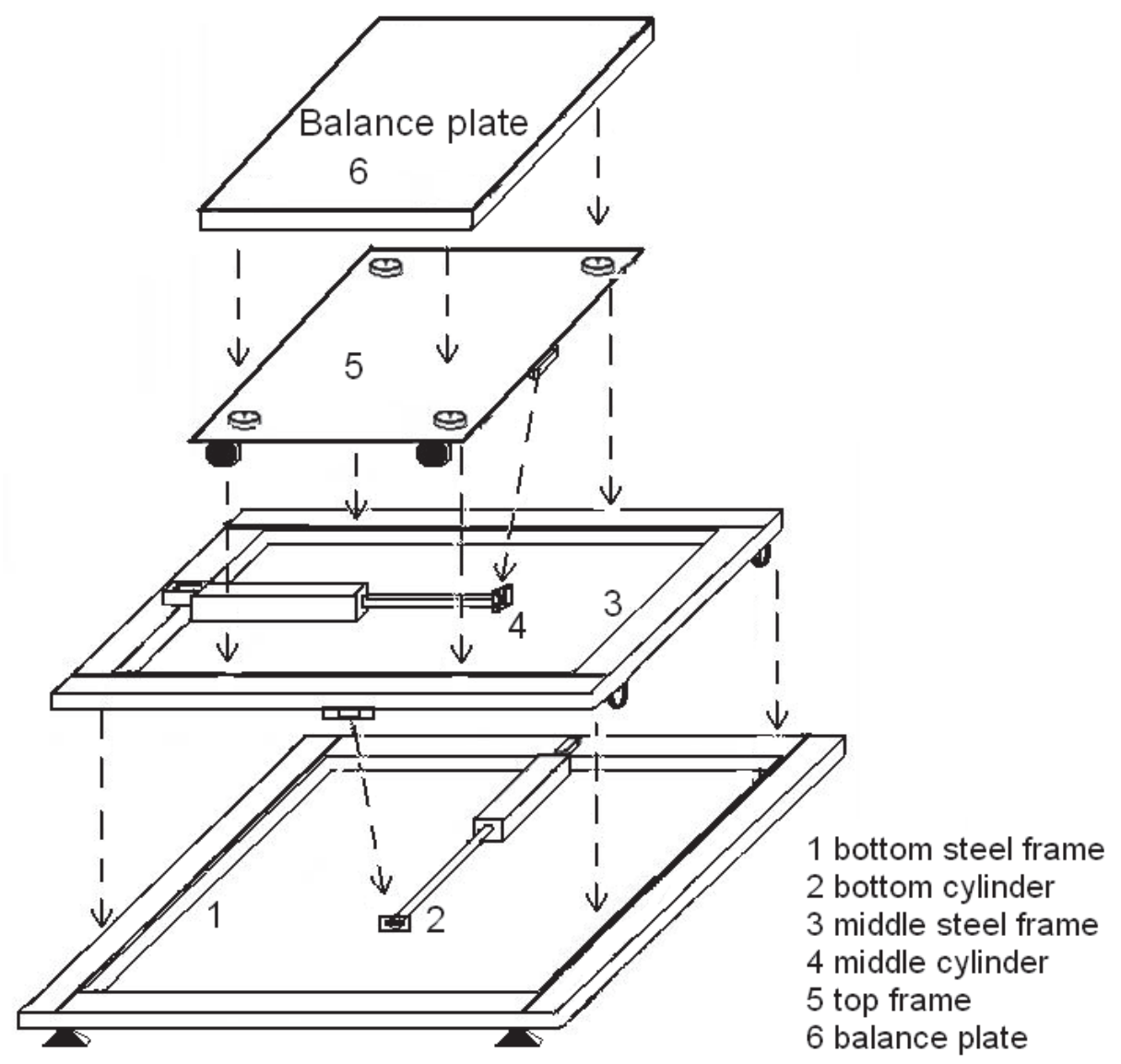

FIGURE 5 Horizontal dynamic balance measurement system. The bottom cylinder moves the middle frame in the anterior-posterior direction, and the middle cylinder moves the top frame in the medial-lateral direction.

\subsection{Measurements}

\subsubsection{Static balance (article I)}

Static balance control was measured using a balance trainer (BT4 balance platform, Hurlabs Oy, Tampere, Finland). The participants stood quietly for at least $5 \mathrm{~s}$ (pre-phase) before the measurement. After the pre-phase, static balance was measured for the next $5 \mathrm{~s}$. Static balance was measured twice and the attempt with the least average sway in the $\mathrm{x}$ - and $\mathrm{y}$-directions was used for analysis. Maximal anterior-posterior (y) and medial-lateral ( $\mathrm{x}$ ) centre-of-pressure swaying distance was assessed. 


\subsubsection{Vertical dynamic balance (articles I, III)}

In protocol I, dynamic balance was measured in the vertical direction with sudden perturbations. Subjects stood on the balance plate for two 30 second sets, which were interrupted by four sudden balance perturbations, one in each direction (left, right, forward, backward). Subjects did not know in advance the direction or exact timing of the perturbation. During each perturbation, one side of the plate dropped $12.5 \mathrm{~cm}$ free fall and stopped suddenly. The plate returned to the starting position 1 second after the perturbation. Perturbations were induced approximately every six seconds during a 30 second period. A black mark was placed on the wall to enable the subjects to focus on a fixed point during the measurements. Dynamic 30 second sets were measured twice and the attempt with the least average COP sway in the $x$ - and $y$-directions was chosen for analysis. Because perturbations were given in four directions, the average of the perturbations in the left-right $(\mathrm{x})$ and backward-forward $(\mathrm{y}) \mathrm{di}$ rections were used to indicate medio-lateral and antero-posterior balance displacement, respectively. Maximal swaying distance in medio-lateral $(\mathrm{x})$ and anterior-posterior (y) stabilograms were analysed during a 1 second period after the disturbance with the platform remaining in the tilted position.

\subsubsection{Horizontal dynamic balance (article IV)}

In protocol II, the dynamic balance measurement system was modified to move in the horizontal direction, where balance was measured in two different conditions (Slow: $\max$ acceleration $0.3 \mathrm{~m} / \mathrm{s}^{2}$, max velocity $15 \mathrm{~cm} / \mathrm{s}$, displacement 7.5 $\mathrm{cm}$; Fast: max acceleration $4.0 \mathrm{~m} / \mathrm{s}^{2}$, max velocity $25 \mathrm{~cm} / \mathrm{s}$, displacement 12.5 $\mathrm{cm})$. These conditions were chosen to enable comparisons of Slow and Fast perturbations, but also to enable stretch reflexes to be analysed in the Fast condition. In both conditions, 10 balance perturbations were delivered in both anterior (plate moved forward) and posterior (plate moved backward) directions, in 8 to 12 second intervals in a random order. Similar to vertical perturbations, a black mark was fixed on the wall $2.8 \mathrm{~m}$ from the subject at eye level in order to stabilize the subject's visual focus during the measurements. COP displacement was analysed and the average of ten perturbations was calculated from each direction and speed. Peak displacement and time to peak displacement were analysed. In addition, peak-to-peak displacement during the recovery phase was analysed $500 \mathrm{~ms}$ from the end of plate movement. RMS EMG from SOL (soleus), MG (medial gastrocnemius) and TIB (tibialis anterior) was analysed during the perturbation phase (from onset to end of perturbation; $1000 \mathrm{~ms}$ during Slow and $600 \mathrm{~ms}$ during Fast) and the recovery phase (500 ms window from end of perturbation). EMG results were normalized to maximal EMG activity measured during Fast perturbations within a 100 ms window. 


\subsubsection{Electromyography (EMG) (articles I, II, III and IV)}

EMG was measured from five muscles (vastus lateralis (VL), rectus femoris (RF), biceps femoris (BF), soleus (Sol) and medial gastrocnemius (MG)) in protocol I and three muscles (Sol, MG and tibialis anterior (TIB)) in protocol II using bipolar EMG electrodes (Ag- $\mathrm{AgCl}, 2 \mathrm{~cm}$ interelectrode distance). Before placement, the skin was shaved, abraded with sand paper and cleaned with alcohol. The impedance of the electrodes was measured and if the resistance was higher than $10 \mathrm{k} \Omega$, the preparation was repeated. Electrodes were placed according to the recommendations of SENIAM (Hermens et al. 1999). Data were sampled at 1000 $\mathrm{Hz}$ using an EMG measuring system (Noraxon Telemyo 2400R, Scottsdale, USA in protocol I and Neurolog NL 900 D, Digitimer Ltd, Hertfordshire, England in protocol II), amplified (gain 1000) and band pass filtered (10-500 Hz).

\subsubsection{Torque production (articles I, III, IV)}

Plantar flexor MVC was measured using a custom-built force dynamometer (University of Jyväskylä, Finland). Torque values were calculated by multiplying the force with the lever arm (from ankle joint to distal head of the first metatarsal bone). Subjects sat in the dynamometer with hip, knee and ankle joint angles at 110, 180 and $90^{\circ}$, respectively. Subjects performed five MVCs at $1 \mathrm{~min}$ intervals. Knee extension rapid torque production was measured using a knee dynamometer (hip joint $110^{\circ}$ and knee joint $120^{\circ}$; Hurlabs Oy, Tampere, Finland). Subjects performed three isometric MVCs with 1 min rest between trials and they were instructed to perform the MVCs as fast as possible. Maximal EMG (RMS) was analysed using a $200 \mathrm{~ms}$ window around the MVC, which was used for normalization in protocol I. A force transducer was placed just above the ankle joint. Torque at $200 \mathrm{~ms}$ from the onset of torque production and EMGs (0-200 ms) were analysed in both isometric conditions. Torque values were calculated again by multiplying the force with the lever arm. Torque and EMG data were collected and analysed using an A/D converter (CED Power 1401, CED Ltd., Cambridge, UK) and Spike 5.14 software (CED Ltd., Cambridge, UK).

\subsubsection{Activation level and neural drive (article I)}

In protocol I, superimposed twitch (figure 5) was measured from the quadriceps muscle group (Merton 1954). Measurements were performed during knee extension MVC with supramaximal stimulation intensity (passive twitch max + $25 \%)$. Voluntary torque and superimposed stimulation torque were analysed, and activation level was calculated using the following formula (Strojnik and Komi 1998): 


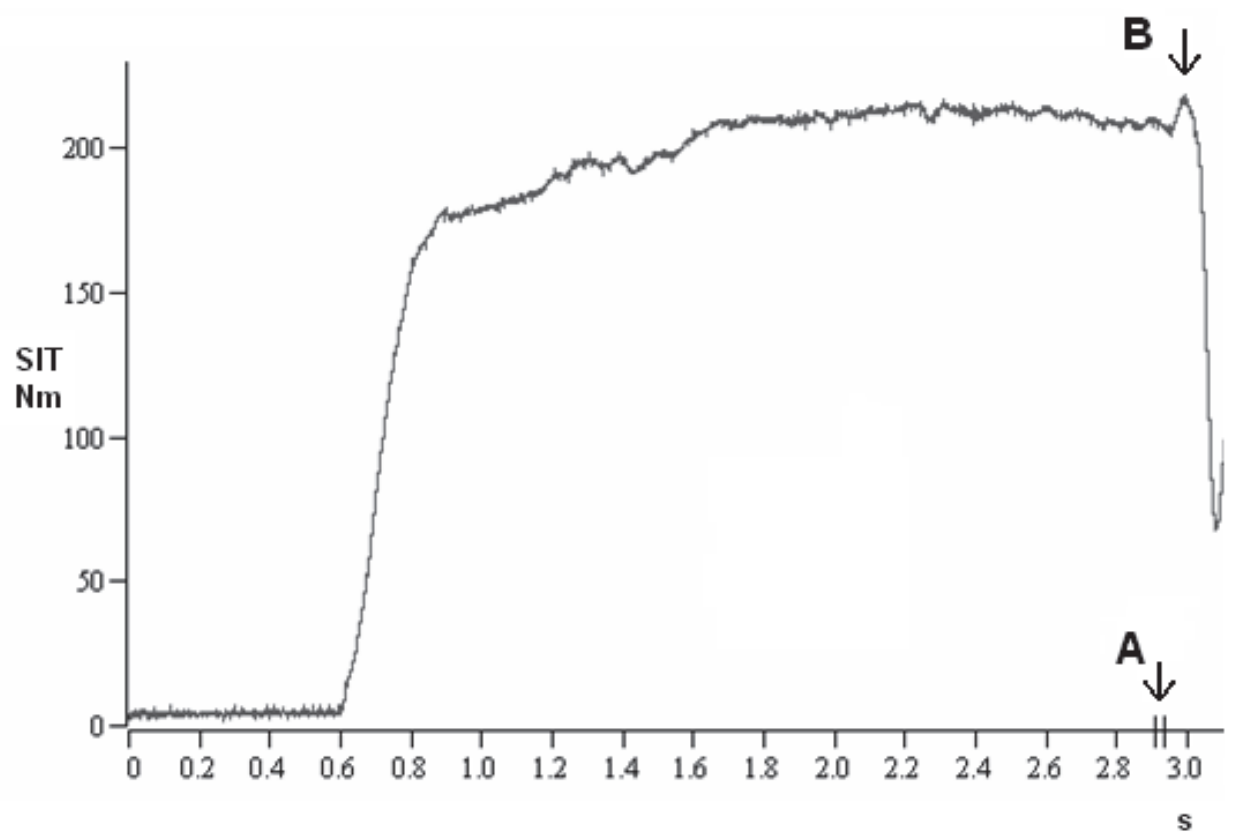

FIGURE 5 Illustration of the superimposed twitch test. The bottom arrow (A) indicates the location of the double pulse stimulation, and the arrow above the force curve (B) shows the additional force caused by stimulation.

$$
\mathrm{AL}=100-\mathrm{D}^{*}(\mathrm{TDST} / \mathrm{TMVC}) / \mathrm{TDTW}^{*} 100
$$

where $\mathrm{D}$ is the difference between the torque level before the twitch and maximal torque, TDST is maximal torque after a double stimulation pulse, TMVC is maximal voluntary contraction torque and TDTW is maximal passive twitch torque.

The V-wave was measured from the soleus muscle in the same way as the H-reflex in standing rest conditions, but with a supramaximal stimulation intensity and during plantar flexion MVC. The participants performed five MVCs for $3 \mathrm{~s}$ each with $1 \mathrm{~min}$ between contractions. Peak-to-peak amplitudes of Vwaves and maximal M-waves were analysed and the average of five performances was calculated. The level of efferent neural drive from spinal alphamotoneurons was evaluated by calculating the V/Mmax ratio (Aagaard et al. 2002). 


\subsubsection{Drop jumps (articles II, III)}

Maximal drop jumps were performed on a sledge ergometer (figure 6). Sledge ergometer force was measured using a force plate which was placed perpendicular to the jumping direction. Jumping height was measured using an electronic odometer, which was also used to assess the transition point (lowest point) between the braking and push-off phases. Take-off velocity was calculated from the odometer signal. The system is described in more detail in previous papers (Aura and Komi 1986a; Kyröläinen et al. 1990). Optimal dropping height was assessed by increasing the dropping height by $10 \mathrm{~cm}$ after each jump until the rebound jump height no longer increased. Subjects performed 5 to 10 jumps in total depending on the optimal dropping height. Subjects were allowed to choose an appropriate knee angle during the landing, but it was visually controlled to be between 70-90 degrees (full extension 180 degrees), and verified by checking the odometer signal from the computer. Average forces during the braking and push-off phases were analysed. Three different time windows were used to analyse EMG during drop jump performances: pre-activity (-100 $\mathrm{ms}-0 \mathrm{~ms}$ ) before ground contact, braking phase and push-off phase. The braking phase was determined from the beginning of force production to the lowest sledge position, and the push-off phase from the lowest sledge position to takeoff from the force plate. EMGs were normalized to maximal EMG measured in isometric conditions.

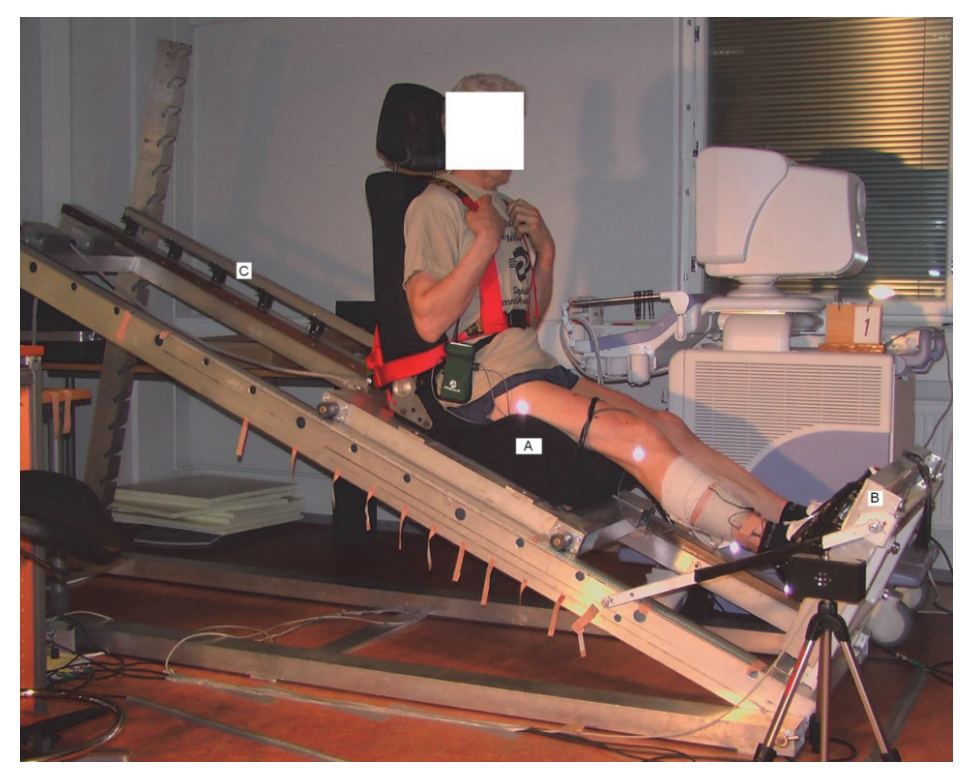

FIGURE 6 Sledge ergometer. A) sledge seat; B) force plate; C) electronic odometer. Jumping angle can be modified between 0-40 degrees from horizontal in approximately 2 degree steps. 


\subsubsection{H-reflex (articles I, II, III and IV)}

H-reflexes were measured during standing rest in both protocol I and protocol II. During the measurement, subjects stood relaxed with earmuffs on. H-reflex and M-wave responses were measured from the soleus muscle by stimulating the tibial nerve in the popliteal fossa. The most appropriate stimulation point was located based on the strength of the EMG signal (highest M-wave peak-topeak response). An increasing intensity interval ( $\mathrm{mA}$ ) was then chosen in a way that the H-reflex excitability curve (figure 7) could be measured with at least 30 measurement points up to the maximal M-wave. During the stimulations, a cathode $(1.5 \times 1.5 \mathrm{~cm})$ was placed over the tibial nerve and an anode $(5 \times 8 \mathrm{~cm})$ was placed superior to the patella. Electrodes were fixed in place using elastic tape. The stimulation pulse was rectangular with a duration of $0.2 \mathrm{~ms}$ and was given at 10 second intervals (Digitimer model DS7A, Digitimer Ltd., Welwyn Garden City, England). From the standing rest measurement, Hmax and Mmax were measured and Hmax/Mmax-ratios were analysed and calculated. Background EMG activity (RMS) was analysed during a $200 \mathrm{~ms}$ (protocol I) or 100 ms (protocol II) window before the electrical stimulation, and values were normalized to maximal EMG activity obtained during a $200 \mathrm{~ms}$ window around the point of isometric MVC in protocol I, and a $100 \mathrm{~ms}$ window around the point of maximal EMG during Fast balance perturbations in protocol II. In addition, Hmax and Mmax latencies were analysed by visual inspection from the stimulus artifact to the first deflection of each response in protocol II. M-wave latency was deducted from H-reflex latency, and the result was normalized to subject height to yield H-reflex propagation time, which incorporates nerve conduction velocity and synaptic transmission time.

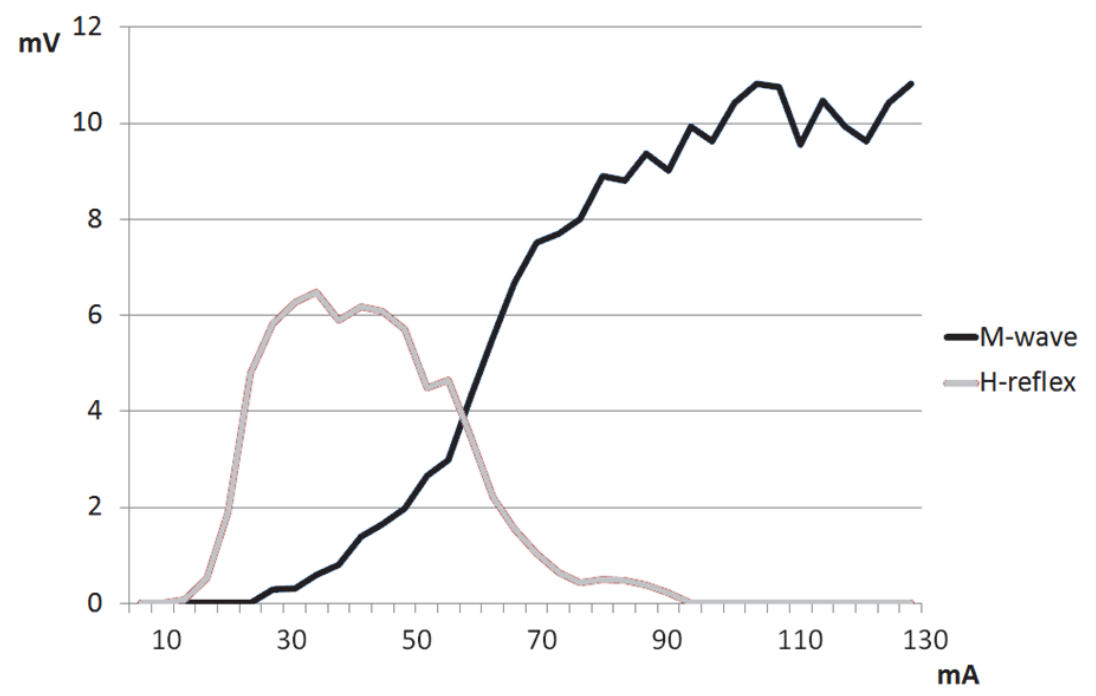

FIGURE 7 Example of the M-wave and H-reflex recruitment curves measured during standing rest as a function of stimulation intensity. 
In protocol I, H-reflexes (figure 8) were also measured in the sledge ergometer during maximal drop jumps (Avela et al. 2006). The same electrode and stimulus settings were used as in resting H-reflex measurements, and the stimulus was given $20 \mathrm{~ms}$ after ground contact. This delay was used to avoid collision of the stretch reflex response with $\mathrm{M}$-wave and H-reflex responses, and to ensure that the excitability of the H-reflex would be highest (Dyhre-Poulsen et al. 1991). The stimulus intensity was adjusted so that the current intensity corresponded to $20 \pm 5 \%$ of the maximal M-wave amplitude during the subsequent jumps. Each trial was checked after the jump to secure the correct M-wave level, and five successful trials were performed and analysed individually. Peak-to-peak M-wave $20 \%$ (from maximal M-wave), H-reflex and H/M20\%-ratio were analysed. During drop jumps, the $20 \%$ M-wave level was similar between the age groups (article II) and training groups (article III) making them directly comparable.

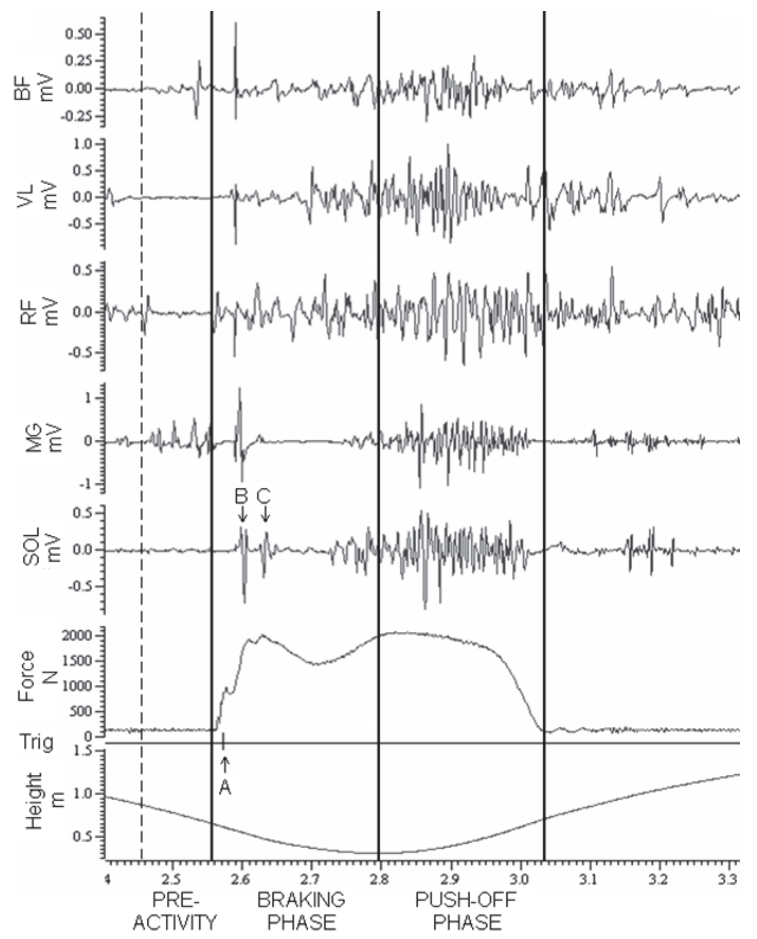

FIGURE 8 Typical example of a drop jump performance where H-reflex was measured. A) stimulation trigger; B) $20 \pm 5 \%$ of the maximal M-wave; C) $\mathrm{H}$-reflex response.

In protocol II (article IV), H-reflexes were measured $10 \mathrm{~ms}, 30 \mathrm{~ms}$ and $90 \mathrm{~ms}$ after each balance perturbation. The stimulus was triggered using a clock pulse from the balance perturbation device via a Neurologger timer (Neurolog NL 405, Digitimer Ltd, Hertfordshire, England), where an appropriate delay was set. The delay between the clock pulse and the onset of the balance board movement was $10 \mathrm{~ms}$, which was taken into account when adjusting the appro- 
priate delay. The maximal M-wave was measured during the first balance perturbation. The stimulus intensity was then adjusted so that the current intensity corresponded to $20 \pm 4 \%$ of maximal M-wave amplitude. Ten successful trials were measured and averaged from both perturbation directions, at both perturbation velocities and with all three stimulation delays. From the stimulation responses, peak-to-peak M-wave (20\% of M-max) and H-reflex responses were analysed and the H/M20\%-ratio was calculated. In all cases, to achieve 10 successful trials, 2-4 additional perturbations were measured because of M-wave values that were too low or too high. This resulted in a total of 140-160 trials. Stimulation delays were varied randomly and 2 minute rest periods were given after every 20 perturbations to minimize possible muscle fatigue. EMG activity (100-0 ms before the stimulation) normalized to maximal EMG from the Fast perturbation was used to denote background EMG for standing rest before the perturbation.

\subsubsection{Stretch reflex (article IV)}

For the stretch reflex analysis (figure 9), EMG data from ten trials were rectified and averaged from posterior (SOL) and anterior (TIB) perturbations. Firstly, background muscle activity was analysed within a $50 \mathrm{~ms}$ window before the SLR and MLR components in SOL and TIB, respectively. The onset of these components was determined relative to ankle joint displacement measured with a goniometer using the background EMG +3 SD criterion and visual inspection (Kawashima et al. 2004; Nardone et al. 1995; Petersen et al. 1998). The SOL MLR and LLR components were analysed approximately $20 \mathrm{~ms}$ and $50 \mathrm{~ms}$ after the onset of the SLR, and TIB LLR $30 \mathrm{~ms}$ after the onset of the MLR (Kawashima et al. 2004; Petersen et al. 1998). Reflex responses were then normalized to maximal EMG measured during Fast anterior (TIB) and posterior (SOL) perturbations. 

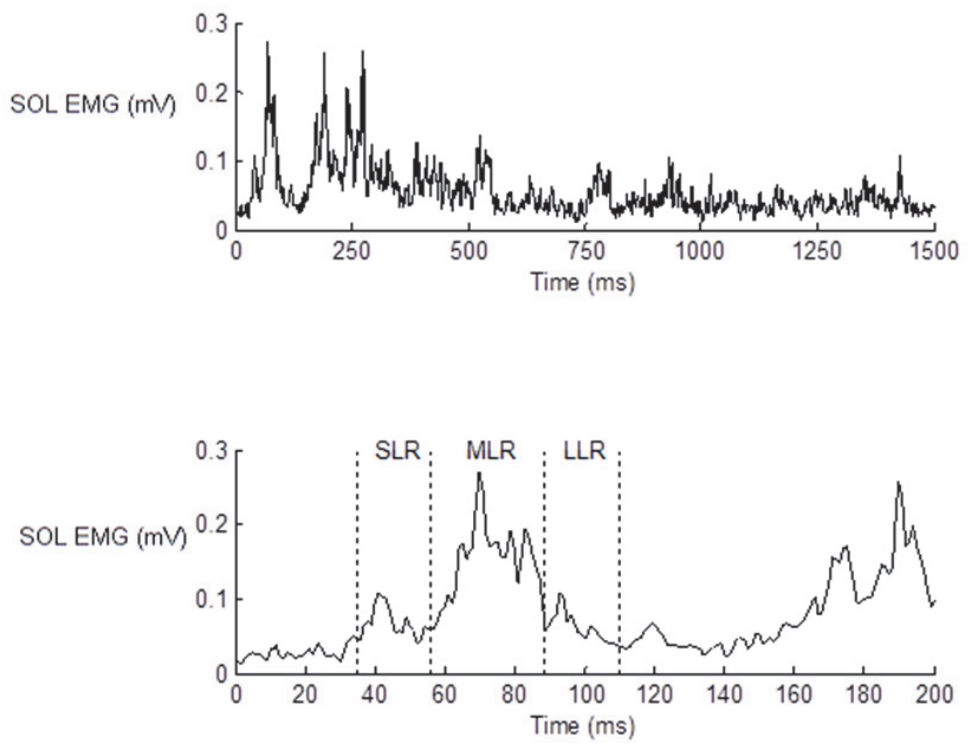

FIGURE 9 Soleus muscle full-wave rectified EMG (top) and stretch reflex (bottom) responses during a Fast posterior perturbation.

\subsubsection{Explosive training (article III)}

Subjects trained 2 times per week during weeks 1-3 and 9-12 of the 12-week training period. In weeks 5-7 they trained 3 times per week, while in weeks 4 and 8 they had only one session which was a control measurement session. PLY trained the legs using a sledge apparatus (University of Jyväskylä, Finland) that enables drop jumps to be performed more safely than standard vertical jumping, and was thus deemed more suitable for older subjects. The PNE group trained using pneumatic leg extension (knee extensions) and calf raise (plantar flexion) devices (HUR, Kokkola, Finland) with a load of $40 \%$ of MVC, which was measured and updated every four weeks. This was measured by increasing the load by $10 \mathrm{Nm}$ after each trial until full leg extension (180 degrees) and plantar flexion (150 degrees) were no longer achieved. In both groups, 6 repetitions and 5 sets with 3 minute intervals between the sets were used during the entire period and trials were performed as explosively as possible. In the PLY, the jumping angle was 23.6 degrees from horizontal and the load consisted of sledge weight $(33 \mathrm{~kg})$ and each subject's own body mass. Jumps were performed as continuous countermovement jumps. The lowest knee angle during the jumps was 70-90 degrees, which was controlled by visual feedback. In PNE, knee joint range of motion was 90 degrees (from 90 to 180 degrees) during knee extension and approximately 60 degrees (from 90 to 150 degrees) during plantar flexion. Because of the nature of the different training tasks, it was not possible to match the training loads between groups. The average load in PLY was $459 \pm$ $38 \mathrm{~N}$ during the entire 12-week training period. For leg extension, absolute loads were $94 \pm 13 \mathrm{~N}, 118 \pm 20 \mathrm{~N}$ and $148 \pm 20 \mathrm{~N}$ in weeks 1-4, 5-8 and 9-12, re- 
spectively. Corresponding values for calf raises were $147 \pm 22 \mathrm{~N}, 200 \pm 27 \mathrm{~N}$ and $308 \pm 48 \mathrm{~N}$, respectively. Both groups used the same additional training protocol for the upper body to improve overall strength gains and thereby improve training motivation. However, as the present thesis focused on lower limb characteristics and balance control, adaptations of the upper body were not measured during the training period. In addition to the training period, 12 subjects (5 from PLY and 7 from PNE) participated in detraining measurements (DET) for dynamic balance control and rapid isometric knee extension torque production 8 weeks after the training period.

\subsection{Statistical methods}

Mean values and standard deviations (SD) were calculated (protocol I and protocol II). In protocol I, age related differences were measured using nonparametric dependent-samples T-tests (vertical balance) and independent samples T-tests (neuromuscular system) depending on the normality of the results. In protocol II, multivariate tests (MANOVA, Wilks` lambda) between independent variables (age*speed) were used to assess horizontal balance, H-reflex and EMG parameters, and where significance was observed, results were further analysed using one-way ANOVA. For other dependent variables, differences between groups were examined using independent samples T-tests and within groups using paired samples T-tests.

For training data, two-way repeated measures ANOVA was used to assess the effects of measurement interval (pre, 4, 8 and 12 weeks) and training mode (PNE, PLY). Mauchly's test of sphericity was used, and where this assumption was violated, Geisser-Greenhouse adjustments were applied. Where significant main effects were observed, pairwise comparisons were used to identify the location of differences between measurement intervals and training modes. For variables that were only examined pre and post training, dependent samples (within groups) and independent samples (between groups) $t$ tests were used. Correlations between balance parameters and neuromuscular function were assessed using Spearman's principle (protocol I) and Pearson's rank correlation coefficient (protocol II). The results were considered statistically significant for p-values below 0.05. Data were analyzed using SPSS statistical software (Chicago, IL, USA). 


\section{RESULTS}

\subsection{Cross-sectional study: Age-related differences}

The main results of this thesis are presented in this section. Additional information can be found from the original articles.

\subsubsection{Balance control}

In protocol I, balance was measured in static and dynamic (vertical) conditions. In static conditions, no age-related differences were observed, whereas in dynamic conditions, Young showed smaller balance displacement in the anteriorposterior $(p<0.05)$ direction (figure 10$)$. However, in the medial-lateral direction, no age-related differences were observed.

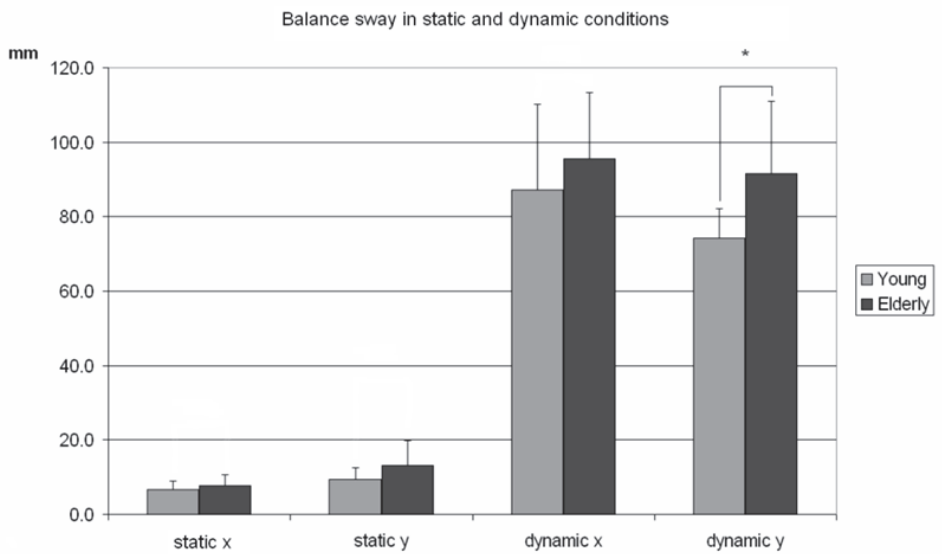

FIGURE 10 Postural sway in static and dynamic balance conditions, ${ }^{*} \mathrm{p}<0.05$. 
In protocol II, balance was measured only in dynamic (horizontal) conditions at two different velocities (figure 11). In Slow, Young showed smaller $(\mathrm{p}<0.05$, figure 12) maximal balance displacement during anterior perturbations. In Fast, no age-related differences were observed in peak displacement, however in the recovery phase, Young showed a trend $(p=0.086)$ towards faster recovery. No age-related differences were observed in posterior perturbations in Slow or Fast conditions. In addition, time to anterior peak displacement in Elderly increased significantly ( $p<0.05$, figure 13 ) from Slow to Fast, which was not observed in Young. No age-related EMG differences were observed in the Slow situation. In Fast, Elderly showed higher TIB activity $(p<0.05)$ in the recovery phase after Fast anterior perturbations compared to Young (table 2).

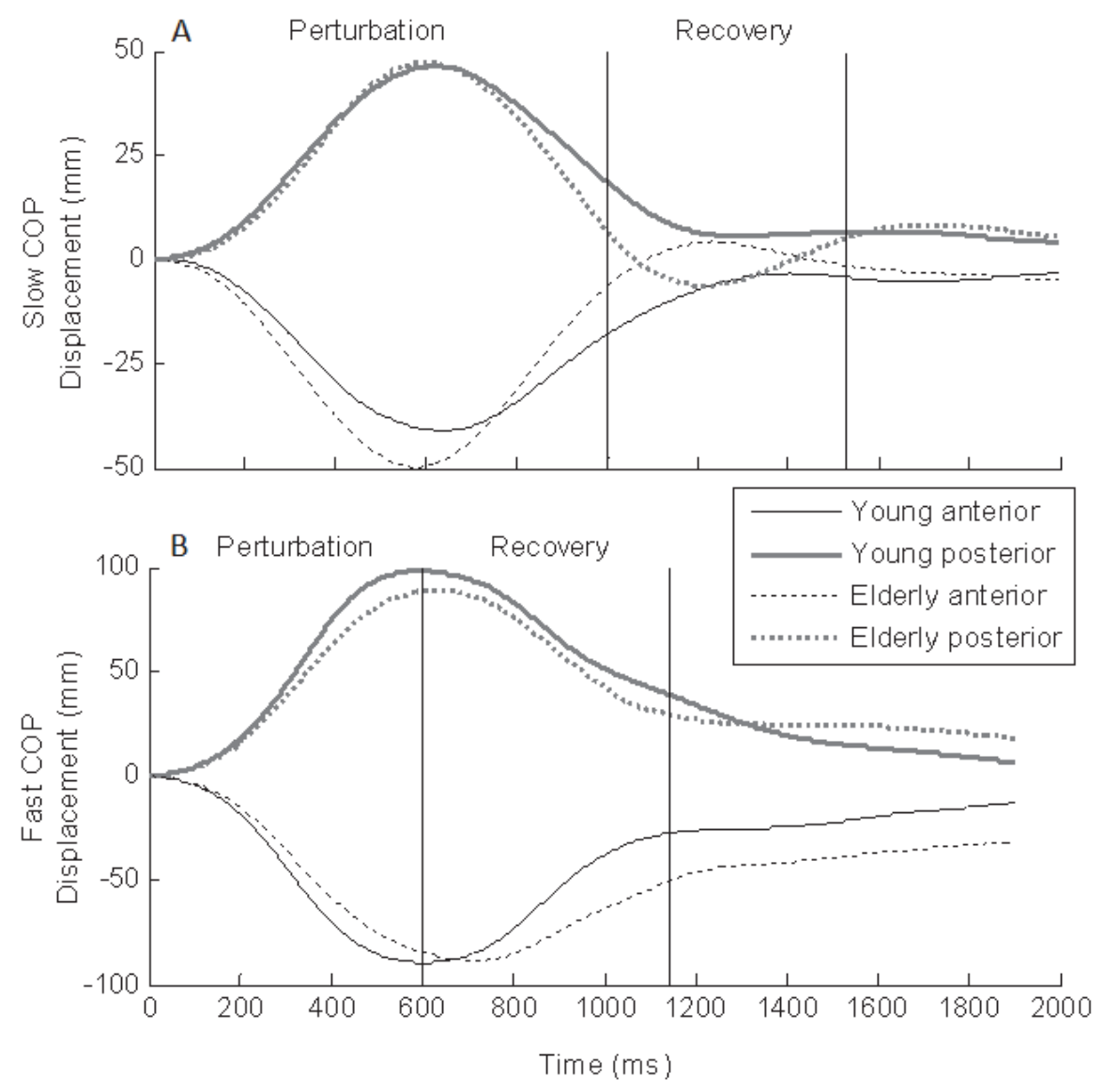

FIGURE 11 Anterior and posterior balance displacement after Slow (A) and Fast (B) perturbations. Values are group means. Positive values denote anterior displacement. Time 0 on the $x$-axis denotes perturbation onset. 


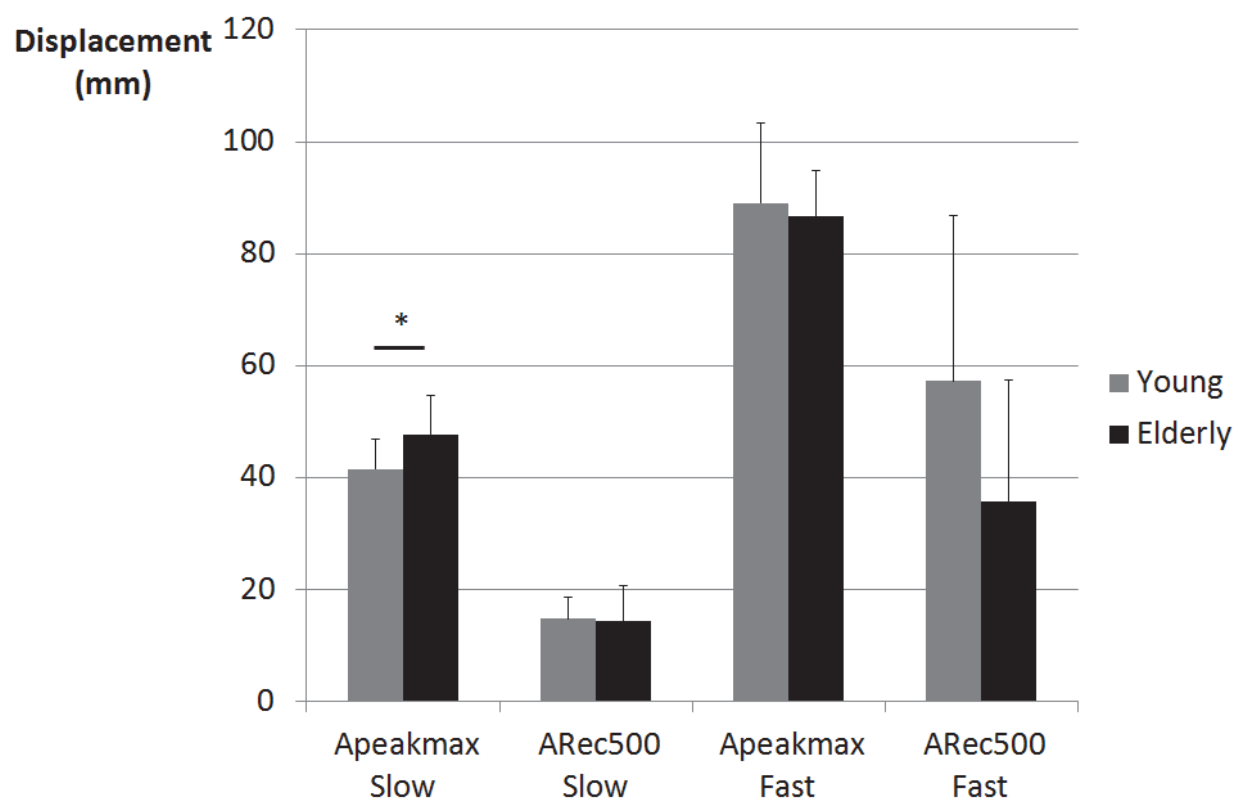

FIGURE 12 Balance displacement during and after Slow and Fast anterior perturbations (Apeakmax $=$ peak displacement; Arec500 = peak-to-peak displacement 0-500 ms after the perturbation), ${ }^{*} \mathrm{p}<0.05$.

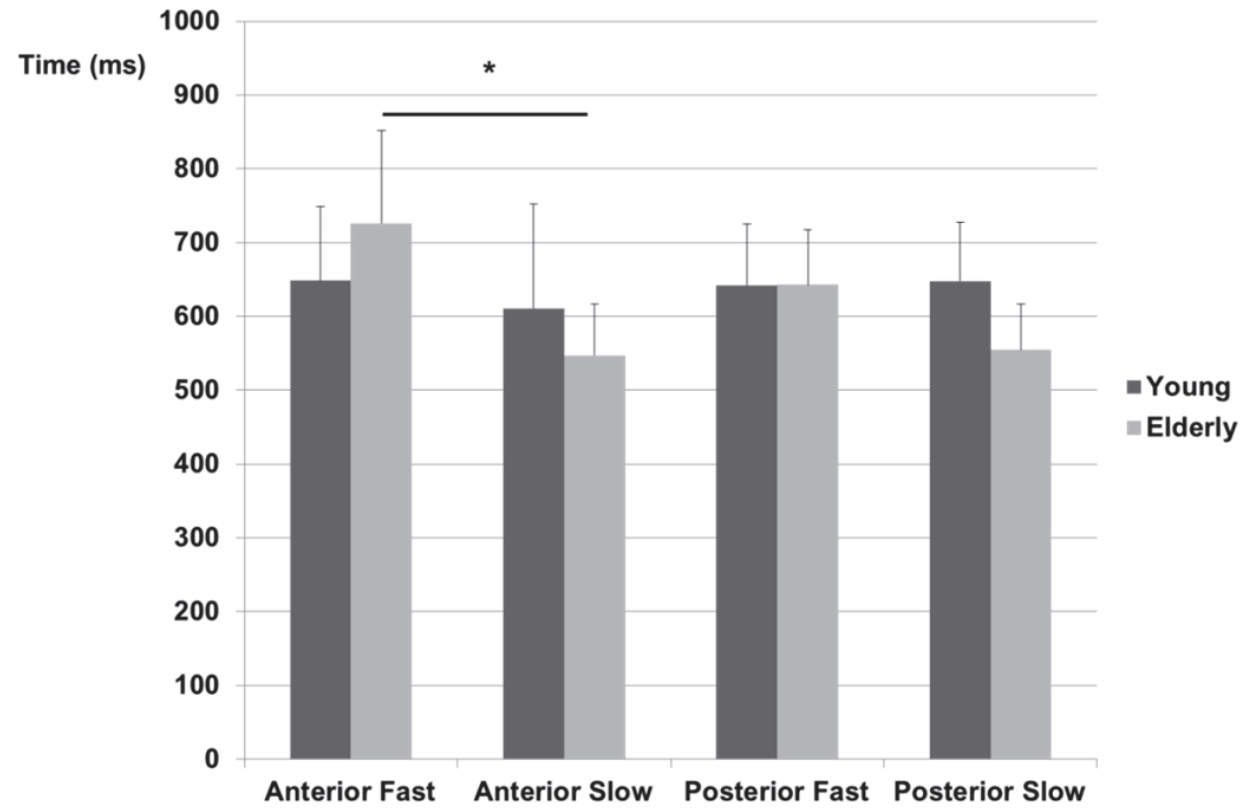

FIGURE 13 Time to peak displacement during Slow and Fast anterior and posterior perturbations, ${ }^{*} \mathrm{p}<0.05$. 
TABLE 2 Normalized SOL, MG and TIB EMG activity measured during Slow and Fast perturbations. SA (Slow anterior), B (background EMG), P (perturbation), R (recovery), SP (Slow posterior), FA (Fast anterior), FP (Fast posterior). ${ }^{*} \mathrm{p}<0.05$, $£ \mathrm{p}<0.01$, between age groups; \# $\mathrm{p}<0.05$, $\mathrm{a} \mathrm{p}<0.01, \$ \mathrm{p}<0.001$, between perturbation velocities.

Young Elderly

\begin{tabular}{ccccccc}
\hline & SOL & MG & TIB & SOL & MG & TIB \\
\hline SA B & $0.152 \pm 0.066$ & $0.113 \pm 0.039$ & $0.013 \pm 0.006$ & $0.154 \pm 0.057$ & $0.127 \pm 0.083$ & $0.022 \pm 0.013$ \\
SA P & $0.125 \pm 0.048$ & $0.105 \pm 0.041$ & $0.106 \pm 0.048$ & $0.180 \pm 0.074$ & $0.130 \pm 0.046$ & $0.137 \pm 0.066$ \\
SA R & $0.146 \pm 0.055$ & $0.111 \pm 0.049$ & $0.028 \pm 0.019$ & $0.199 \pm 0.096$ & $0.141 \pm 0.062$ & $0.037 \pm 0.024$ \\
SP B & $0.158 \pm 0.066$ & $0.121 \pm 0.045$ & $0.013 \pm 0.005$ & $0.169 \pm 0.075$ & $0.115 \pm 0.065$ & $0.021 \pm 0.017$ \\
SP P & $0.200 \pm 0.074$ & $0.212 \pm 0.081$ & $0.018 \pm 0.013$ & $0.243 \pm 0.075$ & $0.205 \pm 0.070$ & $0.048 \pm 0.036$ \\
SP R & $0.177 \pm 0.065$ & $0.142 \pm 0.064$ & $0.015 \pm 0.007$ & $0.190 \pm 0.061$ & $0.149 \pm 0.006$ & $0.042 \pm 0.022 £$ \\
\hline FA B & $0.147 \pm 0.054$ & $0.143 \pm 0.056$ & $0.031 \pm 0.019$ & $0.171 \pm 0.067$ & $0.135 \pm 0.065$ & $0.027 \pm 0.020$ \\
FA P & $0.136 \pm 0.030$ & $0.136 \pm 0.049$ & $0.387 \pm 0.100 \$$ & $0.156 \pm 0.069$ & $0.088 \pm 0.030$ & $0.460 \pm 0.082 \$$ \\
FA R & $0.158 \pm 0.062$ & $0.133 \pm 0.064$ & $0.136 \pm 0.096$ a & $0.212 \pm 0.084$ & $0.149 \pm 0.085$ & $0.264 \pm 0.119 \$ *$ \\
FP B & $0.167 \pm 0.063$ & $0.147 \pm 0.066$ & $0.017 \pm 0.010$ & $0.202 \pm 0.066$ & $0.138 \pm 0.061$ & $0.034 \pm 0.032$ \\
FP P & $0.400 \pm 0.072 \$$ & $0.432 \pm 0.054 \$$ & $0.071 \pm 0.063 \#$ & $0.509 \pm 0.131 \$ *$ & $0.453 \pm 0.065 \$$ & $0.019 \pm 0.006$ \\
FP R & $0.264 \pm 0.067 \#$ & $0.266 \pm 0.068 \propto$ & $0.056 \pm 0.039 \propto$ & $0.269 \pm 0.069 \#$ & $0.281 \pm 0.081 \propto$ & $0.125 \pm 0.079$ ** \\
\hline
\end{tabular}

\subsubsection{Torque production}

Isometric torque was measured from knee extensor (protocol I) and plantar flexor muscles (protocol I and II). In protocol I, Young showed higher maximal knee extensor torque $(\mathrm{p}<0.01)$ and rapid torque production $(\mathrm{p}<0.01)$, whereas in the plantar flexors, a significant difference was only observed in rapid torque production $(\mathrm{p}<0.01)$. In protocol II, Young showed higher values in both maximal $(\mathrm{p}<0.05)$ and rapid $(\mathrm{p}<0.05)$ plantar flexor torque production. Force data are summarized in table 3. No age-related differences were observed in EMG responses during the first $200 \mathrm{~ms}$ of torque production in either muscle group in protocol I. There was a negative correlation between $200 \mathrm{~ms}$ torque produc- 
tion and dynamic y-direction sway when both groups' data were combined ( $\mathrm{r}=-$ $0.425, \mathrm{p}<0.05)$, but no such relationship was observed for either group separately.

TABLE 3 Maximal and rapid isometric knee extension (KE) and plantar flexion (PF) torque production in $\mathrm{Nm},{ }^{*} \mathrm{p}<0.05,{ }^{* *} \mathrm{p}<0.01$.

\begin{tabular}{lllll}
\hline Article I & KE max & KE rapid & PF max & PF rapid \\
\hline Young (N=10) & $181( \pm 42)$ & $107( \pm 33)$ & $181( \pm 15)$ & $68( \pm 16)$ \\
Elderly (N=20) & $135( \pm 39) * *$ & $66( \pm 25) * *$ & $178( \pm 46)$ & $40( \pm 15) * *$ \\
Article IV & & & PF max & PF rapid \\
\hline Young (N=9) & & $270( \pm 38)$ & $160( \pm 35)$ \\
Elderly (N=10) & & $223( \pm 40) *$ & $117( \pm 35)^{*}$ \\
\hline
\end{tabular}

\subsubsection{Activation level and V-wave response}

Activation level (table 4) of the knee extensor muscles was higher in Young ( $<<$ 0.01 ). From the plantar flexors, neural drive was measured using the $\mathrm{V}$-wave method, but no age-related differences were observed. V-wave and M-wave peak-to-peak amplitudes were $2.94 \pm 2.01 \mathrm{mV}$ and $10.9 \pm 2.72 \mathrm{mV}$ and $1.48 \pm$ $0.965 \mathrm{mV}$ and $7.41 \pm 2.11 \mathrm{mV}$ in Young and Elderly, respectively.

TABLE 4 Activation level (quadriceps) and V-wave (soleus) responses, ${ }^{* *} \mathrm{p}<0.01$ difference between groups.

\begin{tabular}{lll}
\hline Article I & Activation level (\%) & V/Mmax-ratio \\
\hline Young $(\mathrm{N}=10)$ & $96,2( \pm 0,8)$ & $0.268( \pm 0.174)$ \\
Elderly $(\mathrm{N}=20)$ & $93,8( \pm 2,1) * *$ & $0.217( \pm 0.164)$ \\
\hline
\end{tabular}

\subsubsection{Drop jump}

Age related differences were clearly evident in jump performance. During drop jumps, average jump height was higher $(p<0.001)$ in Young. In addition, pushoff phase force was higher $(p<0.05)$ and phase durations shorter (braking phase $\mathrm{p}<0.01$; push-off phase $\mathrm{p}<0.01)$ in Young. From the normalized EMG responses of all measured muscles, the only differences were observed in soleus 
EMG activity, which was higher in the braking phase ( $Y, 70 \pm 37 \%$ vs. E, $56 \pm 16$; $\mathrm{p}<0.05)$ in Young than in Elderly. Absolute drop jump parameters are summarized in Table 5.

TABLE 5 Summary of drop jump parameters, ${ }^{* *} \mathrm{p}<0.01,{ }^{* * *} \mathrm{p}<0.001$

\begin{tabular}{ccc}
\hline & YOUNG & ELDERLY \\
\hline Jump Height $(\mathrm{m})$ & $0.79 \pm 0.06$ & $0.55 \pm 0.08^{* * *}$ \\
DJ braking force (N) & $1875 \pm 318$ & $1238 \pm 304 * * *$ \\
DJ push-off force (N) & $1884 \pm 584$ & $1302 \pm 310^{* *}$ \\
braking time (s) & $0.23 \pm 0.05$ & $0.31 \pm 0.05 * *$ \\
push-off time (s) & $0.26 \pm 0.04$ & $0.34 \pm 0.05^{* *}$ \\
\hline
\end{tabular}

\subsubsection{H-reflex (Standing rest)}

H-reflex (Hmax/Mmax-ratio, figure 14) responses were measured during standing rest (Hmax, Young $3.13 \pm 2.28 \mathrm{mV}$ vs. Elderly $2.47 \pm 1.48 \mathrm{mV}$; Mmax, Young $8.64 \pm 2.82 \mathrm{mV}$ vs. Elderly $7.29 \pm 1.83 \mathrm{mV}$ ), where no significant agerelated differences were observed. In addition, no differences were observed in background muscle activity during standing rest (Young $0.116 \pm 0.043$ vs. Elderly $0.138 \pm 0.080)$. In protocol I, H-reflex (H/M20\%-ratio) responses were also measured during drop jumps in the early phase of ground contact. M-wave amplitude (M20\%, Young $18.0 \pm 2.3 \%$ vs. Elderly $18.7 \pm 3.7 \%$ ) and normalized background muscle activity (Young $0.273 \pm 0.206$ vs. Elderly $0.217 \pm 0.107$ ) were similar in both groups during the jumps. Similar to standing rest conditions, no significant age-related differences were observed in the H/M20\%-ratio. However, the H/M20\%-ratio correlated significantly with several jump parameters in the young but not in the elderly (table 6). 


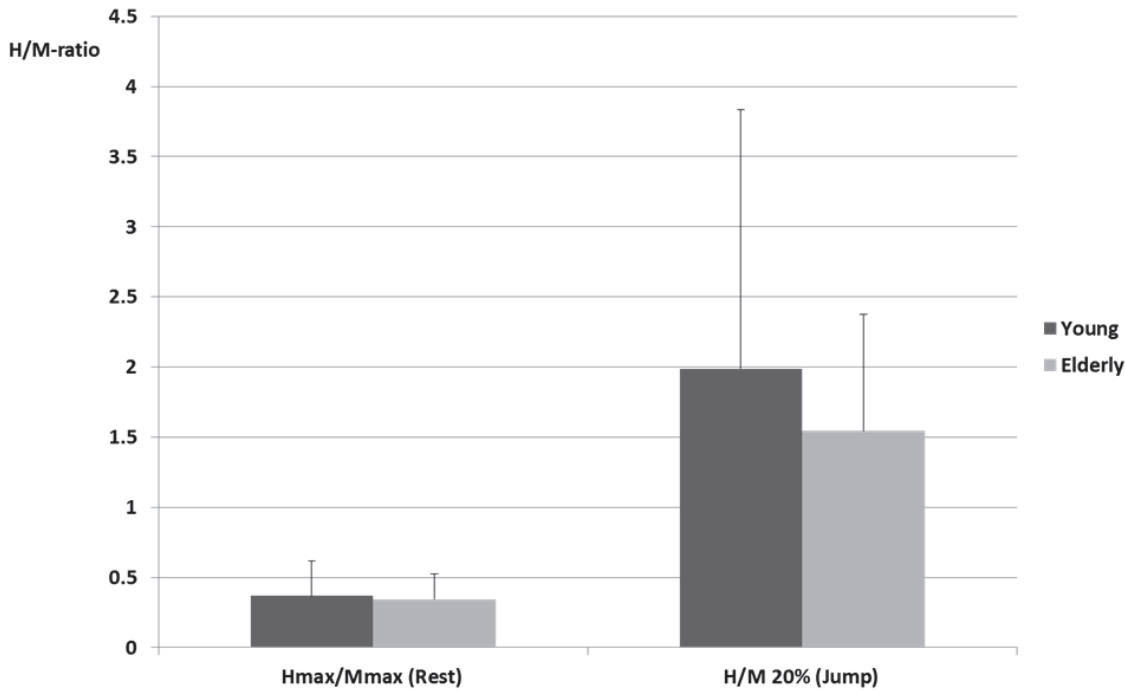

FIGURE 14 H-reflex responses measured during standing rest (Hmax/Mmax) and $20 \mathrm{~ms}$ after ground contact during drop jumps (protocol I).

TABLE 6 Correlations between the H/M20\%-ratio and drop jump parameters in both groups, ${ }^{*} \mathrm{p}<0.05,{ }^{* *} \mathrm{p}<0.01$

\section{YOUNG ELDERLY}

\begin{tabular}{ccc}
\hline Contact time & $\mathrm{r}=-.857^{* *}$ & $\mathrm{r}=.114$ \\
DJ braking force & $\mathrm{r}=.690$ & $\mathrm{r}=-.029$ \\
DJ push-off force & $\mathrm{r}=-.857^{* *}$ & $\mathrm{r}=.082$ \\
braking time & $\mathrm{r}=-.833^{*}$ & $\mathrm{r}=.224$ \\
push-off time & $\mathrm{r}=-.857^{* *}$ & $\mathrm{r}=.154$ \\
\hline
\end{tabular}

In protocol $\mathrm{II}$, the $\mathrm{H}_{\max } / \mathrm{M}_{\max }$-ratio during standing rest was similar between the groups (Young $0.45 \pm 0.19$, Elderly $0.31 \pm 0.14$ ). M-wave latency was similar between groups ( $6.2 \pm 0.7 \mathrm{~ms}$ vs. $6.9 \pm 1.2 \mathrm{~ms})$, while Elderly showed a significantly longer H-reflex latency $(33.7 \pm 2.3 \mathrm{~ms}$ vs. $36.4 \pm 1.7 \mathrm{~ms}, \mathrm{p}<0.01)$. Similarly, H-reflex propagation time was significantly longer (15.1 $\pm 1.2 \mathrm{~ms}$ vs. $17.0 \pm$ $1.4 \mathrm{~ms}, \mathrm{p}<0.01)$ in Elderly. In Young, H-reflex propagation time correlated positively with time to peak displacement in the Fast anterior condition $(r=0.818, p$ $<0.01$ ), which was not observed in Elderly. When combining both groups' data, 
H-reflex propagation time correlated negatively with recovery displacement in the Fast anterior condition $(\mathrm{r}=-0.535, \mathrm{p}<0.05)$. When H-reflexes $(\mathrm{H} / \mathrm{M} 20 \%$-ratio) were measured during balance perturbations, significant differences were observed. In Slow, Young showed significantly higher H-reflex responses $30 \mathrm{~ms}(\mathrm{p}$ $<0.05$ ) after posterior perturbations, whereas in Fast, age-related differences were observed $10 \mathrm{~ms}$ and $30 \mathrm{~ms}$ after both anterior $(\mathrm{p}<0.05)$ and posterior $(\mathrm{p}<$ 0.05) perturbations (figure 15).

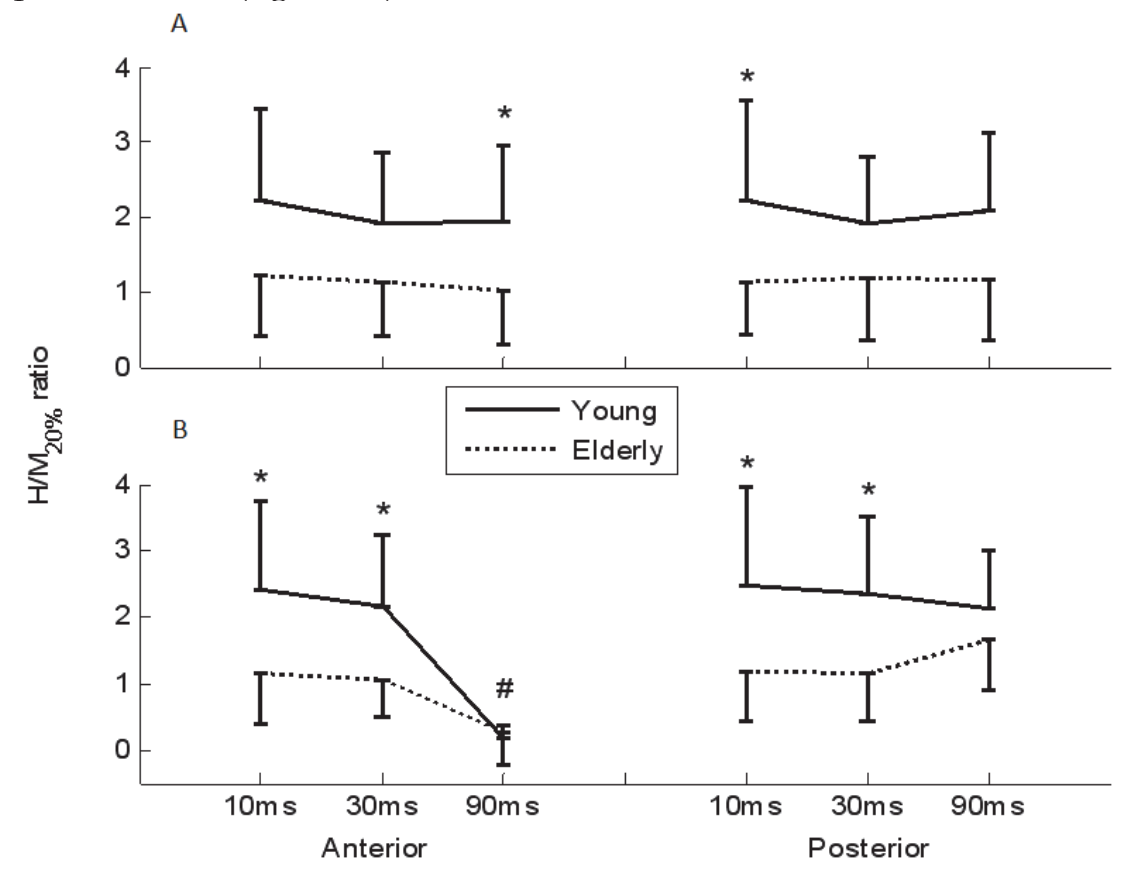

FIGURE 15 H-reflex responses during Slow (A) and Fast (B) perturbations, *p $<0.05$ between-group difference, $\# p<0.05$ between time point difference.

\subsubsection{Stretch reflex}

During Fast horizontal perturbations, Young showed (figure 16) a shorter SOL SLR latency $(p<0.001)$ and TIB MLR latency $(p<0.001)$. Surprisingly, both groups showed similar normalized SLR amplitudes (figure 17) in SOL and MLR amplitudes in TIB, with similar background EMG levels (SOL 0.15 $\pm 0.05,0.16 \pm$ 0.05 ; TIB $0.03 \pm 0.02,0.02 \pm 0.01)$. However, Elderly showed significantly larger SOL MLR $(\mathrm{p}<0.05)$ and LLR $(\mathrm{p}<0.05)$ amplitudes. In TIB, no age-related differences were observed in LLR amplitude. Similar to H-reflex responses, no age-related correlations were observed. However, in the combined group data, TIB MLR latency correlated negatively $(\mathrm{r}=-0.496, \mathrm{p}<0.05)$ with recovery displacement. In addition, SOL SLR latency $(\mathrm{r}=0.685, \mathrm{p}<0.01)$ correlated positively with H-reflex propagation time. 


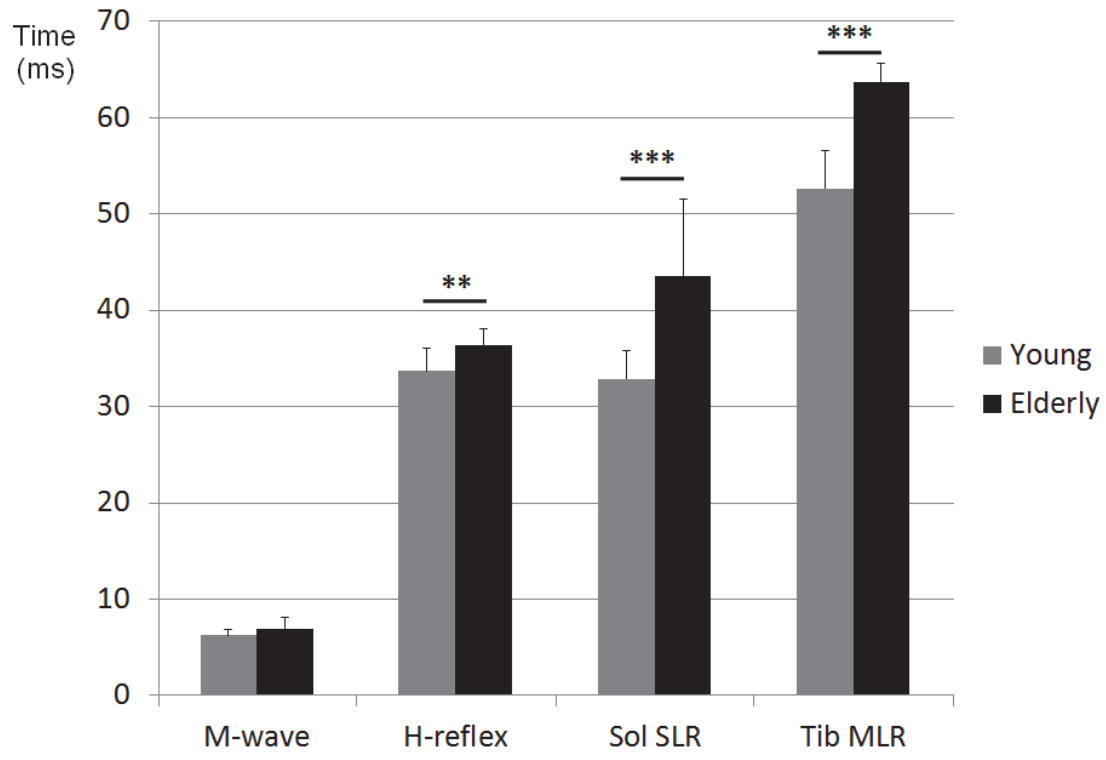

FIGURE 16 Soleus (SLR) and tibialis (MLR) stretch reflex latencies, and soleus M-wave and H-reflex latencies, ${ }^{* *} \mathrm{p}<0.01,{ }^{* * *} \mathrm{p}<0.001$

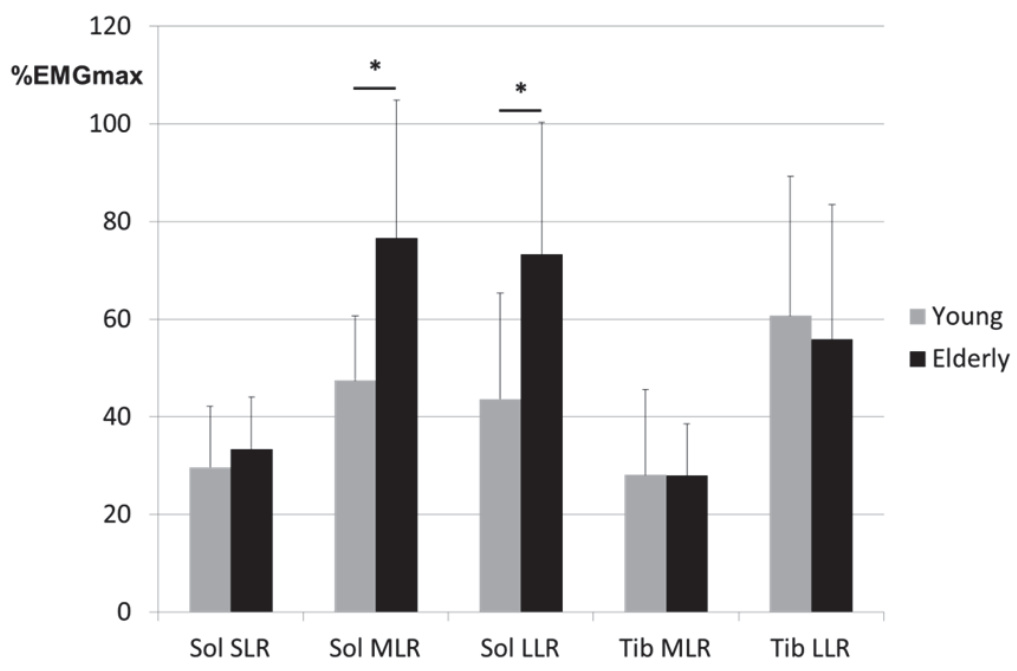

FIGURE 17 Soleus and tibialis short-, medium-, and long-latency stretch reflex amplitudes, ${ }^{*} \mathrm{p}<0.05$. 


\subsection{Intervention study: Effects of power training on neuromuscular function and dynamic balance control}

\subsubsection{Dynamic balance control}

Both groups showed similar anterior-posterior (figure 18a) and medial-lateral COP displacement at the beginning of the training period. After 4 weeks of training, both training groups improved anterior-posterior balance control $(\mathrm{p}<$ 0.001), which remained at the same level for the rest of the training period. In the medial-lateral direction (figure 18b), PLY showed no significant improvements during the entire training period, whereas in PNE, medial-lateral balance control improved $(p<0.01)$ after 8 weeks of training with no changes thereafter. No significant differences were observed in COP displacement between groups at any time point. Subjects who participated in DET measurements showed significantly smaller COP displacement after 12 weeks of training $(89 \pm 14 \mathrm{~mm}$ to $59 \pm 16 \mathrm{~mm}, \mathrm{p}<0.001)$, but the displacement increased significantly again after 8 weeks of detraining $(59 \pm 16 \mathrm{~mm}$ to $79 \pm 11 \mathrm{~mm}, \mathrm{p}<0.01)$. They also showed smaller displacement in the medial-lateral direction after 12 weeks of training (92 $\pm 15 \mathrm{~mm}$ to $77 \pm 19 \mathrm{~mm}, \mathrm{p}<0.05$ ), with no significant changes after the detraining period.

\subsubsection{Isometric torque production}

Compared to the pre values, PNE showed significantly higher plantar flexion torque ( $43 \pm 11$ to $52 \pm 17 \mathrm{Nm}, \mathrm{p}<0.01)$ and soleus muscle EMG activity $(65 \pm 32 \%$ to $80 \pm 36 \%, p<0.01$ ) during the first $200 \mathrm{~ms}$ of MVC after 12 weeks of training. Conversely, PLY showed no significant change in torque ( $36 \pm 17$ to $43 \pm 11 \mathrm{Nm}$ ) or EMG of soleus and MG muscles. There were no differences between the groups in plantar flexor MVC in pre (PLY $185 \pm 54$; PNE $177 \pm 33 \mathrm{Nm}$ ) or post training (PLY $185 \pm 31$; PNE $186 \pm 38 \mathrm{Nm}$ ) values. At pre, rapid knee extension torque production (Figure 19a) was similar in both training groups. PNE showed an increase in torque after 4 weeks $(p<0.01)$, a further increase compared to the pre-level after 8 weeks $(p<0.001)$ and no change between 8 and 12 weeks, although torque remained higher $(\mathrm{p}<0.01)$ than the pre level. PNE also showed a significant increment (Figure 19b) in VL muscle EMG $(p<0.01)$ after 4 weeks of training compared to the pre level, which did not change thereafter. Conversely, PLY only showed significantly higher rapid torque development after 12 weeks of training and a significant increment in VL EMG after 8 weeks of training. In addition, significant $(p<0.05)$ differences between groups were observed in VL EMG activity after 4, 8 and 12 weeks of training. PNE showed increased knee extension MVC (figure 20) already after 4 weeks of training ( $\mathrm{p}$ 0.01). After 12 weeks of training, MVC was decreased compared to the 8 week value $(p<0.05)$, although it was still higher than at pre $(p<0.001)$. On the other hand, PLY only showed an increase after 8 weeks of training $(p<0.001)$, which 
remained at the same level during the rest of the training period. There was a difference between the groups in knee extension MVC $(p<0.05)$ after 12 weeks of training. Subjects who participated in DET measurements showed increased rapid knee extension torque production after 12 weeks of training $(64 \pm 24 \mathrm{Nm}$ to $105 \pm 30 \mathrm{Nm} \mathrm{p}<0.001)$. However, no changes $(105 \pm 30 \mathrm{Nm}$ to $93 \pm 28 \mathrm{Nm})$ were observed after 8 weeks of detraining.

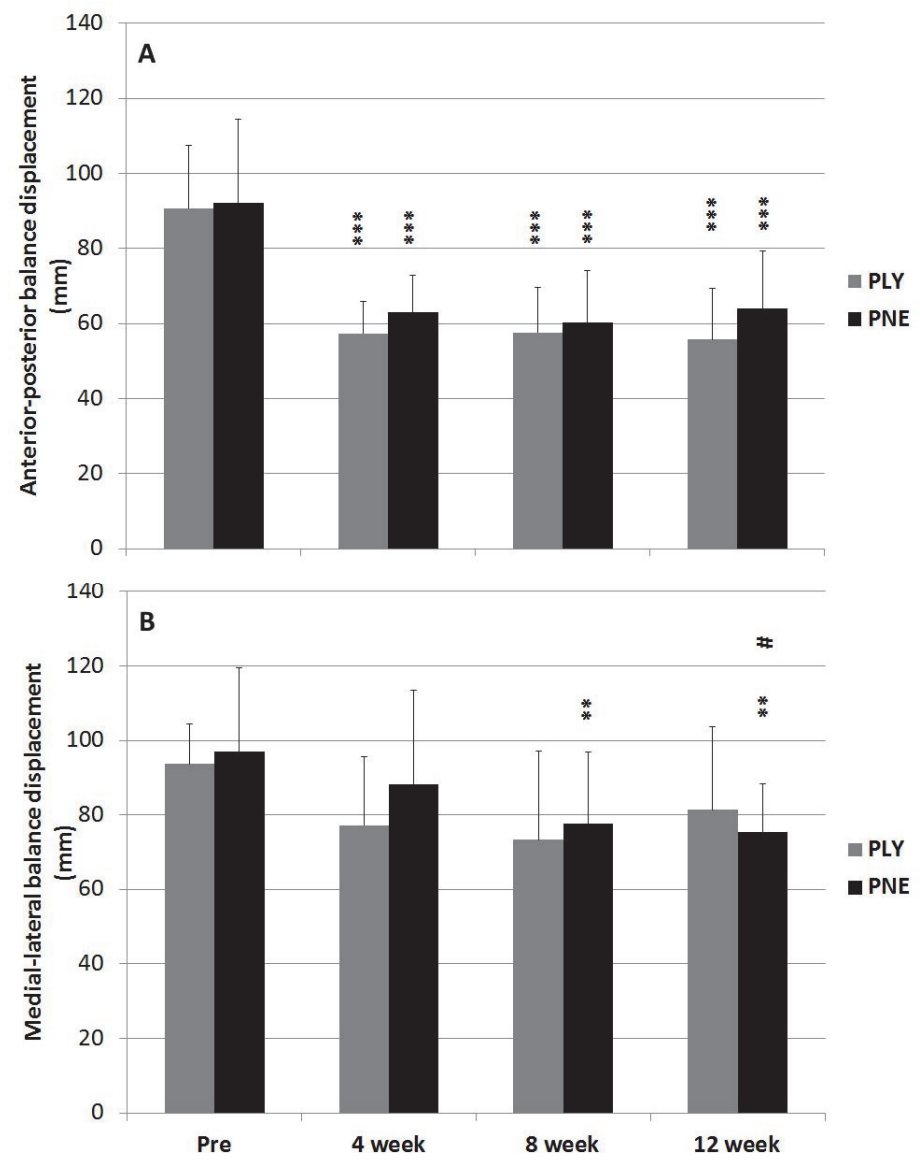

FIGURE 18 Anterior-posterior (A) and medial-lateral (B) COP displacement during and after 12 weeks of pneumatic or plyometric training, ${ }^{* *} \mathrm{p}<0.01{ }^{* * *} \mathrm{p}<0.001$ compared to pre-level, \# between weeks 4 and 12.

Relative changes in anterior-posterior balance displacement correlated negatively with knee extension rapid torque production after 12 weeks of training in both groups (PLY r=-0.775, $\mathrm{p}<0.05$; PNE $\mathrm{r}=-0.734$, $\mathrm{p}<0.05$ ). In addition, both groups showed negative correlations between VL early torque production EMG activity $(0-200 \mathrm{~ms})$ and anterior-posterior balance displacement after 8 weeks $($ PNE; $r=-0.688, p<0.05)$ or 12 weeks of training (PLY; $r=-0.868, p<0.01$ ). 


\subsubsection{Jump performance and H-reflex}

Before training, take-off velocity during drop jumps was similar in both groups. PNE showed increased velocity $(p<0.001)$ and increased dropping height $(p<$ $0.05)$ after 4 weeks of training, while PLY showed improved velocity $(p<0.01)$ and dropping height $(\mathrm{p}<0.01)$ only after 8 weeks of training. PLY also showed a trend towards higher optimal dropping height after 8 weeks $(p=0.051)$. Braking phase force production significantly increased after 8 weeks of training in PLY ( $p<0.05)$, whereas no changes were observed during the entire training period in PNE. Dropping heights, take-off velocities, contact times and forces are presented in table 7.

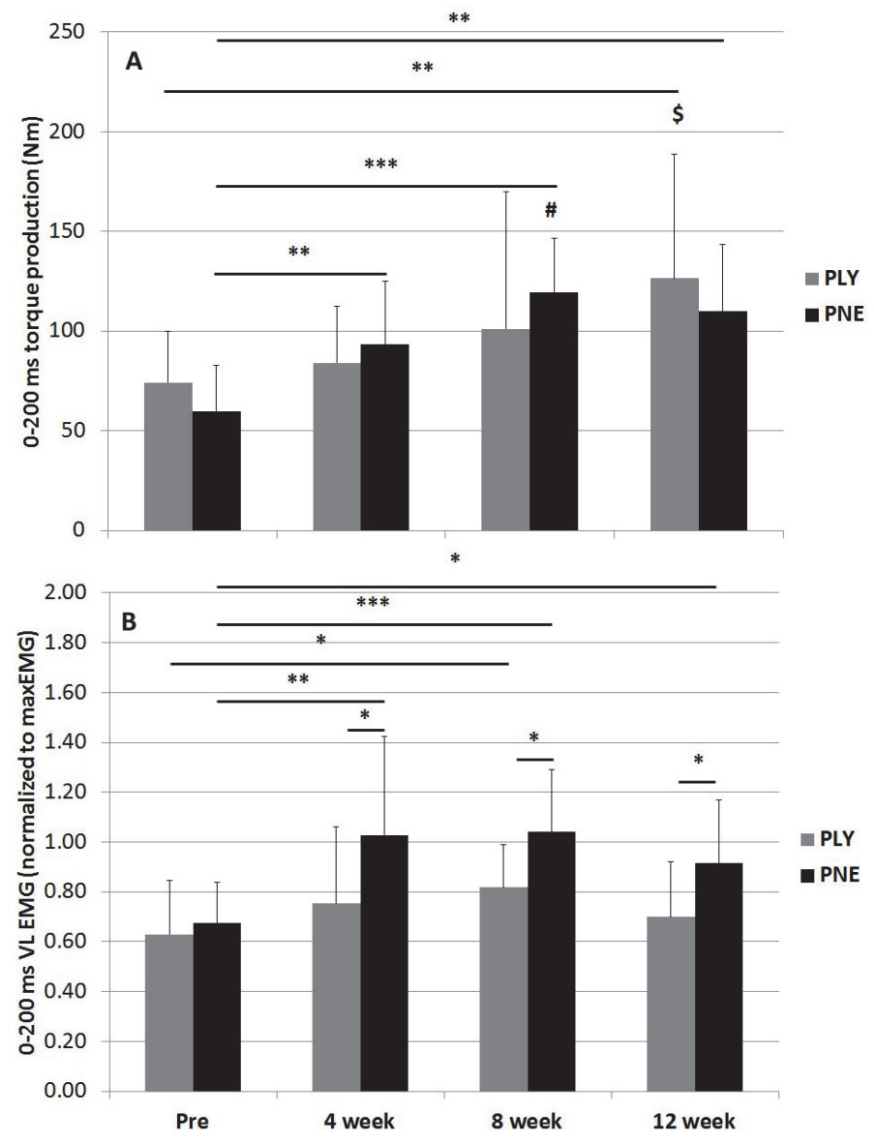

FIGURE 19 Explosive isometric knee extension torque production (A) and vastus lateralis EMG (B) activity (0-200 ms) before, during and after 12 weeks of pneumatic or plyometric training, ${ }^{*} \mathrm{p}<0.05,{ }^{* *} \mathrm{p}<0.01,{ }^{* * *} \mathrm{p}<0.001$; $\# \mathrm{p}<0.05$ between weeks 4 and $8, \$ p<0.05$ between weeks 4 and 12 . 


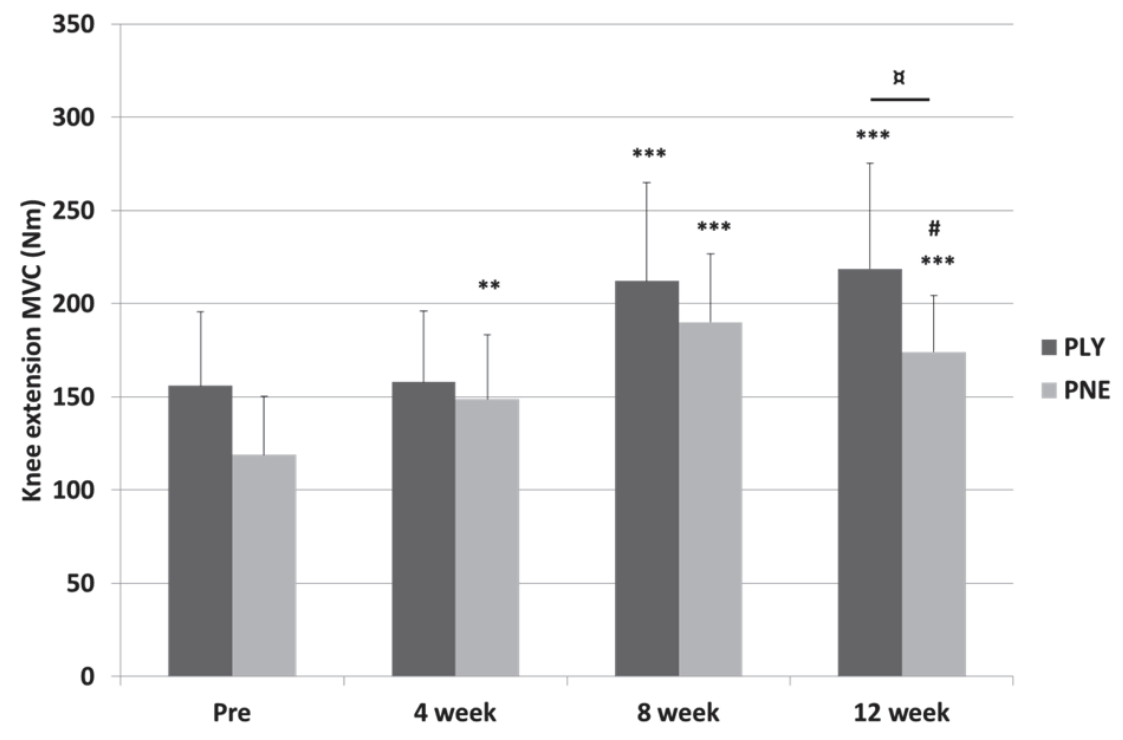

FIGURE 20 Maximal isometric knee extension torque production before, during and after 12 weeks of pneumatic or plyometric training, ${ }^{* *} \mathrm{p}<0.01,{ }^{* * *} \mathrm{p}<0.001$; compared to pre, $\# \mathrm{p}<0.05$ between weeks 8 and 12, a $\mathrm{p}<0.05$ between the groups.

TABLE 7 Drop jump parameters before, during and after the 12 week training period, ** $p<0.01,{ }^{*} p<0.05$ compared to PRE level; \#\# between weeks 4 and 8 ; \# between weeks 4 and 12 .

\begin{tabular}{|c|c|c|c|c|c|}
\hline GROUP & PARAMETER & PRE & 4 WEEK & 8 WEEK & POST \\
\hline \multirow[t]{5}{*}{ PLYOMETRIC } & Optimal drop height (cm) & $83 \pm 14$ & $89 \pm 11$ & $104 \pm 14 * * \# \#$ & $103 \pm 14 * \#$ \\
\hline & Take-off velocity (m/s) & $2.11 \pm 0.17$ & $2.21 \pm 0.18$ & $2.23 \pm 0.16 * *$ & $2.19 \pm 0.17$ \\
\hline & Contact time (s) & $0.67 \pm 0.11$ & $0.69 \pm 0.11$ & $0.67 \pm 0.07$ & $0.64 \pm 0.05$ \\
\hline & Force $_{\mathrm{ECC}} / \mathrm{BW}(\mathrm{N} / \mathrm{kg})$ & $13.9 \pm 2.1$ & $14.2 \pm 2.1$ & $16.0 \pm 1.6 *$ & $15.4 \pm 2.5$ \\
\hline & Force $_{\mathrm{CON}} / \mathrm{BW}(\mathrm{N} / \mathrm{kg})$ & $13.6 \pm 1.9$ & $13.7 \pm 1.8$ & $13.3 \pm 1.3$ & $13.9 \pm 1.3$ \\
\hline \multirow[t]{5}{*}{ PNEUMATIC } & Optimal drop height (cm) & $87 \pm 14$ & $94 \pm 14 *$ & $93 \pm 14$ & $98 \pm 14 * *$ \\
\hline & Take-off velocity (m/s) & $2.05 \pm 0.16$ & $2.12 \pm 0.16 *$ & $2.13 \pm 0.19$ & $2.12 \pm 0.16 *$ \\
\hline & Contact time (s) & $0.64 \pm 0.09$ & $0.61 \pm 0.07$ & $0.62 \pm 0.09$ & $0.63 \pm 0.11$ \\
\hline & Force $_{\mathrm{ECC}} / \mathrm{BW}(\mathrm{N} / \mathrm{kg})$ & $15.0 \pm 1.8$ & $15.5 \pm 2.0$ & $15.8 \pm 2.9$ & $16.1 \pm 2.4$ \\
\hline & Force $_{\mathrm{CON}} / \mathrm{BW}(\mathrm{N} / \mathrm{kg})$ & $13.8 \pm 1.5$ & $14.3 \pm 1.3$ & $14.2 \pm 1.3$ & $14.1 \pm 1.7$ \\
\hline
\end{tabular}


In terms of drop jump EMG activity, after 12 weeks of training, PLY showed significantly increased soleus muscle activity (Figure 21a) in all phases of the drop jump relative to pre ( $\mathrm{p}<0.05$ in all cases), which was not observed in PNE. Conversely, PNE showed significantly increased VL (Figure 21b) muscle activity in all phases of the drop jump (pre-activity $p<0.001$, braking phase $p<0.05$ and push-off phase $\mathrm{p}<0.05$ ) after 12 weeks of training, which was not observed in PLY. In addition, PNE showed significantly higher VL braking phase EMG activity $(\mathrm{p}<0.001)$ compared to PLY after 12 weeks of training. During drop jumps, PLY showed a lower H/M-ratio $(0.58 \pm 0.38)$ than PNE $(1.01 \pm 0.57)$ before training, although this difference was not statistically significant. After 12 weeks of training, the $\mathrm{H} / \mathrm{M}$ ratio was unchanged relative to pre in both PLY $(0.58 \pm 0.28)$ and PNE $(0.70 \pm 0.57)$. 

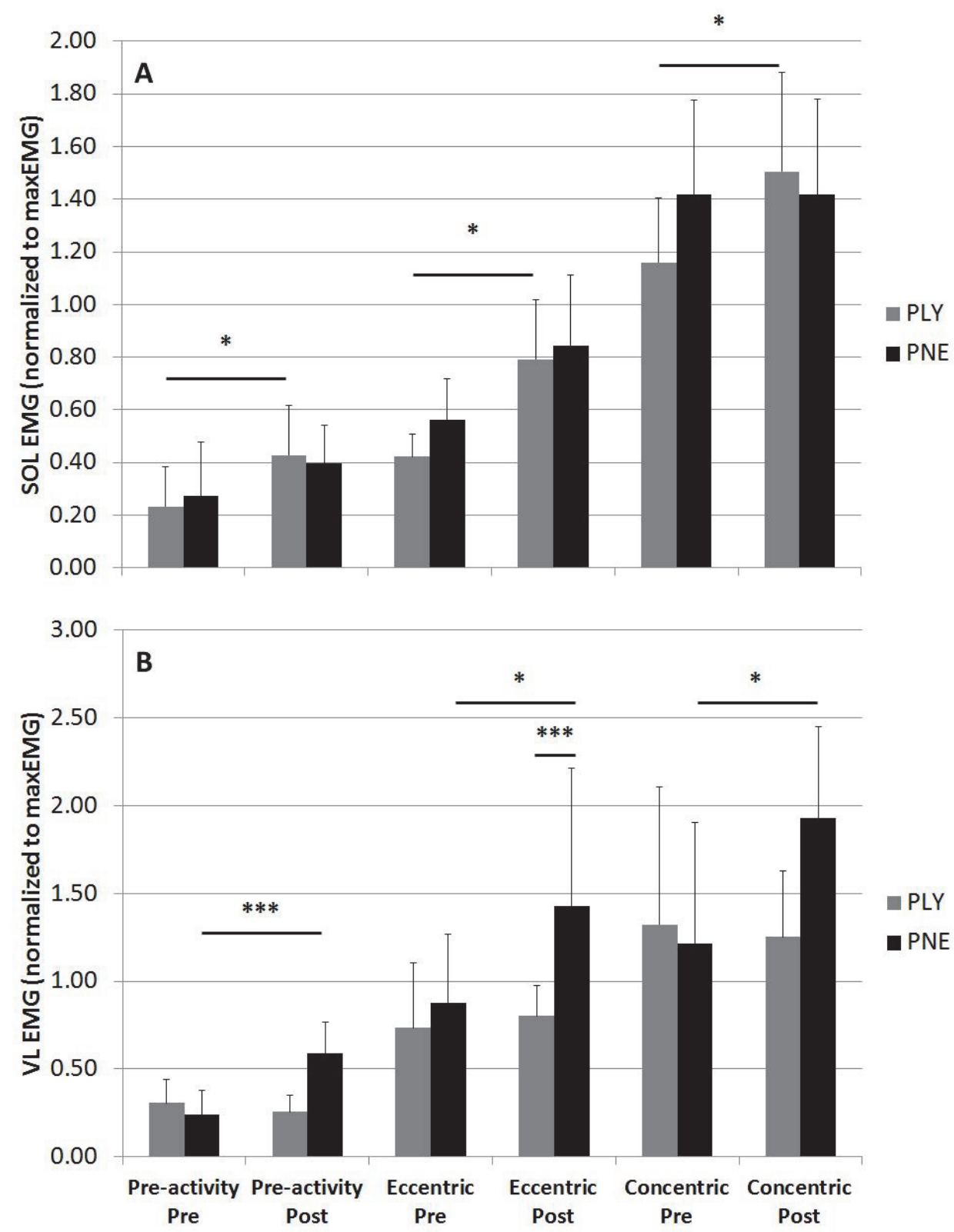

FIGURE 21 Plyometric and pneumatic group SOL (A) and VL (B) EMG activity during maximal drop jumps before and after 12 weeks of training, ${ }^{*} p<0.05, * * *$ $\mathrm{p}<0.001$. 


\section{DISCUSSION}

The main findings of this study were:

1) Age-related differences in torque production and neural activity were more evident in knee extensors than plantar flexors (article I). In the knee extensors, rapid $(p<0.01)$ and maximal $(p<0.01)$ torque production were lower in Elderly, while in the plantar flexors, only rapid torque production was lower in Elderly $(\mathrm{p}<0.01)$ in protocol I. In addition, quadriceps muscle activation level was lower in Elderly $(p<0.01)$, while in soleus muscle, no age-related differences were observed in Vwave responses.

2) The effects of ageing on balance control were clearer in dynamic than static conditions during vertical perturbations (article I). In static conditions, no age-related differences were observed, while in vertical perturbations, Young showed smaller balance $(\mathrm{p}<0.05)$ displacement in the antero-posterior direction. In horizontal perturbations, age-related differences were more evident during anterior than posterior perturbations (article IV). In Slow anterior horizontal perturbations, Young showed smaller $(p<0.05)$ balance displacement.

3) Different types of explosive strength training led to different neuromuscular adaptations; however, the effects of training on dynamic balance during vertical perturbations were similar (article III). The PNE group showed increased VL muscle activity $(p<0.05-p<0.001)$ in all phases of the DJ after four weeks of training, while PLY showed enhanced soleus muscle activity $(\mathrm{p}<0.05)$ after 12 weeks of training. In addition, a similar $\mathrm{H} / \mathrm{M} 20 \%$ level from a higher dropping height in PLY, as well as increased soleus muscle activity $(p<0.05)$ in the braking phase of drop jumps, may be indicative of enhanced reflex activity.

4) Stretch reflex latencies during horizontal perturbations were longer in both tibialis anterior $(p<0.001)$ and soleus $(p<0.001)$ muscles in El- 
derly. Shorter H-reflex propagation time in younger individuals was associated $(\mathrm{r}=0.818, \mathrm{p}<0.01)$ with faster balance recovery after a perturbation, which was not observed in Elderly. However, reflex amplitude seems to play a smaller role in balance control (article IV).

\subsection{Age-related differences}

\subsubsection{Balance control}

In protocol I, vertical free fall perturbations were used to measure dynamic balance control. Baloh et al. (1994) showed that age-related impairment in balance control is especially evident in dynamic situations. Their results showed that the young participants were able to control their balance after a disturbance better than the elderly participants, especially in the anterior-posterior direction. However, in the static condition, age-related differences in balance were not observed. This suggests that even though a vertical dropping disturbance does not directly simulate natural falling conditions, there are age-related differences between static and dynamic conditions. This indicates that the ability to restabilize balance after a sudden disturbance decreases with age.

In protocol II, dynamic balance was measured during horizontal perturbations with two different conditions, where velocity, acceleration and amplitude varied between the conditions. In response to Slow balance perturbations, Elderly showed significantly larger peak COP displacement and shorter time to peak displacement. These results indicate that balance control is impaired in elderly subjects even after Slow perturbations. Possible reasons for this may be the degeneration of motor units (Roos et al. 1999), reduced reflex sensitivity (Mynark \& Koceja 2001) or reduced activation level of the muscles (Stevens et al. 2003), which is discussed in more detail below. In Fast, both groups showed similar peak COP displacements during the perturbation phase, whereas in the recovery phase, a trend towards faster recovery was observed in Young. This may indicate a slowing of the processing of sensory feedback in Elderly. One reason for the lack of differences observed in Fast balance control might be the relatively short perturbation amplitude, which was an unavoidable limitation of the balance system. In the future, dynamic balance testing should be performed in the horizontal direction, with different velocities, accelerations and amplitudes. To obtain more precise information about age-related differences, future studies should assess the thresholds of different control strategies (ankle, hip, arms, step), as well as their connections to neuromuscular function.

\subsubsection{Torque production and drop jumps}

It is well known that maximal knee extension strength and rapid torque production capacity decrease during ageing (Vandervoort 2002), which was also the case in protocol I. Degeneration of high threshold motor units may decrease 
muscle cross-sectional area, which is related to decreased muscle strength and power (Häkkinen \& Häkkinen 1991; Häkkinen et al. 1998). It has been shown that there may be a connection between maximal strength and balance control (Buchner et al. 1996; Moxley Scarborough et al. 1999). In the present study, such a relationship between maximal force production and balance control was not observed. Despite the differences observed in maximal torque production, the ability to produce force rapidly may be more important in the prevention of falling. Differences due to sudden vertical perturbations were evident in anterior-posterior sway, which was significantly correlated with 200 ms knee extension torque production when both groups' data were combined. In the plantar flexors, a significant difference between the age groups was only observed in $200 \mathrm{~ms}$ rapid torque production, but not in maximal torque, which may indicate muscle-group-specific degeneration in the elderly. In addition, it has been suggested that force production properties of the ankle muscles are not a limiting factor in balance control (Hall et al. 1999).

In protocol II, younger individuals produced higher plantar flexor torque in both rapid and maximal conditions. Several studies have reported similar results, indicating an age-related degeneration of neuromuscular function (Kallio et al. 2012; Morse et al. 2004; Simoneau et al. 2007). Despite the agerelated differences in the present study, torque production properties did not correlate with any balance control parameters or reflex responses. This may be at least partly attributable to a higher number of slow twitch fibers in plantar flexors such as soleus, compared to the quadriceps muscles. Accordingly, it is possible that during sudden perturbations where high force production is important, high power production from other muscle groups, for example knee extensors, may be more crucial to prevent falling (Carty et al. 2012). This suggestion is also supported by the results of protocol I.

Despite the age-related findings in isometric conditions in both protocols, possible differences in dynamic movements such as drop jumps, which utilize the SSC, may be even more relevant for dynamic balance control. Bosco and Komi (1980) showed decreased jumping height during vertical drop jump performance in the elderly, as was the case in the present study. The first possible reason for decreased jump performance is reduced muscle stiffness and thus a reduced ability to utilize elastic energy (Hoffren et al. 2007), which is an important mechanism in SSC-type actions. Efficient SSC performance requires high agonist activation in the preactivation and braking phases (Horita et al. 1996; Yoon et al. 2007). In the present study, the only significant age-related difference in this regard was observed in braking phase soleus activity, which was higher in the young. Neural modulation may vary at the spinal cord level due to several mechanisms, leading to possible age related differences in EMG modulation. Therefore, measures capable of revealing changes in spinal excitability could be useful to explain age-related differences in muscle activation strategies. 


\subsubsection{Neural control}

\section{Muscle activation}

One of the main reasons for decreased force production may be lower activation levels in the elderly. Morse et al. (2004) suggested that reduced plantar flexor activation was associated with reduced physical activity. In protocol I, plantar flexor maximal force production was similar between the two age groups, which reflects the high physical fitness level of the Elderly participants. This may be one reason why there were no significant differences in static balance conditions. It has been suggested previously that physical fitness level influences both static and dynamic balance control (Paterson et al. 2007). In protocol I, the Elderly participants were aged between 60 and 70 and were physically active, which might partly explain the lack of age-related differences. In several previous studies, the average age has been higher, and therefore the effects of ageing could have been more pronounced (Scaglioni et al. 2002; Scaglioni et al. 2003). However, the clear age-related differences observed in the knee extensors indicate decreased performance capacity in the elderly.

It has been suggested that neural drive from the central nervous system may change during ageing (Izquierdo et al. 1999b). In protocol I, no significant differences in neural drive to the soleus muscle were observed between groups, as revealed by $\mathrm{V}$-wave responses. In addition, no relationship was observed between vertical balance control and V-wave responses. However, activation level measured from the quadriceps muscle group was significantly lower in the elderly than the young. It has been suggested previously that reduced quadriceps activation could be caused by a reduction in the number of active motor units or reduced motor unit firing rates (Sale 2003). The lower activation level in the elderly participants might suggest that impaired neural drive leads to decreased strength and thus impaired balance control. However, we found no evidence of a relationship between activation level and dynamic balance control in protocol I, suggesting that reduced neural drive may not be a limiting factor in the control of balance. Even if activation level was significantly lower in the elderly, it may still be high enough to cause appropriate activation in the muscles during different tasks. As shown, muscle activation was different in the quadriceps but not in the plantar flexors, which may indicate that central components also play a role in balance disturbances, even if this role is less important than that of peripheral structures.

Aside from maximal voluntary activation, some other MU properties may have an influence on dynamic balance control. A loss of (particularly fast) motor units leads to motor unit rearrangement, whereby remaining motor units innervate some of the muscle fibers previously belonging to lost units (Doherty et al. 1993a; Narici and Maffulli 2010; Vandervoort 2002). This increases the size of individual motor units whilst decreasing the total number of motor units, potentially compromising fine motor control (Roos et al. 1997) and force production capacity (Roos et al. 1999). This may be one of the reasons why elderly people showed poorer balance control even in response to Slow perturbations 
in protocol II. In the same study, an "over-shooting" effect was observed in the elderly after Slow perturbations, whereby the COP moved beyond the baseline during the recovery phase.

\section{Reflex sensitivity}

Several studies have reported that ageing leads to decreased H-reflex activity (Kallio et al. 2010; Kido et al. 2004; Sabbahi and Sedgwick 1982; Scaglioni et al. 2002), but there are also some contradictory results (Scaglioni et al. 2003; Vandervoort and Hayes 1989). Within its limitations, the H-reflex method has been used as an indicator of alpha-motoneuron pool activity, but it is also strongly influenced by PSI (Zehr 2002). In addition, the H-reflex method primarily measures the excitability of the slow motor units (Maffiuletti et al. 2001), where the effects of ageing may be minor compared to fast units. From a technical point of view, H-reflex measurements during movement are also very challenging. Nonetheless, age-dependent H-reflex responses have also been measured previously in dynamic situations (e.g. Chalmers \& Knutsen, 2000).

An age-dependent increase in PSI is known to decrease the ability to modulate reflex output, and may influence the ability of the central nervous system to respond effectively to balance perturbations (Mynark and Koceja 2002). Impaired postural control may also be associated with decreased proprioceptive input (Shumway-Cook and Woollacott 2000). Several studies have shown that H-reflex excitability decreases with ageing, although the $\mathrm{H} / \mathrm{M}$ ratio does not necessarily follow the same pattern (Chalmers and Knutzen 2000; Scaglioni et al. 2003). In both of the current protocols, no significant differences in the Hmax/Mmax ratio were observed between the two age groups. Maximal M-wave amplitude may also decrease with ageing (Scaglioni et al. 2003). The main reason for this phenomenon may be the loss of fast motor units, which can lead to reorganization of the entire neuromuscular system (Macaluso and De Vito 2004). In this study, similar to Hmax/Mmax ratios, no significant differences in the maximal M-wave amplitude of the soleus muscle were observed between the young and elderly. This may be because the soleus muscle consists mainly of slow twitch muscle fibres (Edgerton et al. 1975), and thus the effects of ageing could be less pronounced.

However, age-related differences in H-reflexes may be clearer during movement. Chalmers and Knutzen (2000) studied the effects of ageing on soleus muscle H-reflex responses during walking. They found that the excitability of the H-reflex was lower in elderly people in the middle of the stance phase, but the shape of the excitability pattern was quite similar in the young and elderly groups. They suggested that lower H-reflex activity may be related to impaired neural drive of the ankle extensors and reduced muscle stiffness during walking. Other reasons for decreased H-reflex activity may be increased PSI (Hultborn et al. 1987), insufficient muscle spindle activation (Miwa et al. 1995) and reciprocal or recurrent inhibition (Mynark and Koceja 2001; Renshaw 1946), decreased number of spinal alpha-motoneurons (Doherty et al. 1993a), de- 
creased nerve conduction velocity (Scaglioni et al. 2003) and decreased propagation between Ia-afferents and alpha-motoneurons (Morita et al. 1995).

No significant age-related differences in H-reflex activation were observed during the early contact phase of drop jumps. As the background EMG activity was similar between groups, it seems that differences in activation level between the tasks did not have any effects on the H-reflex comparison between the groups. It should be noted that modulation of the H-reflex seems to be taskdependent, as shown in hopping (Dyhre-Poulsen et al. 1991) and walking (Chalmers and Knutzen, 2000). At present, we do not know how the excitability pattern of the H-reflex changes during different phases of the jump performance in the elderly, since only the early contact phase was measured. DyhrePoulsen et al. (1991) showed in young subjects that H-reflex activity slightly decreased during the entire braking phase and was depressed even more rapidly in the concentric phase during hopping-type drop jumps. One possible explanation for the differences in jumping performance in the current experiment might also be different jumping strategies. Younger subjects may act more reactively and use their muscles in a more spring-like fashion, whereas elderly subjects may use their muscles more like a damping unit during landing (DyhrePoulsen et al., 1991). These suggestions are supported by the shorter contact time and significantly higher soleus EMG activity in the early contact phase in young subjects in this study.

In addition, correlations between H-reflex activity and jump performance parameters in the young suggest the importance of mechanisms related to alpha-motoneuron pool activity during SSC actions. Interestingly, these correlations were not observed in the elderly. This might indicate more efficient feedback and feed-forward control in the young subjects leading to enhanced performance. Conversely, in the elderly, weak proprioceptive feedback may lead to a weaker response and thus weaker feed-forward control. This suggestion is supported by the soleus EMG responses, which were significantly higher in the young group in the braking phase, which may also indicate larger stretch reflex responses. On the other hand, it should be noted that there were no age-related differences in H-reflex responses during drop jumps. Although the relative difference was quite substantial, it was not statistically significant, probably because in the young group the standard deviation of H-reflex amplitude was rather high. This could result from differences in its plasticity due to motor learning or physical training (Perot et al. 1991). The analysis of stretch reflex responses could have made it possible to speculate about the role of muscle spindle activity in this regard. However, this could not be evaluated because of the stimulation artifact that occurs before the M-wave response.

\section{Neural control and dynamic balance}

In protocol II, more detailed neuromuscular measurements were performed during dynamic balance perturbations, including H-reflex and stretch reflex measurements. Unfortunately, stretch reflexes could not be analyzed from Slow 
perturbations because of small and inconsistent responses. There were no agerelated differences in SOL, MG or TIB muscle activity during or after anterior Slow perturbations. Therefore, the somewhat lower soleus H-reflex response observed in the Elderly may be explained by increased PSI, which may also contribute to differences in balance control (Koceja et al. 1995). This is supported by the significant negative correlation between peak COP displacement and H-reflex amplitude in the combined group data. It should be noted that even though SOL may not be functionally important in anterior perturbations, these findings may be indicative of a general control strategy, and thus the same phenomenon may have been observed in TIB. Of the triceps surae muscles, SOL appeared to play a relatively important role in the present study, as no differences were observed in MG activation between groups and no correlations were observed between MG activation and balance control.

During ageing, nerve conduction velocity may decrease (Doherty et al. 1994) and reaction times may increase (Vaportzis et al. 2013), indicating slower processing and response times. In the present study, slowing of processing is supported by the longer SLR latencies and H-reflex propagation time in Elderly in the Fast condition, which may be attributable to an age-related slowing in peripheral nerve conduction velocity (Doherty et al. 1994), although synaptic transmission efficiency may also be compromised. Nardone et al. (1995) showed significant age-related differences in SLR latencies, however it is unlikely that this difference alone can entirely explain impaired balance control. Interestingly, Elderly showed increased peak COP displacement time from Slow to Fast perturbations, which was not observed in Young. This may indicate that processing of the perturbation at a supraspinal level is slower in Elderly. In Fast, total perturbation time was approximately $600 \mathrm{~ms}$, so central processing may be as crucial as efficient sensory feedback. It has been suggested that group II afferent fibers and supraspinal pathways contribute to MLR and LLR responses, respectively (Grey et al. 2001; Schieppati and Nardone 1997; Shemmell et al. 2010). In the present study, Elderly showed larger SOL MLR and LLR responses during posterior perturbations. Assuming a slowing of Ia spindle feedback in older individuals, this may be indicative of a compensatory increase in spindle type II and/or supraspinal activity. Indeed, Kawashima et al. (2004) found no age-related SLR differences but larger LLR responses in the elderly, and suggested that the increased LLR may be caused by enhanced supraspinal activity. In TIB, MLR and LLR amplitudes were similar between groups. However, similar to SOL, TIB MLR latency was also shorter in Young. In the combined group data, MLR latency correlated negatively with recovery displacement. Thus reflex data from SOL and TIB suggest that reflex latency may be more relevant to rapid balance recovery than reflex amplitude. This is in agreement with the concept of the SLR as the 'first line of defence', rather than the sole contributor to balance recovery (Cronin et al. 2011; Duysens et al. 2008). The apparently differing effects of ageing on SOL and TIB responses may be caused by different control strategies, different structural properties (e.g. fiber type distribution) and/or different functional roles of each muscle. 


\subsection{Effects of power training}

It is well documented over the years that resistance training regimens increase force production properties and improve balance control even in elderly subjects (Fiatarone et al. 1994; Harridge et al. 1999; Häkkinen et al. 1998; Orr et al. 2006). However, during balance perturbations, high muscle power may be more important than maximal force to prevent falling and possible injury. Despite the numerous power-training studies in elderly individuals (e.g. Orr et al. 2006, de Vos et al. 2005, Häkkinen et al. 1998, Häkkinen et al. 2001), the adaptation mechanisms of different training regimens seem to be unclear. One purpose of the present thesis was to investigate the effects of plyometric and pneumatic explosive strength training on neuromuscular adaptations and dynamic balance control during and after a 12 week training period. The two groups showed different neuromuscular adaptations to training that were largely specific to the training mode and test conditions. For example, during drop jumps, PLY showed a training-induced increase in optimal jumping height and soleus muscle activity. Conversely, during rapid knee extension, PNE showed significant improvements in VL activity and torque after just 4 weeks, neither of which were observed in PLY. In spite of these between-group differences, both groups showed similar improvements in dynamic balance control after just 4 weeks of training. In both groups, COP displacement was also negatively correlated with rapid knee extension torque after training, highlighting the importance of this variable for dynamic balance training in older individuals.

\section{Reflex sensitivity}

Voigt et al. (1998) showed that 4 weeks of hopping training increased H-reflex size in young subjects when preferred contact time was used. They suggested that this was caused by a decrease in PSI and that the hopping movement became more automated with less voluntary demand. In our study, H-reflex size during drop jumps did not change significantly during or after 12 weeks of training. In fact, in PLY, where the training task was similar to that employed by Voigt et al. (1998), pre-activity increased during drop jumps after training, indicating an increase in voluntary command from the central nervous system. However, subjects in the present study performed maximal drop jumps, which was not the case in the study of Voigt et al. (1998). Thus, the mechanisms attributed to the results of Voigt et al. (1998) may not apply to those from the present study.

Leukel et al. (2008) found that H-reflexes decrease with increasing dropping height in young individuals and suggested that this was caused by a prevention strategy to protect the tendomuscular system from excessive loads and thus possible injury. In the present study, PLY showed significantly increased dropping height after 12 weeks of training, but no changes in H-reflex responses. This lack of decrease in H-reflex amplitude due to training may be due to 
decreased PSI or increased reflex activity from ascending pathways. The latter possibility is supported by the higher EMG activity observed during the braking phase in PLY. Thus, the improvements in balance control observed in PLY after 4 weeks of training may be due to some combination of increased voluntary drive and spinal level adaptations, which differs from the adaptations observed in younger individuals (Voigt et al. 1998). It should be noted that drop jump training is often performed in the vertical direction, whereas for safety reasons, in the current study a $23^{\circ}$ sledge angle was used. As this decreases acceleration during drop jumping, it may have influenced neural adaptations. Unsurprisingly on the basis of training specificity, post-training differences in jumping strategies were evident between groups. For example, PLY exhibited higher soleus muscle activity in all phases of the jump, as well as higher braking force, potentially indicating that training increased muscle stiffness, leading to more efficient utilization of elastic energy. Conversely, PNE showed an increase in VL muscle activity during drop jumps, but no change in braking force or optimal drop jump height due to training

\section{Muscle activation}

It is well documented that short (3-5 weeks) strength training periods lead to increased neural drive to the muscles (Häkkinen et al. 1992; Moritani and deVries 1979), which is the main reason for increased force in the early phases of training. In this study, PNE showed significantly increased VL muscle activity and knee extensor torque during rapid MVC after just 4 weeks of training. Conversely, PLY did not show significantly higher EMG activities at that point of the study period, and increases in torque were only evident after 12 weeks. Therefore, unlike the observed responses to plyometric training, it can be suggested that neuromuscular improvements due to pneumatic training are mainly attributable to enhancement of voluntary neural drive. It could be argued that as pneumatic training involved single-joint concentric movements and plyometric training involved a multi-joint SSC task, comparisons of MVC responses between groups are somewhat biased because of training/task specificity.

However, as discussed above, it is noteworthy that during drop jumping, the PLY group exhibited possible evidence of adaptations in reflex pathways that were not evident in PNE. In fact, the post-training decrease in Hmax/Mmax-ratio during standing in PNE might even imply a downregulation of peripheral pathways in this group. This supports the suggestion that improvements in neuromuscular performance observed in PNE were primarily due to increased voluntary drive. In PNE, rapid development at the beginning followed by recession at the end of the training period might indicate that the training period was too long for continuous improvement of explosive power. Therefore it can be suggested that periodization should take place after 8 weeks of training to continue improvements in strength properties (Stone et al. 2000). On the other hand, PLY showed major improvements in the middle part of the training period, where training was performed 3/week, which may indi- 
cate that training 2 days/week at the beginning and end of the training period was insufficient from a maximal strength point of view.

Subjects who participated in detraining measurements showed increased anterior-posterior balance displacement after 8 weeks of detraining which indicates that regular strength training should be performed to maintain balance control. Previously it has been shown that even short term detraining may decrease strength properties (Harris et al. 2007; Lovell et al. 2010), which may lead to impaired balance control. Despite the small decrement observed in the present study, no significant change was observed in knee extension rapid torque production after detraining, suggesting that this parameter cannot solely explain impaired balance control after detraining.

\subsection{Practical applications and limitations of the study}

Results of the training intervention showed that power training leads to improved balance control even after a few weeks of training. Training adaptations seem to be dependent on the specific training regimen, although this issue requires further study. The role of the central nervous system in balance control should be studied in more detail, for example by using transcranial magnetic stimulation (TMS). If training adaptations are regimen-related, combined training protocols may lead to improvements in both neural drive and reflex activity, which could in turn lead to more efficient improvements in dynamic balance control. In addition, balance control should be measured in dynamic rather than static conditions, giving more specific information related to balance control during sudden perturbations. Finally, based on these results, explosive strength training is recommended for elderly people to improve their physical performance, and particularly balance control. This training mode could also be incorporated as part of a periodized strength training program to ensure positive training adaptations. This is an important issue because sarcopenia affects muscle mass, which can be developed using hypertrophy type strength training. In addition, increasing maximal strength via neural strength training may lead to enhanced development of rapid force production properties during explosive strength training. Therefore, none of these training types should be explicitly excluded when planning strength training programs for elderly individuals. However, basic health restrictions such as osteoarthritis and cardiovascular diseases must be taken into consideration before planning training programs. Increased strength properties are beneficial for balance control, which is crucial for elderly people to prevent falling accidents and injuries (e.g. bone fractures).

In the intervention used in this study, we did not control additional training during the training period, although subjects were instructed to continue their normal activities as usual. We also did not include young and/or control groups in the intervention, which could have given additional confirmation of the observed training-specific adaptations. This was due to an inadequate number of volunteers. However, subjects who participated in 
detraining measurements showed impaired balance control after 8 weeks of detraining, suggesting that improved balance control during the training period was caused by improved motor control properties rather than simply learning effects.

\section{Limitation of the methods}

When considering the limitations of the methods several issues should be acknowledged. Firstly, activation level was measured using direct muscle stimulation instead of nerve stimulation. It is possible that direct muscle stimulation cannot fully activate the muscle. However, three large electrode pairs were used during the stimulation, which covered almost the entire muscle, thus minimizing the effect of this limitation. Place et al. (2010) have shown that superimposed twitches are similar at high contraction levels regardless of the stimulation method (muscle vs. nerve). In addition, stimulation must always occur during $\mathrm{MVC}$, which leads to problems regarding the timing of the stimulation. In the present study, the time from the onset of torque production to MVC was estimated during MVC measurements (without stimulation). This enabled us to estimate when the performance should start and thus minimized the number of unsuccessful activation level measurements. In addition, the trials, where MVC force/torgue was not maximal during the stimulation, were excluded from the activation level calculations. Movement of the subject may also introduce errors to the results. This was monitored visually before the measurements. Whilst we did not specifically control for possible movement, every effort was made to minimise this source of error.

The H-reflex method is a valuable tool to investigate neuromuscular control, however it is very sensitive to measurement conditions or activation of the neuromuscular system. For example, postural position of the subject, head position, position of the stimulated limb, background muscle activity and post activation depression may all affect H-reflex responses (Misiaszek 2003; PierrotDeseilligny and Mazevet 2000). In order to avoid any position related effects on H-reflex, the position of the subject can be and was well stabilized in the sledge chair. Similarly, when measuring H-reflex during balance perturbation, position of the subject was always the same before the perturbation and a black mark was placed on the wall to enable the participants to focus on a fixed point during the measurements. In addition, the stimulation frequency of the H-reflex measurement was kept around $0.1 \mathrm{~Hz}$ in each condition, in order to avoid the effect of post activation depression. In H-reflex (sledge) measurements, only five accepted performances were measured, and additional accepted trials may have increased the fidelity of the results. However it was necessary to compromise the number of trials to avoid possible fatigue. In addition, all jumps were controlled from force curves and visual feedback to minimize the variability between trials, thus improving the reliability of individual results. 
The V-wave measurement, which is a variation of the H-reflex response, has similar limitations. In addition, $\mathrm{V}$-waves have to be measured during MVC and therefore timing of the stimulation is crucial. In EMG measurements electrode placement may have varied between measurement sessions, however, all placements were marked with a pen and these marks were maintained during the training sessions. In addition, the twitch interpolation technique (quadriceps) and V-wave (soleus) method were used to indicate muscle activation efficiency, and therefore results cannot be fully compared between the muscle groups.

There are no data about the reliability/repeatability of the balance measurement systems used in this thesis. However, there were no statistically significant differences within individuals between trials when measured using prototype I. In addition, perturbations were performed in free fall, which improves perturbation repeatability. Electrical cylinders enable very precise movement control and were therefore used in prototype II to improve stabilization and/or repeatability during horizontal perturbations. Prototype II could be used to design a dynamic balance test that incorporates different perturbation amplitudes, accelerations and velocities to determine thresholds for different balance control strategies. 


\section{PRIMARY FINDINGS AND CONCLUSIONS}

1) The present results suggest that restabilizing balance after a sudden disturbance is an age-related phenomenon, and that ageing has larger effects on dynamic than static balance control. This finding was in line with the study hypothesis. In addition, the effects of ageing seem to be muscle group specific. Surprisingly, in both age groups, central components of neuromuscular function seem to play a less important role than peripheral components in vertical dynamic balance control.

2) There were no age-related differences in the standing rest Hmax/Mmaxratio. Most importantly, the $\mathrm{H} / \mathrm{M}$-ratio measured during jump performance correlated with several other drop jump parameters in the young but not in the elderly, which may be caused by different control strategies during jumping. However, future studies should examine this issue in more detail using additional methods such as TMS to delineate the role of central pathways more clearly.

3) The main adaptation to pneumatic training seems to be increased neural drive, whereas plyometric training may also cause enhancement of reflex loop activity along with improved utilization of elastic energy. Despite the different adaptations between training modes, neither was clearly superior from a balance perspective, as both training types led to improved anterior-posterior balance control in response to sudden vertical perturbations. As improvements in balance control were correlated with rapid knee extension torque, the results highlight the need to target rapid force production in training studies aiming to improve dynamic balance in older individuals. However, during long term training periods, periodization should probably take place to ensure positive development. In addition, it can be suggested according to detraining results that regular strength training should be performed to maintain balance control in elderly subjects. 
4) Age-related declines in dynamic balance control seem to be more evident during anterior than posterior perturbations, which may contribute to the high incidence of slip-related falls in older individuals. Stretch reflex latencies appear to be age-related, whereby shorter latencies in young individuals are associated with smaller balance disturbances during a perturbation or faster balance recovery after a perturbation. Conversely, reflex amplitudes may play a smaller role in balance control in this context. Delayed stretch reflex responses combined with reduced spinal sensitivity (revealed by H-reflex measurements) may be indicative of a greater reliance on central rather than peripheral neural pathways during balance recovery in elderly individuals. Although this finding was expected, the relatively small role of stretch reflex amplitude was somewhat surprising.

5) Horizontal perturbations seem to be more challenging than vertical perturbations, and may simulate natural situations more accurately. It is suggested that in future, dynamic balance testing using sudden perturbations should be performed with several different velocities, accelerations and perturbation amplitudes to identify the thresholds of different control strategies. 


\section{YHTEENVETO}

\section{Ikääntymisen vaikutukset hermo-lihasjärjestelmän toimintaan ja dynaami- seen tasapainoon: Nopeusvoimaharjoittelun vaikutukset}

Kaatumiset ovat yksi yleisimmistä syistä jotka johtavat ikääntyneiden ihmisten loukkaantumisiin. Ikääntymisen myötä hermo-lihasjärjestelmän toiminta heikkenee ja merkittävimmät tähän johtavista tekijöistä ovat lihassolujen koon pieneneminen ja nopeiden motoristen yksiköiden kuoleminen, ns. sarkopenia. Tämän lisäksi lihasten aktivoinnin tehokkuus voi heikentyä, johtumisnopeudet laskea sekä lihasten supistumisominaisuudet heikentyä ja hidastua. Nämä yhdessä johtavat osaltaan voimantuotto-ominaisuuksien ja etenkin nopean voimantuoton heikkenemiseen, joka voi olla yksi keskeisimmistä tekijöistä ikääntyneiden tasapainon muutoksissa. Tasapainoa on yleensä mitattu staattisessa tilanteessa, joka ei välttämättä korreloi dynaamisen tasapainon kanssa. Dynaamista tasapainoa on mitattu eri menetelmillä, eikä sen mittaamiseen ole olemassa yhtä erityistä suositusta.

Voimaharjoitteiden vaikutuksia on ikääntyneiden hermo-lihasjärjestelmän voimantuottoon ja tasapainoon on tutkittu aiemmin laajasti ja todettu niiden positiivinen vaikutus. Toisaalta eri harjoitteiden väliset adaptaatiomekanismit voivat vaihdella suuresti, jonka vuoksi myös niiden vaikutus tasapainoon voi olla erilainen. Tämän tutkimuksen tarkoituksena oli selvittää nuorten (young; Y) ja ikääntyneiden (elderly; E) miesten välisiä eroja hermo-lihasjärjestelmän toiminnassa ja tasapainokontrollissa, tutkia kahden erityyppisen nopeusvoimaharjoittelun vaikutuksia hermo-lihasjärjestelmän toimintaan ja dynaamiseen tasapainoon sekä pyrkiä kehittämään mittausmenetelmä dynaamisen tasapainon mittaamiseen. Tutkimus jaettiin poikkitieteelliseen osaan, jossa selvitettiin ikääntymisen vaikutuksia hermo-lihasjärjestelmän toimintaan ja tasapainokontrolliin ( $E=22, Y=10$, julkaisut I ja II; E=10, $Y=9$, julkaisu IV) sekä seurantatutkimukseen jossa tutkittiin kahden eri tyyppisen nopeusvoimaharjoittelun (Plyometrinen (PLY);n=9, Pneumaattinen (PNE);n=11, julkaisu III) vaikutuksia hermo-lihasjärjestelmän ja dynaamisen tasapainon adaptaatioon ikääntyneillä. Maksimaalinen ja räjähtävä isometrinen voima mitattiin polven ja nilkan ojentajista. Dynaaminen tasapaino mitattiin pystysuuntaan ja vaakasuuntaan yllättäen tapahtuvana häiriönä, joiden lisäksi, staattinen tasapaino määritettiin. Vaakasuuntaan tapahtuva häiriö mitattiin kahdella eri nopeudella, hitaalla ja nopealla. H-refleksi mitattiin seisaaltaan lihasten ollessa mahdollisimman levossa, sekä pudotushyppyjen aikana kelkka-ergometrissä ja vaakasuuntaan tapahtuvan tasapainohäiriön aikana. Venytysrefleksi mitattiin pohje- ja säärilihaksista vaakasuuntaan tapahtuvan häiriön aikana.

Voimantuotto-ominaisuuksien ja hermoston toiminnan perusteella näyttäisi siltä, että ikääntymisen vaikutukset ovat selvemmin havaittavissa reisikuin pohjelihaksissa. Staattisessa tasapainossa ei havaittu eroja nuorten ja ikääntyneiden välillä, kun taas dynaamisessa tilanteessa eteen-taaksepäin suunnan kontrolli oli ikääntyneillä merkitsevästi heikompaa ja eteenkin kun 
häiriö tuli eteenpäin. Venytysrefleksivasteissa johtumisaika näyttäisi olevan suurempi tekijä tasapainon ylläpitämiseen kuin refleksien amplitudit. Hrefleksivasteissa ei havaittu eroja ikäryhmien välillä seisonnan aikana eikä kelkkahypyissä, kun taas tasapainohäiriön aikana ja etenkin nopeassa häiriössä ikääntyneillä havaittiin merkitsevästi alemmat H-refleksi tasot. Ikääntyneille toteutettiin 12 viikon nopeusvoimaharjoittelujakso, jossa testattavat jaettiin kahteen eri harjoitteluryhmään. PNE-ryhmä harjoitteli paineilmalla toimivilla kuntosali laitteilla reisi- ja pohjelihaksia, kun taas PLY-ryhmä harjoitteli kelkkaergometrillä jatkuvana hyppyharjoitteluna. PNE-ryhmässä harjoittelun vaikutukset näkyivät lisääntyneenä keskushermoston aktiivisuutena ja etenkin reisilihaksessa, kun taas PLY-ryhmässä positiivinen adaptaatio oli nähtävissä pohkeissa ja refleksivasteissa. Hieman yllättäen, molemmilla harjoittelumuodoilla oli lähes samanlainen vaikutus dynaamiseen tasapainoon joka parani molemmilla ryhmillä jo ensimmäisen neljän viikon aikana.

Tutkimuksen tulosten perusteella voidaan esittää, että tasapaino tulisi mitata dynaamisessa tilanteessa, koska se näyttäisi erottelevan hyvä- ja heikkokuntoiset staattista tilannetta paremmin. Lisäksi vaakasuuntaan tapahtuva häiriö simuloi luultavasti parhaiten todellisuudessa tapahtuvia häiriöitä, esimerkiksi liukkaalla tiellä tapahtuvia kaatumisia. Nopeanvoimantuoton yhteys tasapainoon vahvistaa osaltaan käsitystä voimantuottokyvyn tärkeydestä tasapainon ylläpitämiseen äkillisesti tulevissa häiriöissä. Lisäksi muutokset refleksivasteissa voivat merkitä erilaista kontrollistrategiaa ikääntyneillä, joka sinällään voi olla seurausta ikääntymisen aiheuttamista muutoksista hermolihasjärjestelmän toiminnassa. Toisaalta, koska vastaavia tutkimuksia ei ole tehty paljoa varsinkaan ikääntyneiden osalta, harjoittelumekanismeja ja eteenkin kortikaalisen aktiivisuuden merkitystä tulisi edelleen tutkia. 


\section{REFERENCES}

Aagaard P., Simonsen E.B., Andersen J.L., Magnusson P. \& Dyhre-Poulsen P. 2002. Neural adaptation to resistance training: changes in evoked V-wave and H-reflex responses. Journal of Applied Physiology 92(6), 2309-2318.

Ahtiainen J.P., Pakarinen A., Alen M., Kraemer W.J. \& Häkkinen K. 2005. Short vs. long rest period between the sets in hypertrophic resistance training: influence on muscle strength, size, and hormonal adaptations in trained men. Journal of Strength and Conditioning Research 19(3), 572-582.

Amaral D.G. 2000. The anatomical organization of the central nervous system. In: Kandel E., Schwartz J., Jessell T. (eds) Principles of neural science. McGraw-Hill, 317-336.

Angulo-Kinzler R.M., Mynark R.G. \& Koceja D.M. 1998. Soleus H-reflex gain in elderly and young adults: modulation due to body position. The Journals of Gerontology Series A, Biological Sciences and Medical Sciences 53(2), $120-125$.

Aura O. \& Komi P.V. 1986a. The mechanical efficiency of locomotion in men and women with special emphasis on stretch-shortening cycle exercises. European Journal of Applied Physiology and Occupational Physiology 55(1), 37-43.

Aura O. \& Komi P.V. 1986b. Mechanical efficiency of pure positive and pure negative work with special reference to the work intensity. International Journal of Sports Medicine 7(1), 44-49.

Avela J., Finni J. \& Komi P.V. 2006. Excitability of the soleus reflex arc during intensive stretch-shortening cycle exercise in two power-trained athlete groups. European Journal of Applied Physiology 97(4), 486-493.

Avela J. \& Komi P.V. 1998. Reduced stretch reflex sensitivity and muscle stiffness after long-lasting stretch-shortening cycle exercise in humans. European Journal of Applied Physiology and Occupational Physiology 78(5), 403-410.

Baloh R.W., Fife T.D., Zwerling L., Socotch T., Jacobson K., Bell T. \& Beykirch K. 1994. Comparison of static and dynamic posturography in young and older normal people. Journal of the American Geriatrics Society 42(4), 405412.

Baudry S., Maerz A.H. \& Enoka R.M. 2010. Presynaptic modulation of Ia afferents in young and old adults when performing force and position control. Journal of Neurophysiology 103(2), 623-631.

Bauer C., Groger I., Rupprecht R. \& Gassmann K.G. 2008. Intrasession reliability of force platform parameters in community-dwelling older adults. Archives of Physical Medicine and Rehabilitation 89(10), 1977-1982.

Benjuya N., Melzer I. \& Kaplanski J. 2004. Aging-induced shifts from a reliance on sensory input to muscle cocontraction during balanced standing. The Journals of Gerontology Series A, Biological Sciences and Medical Sciences 59(2), 166-171. 
Blake A.J., Morgan K., Bendall M.J., Dallosso H., Ebrahim S.B., Arie T.H., Fentem P.H. \& Bassey E.J. 1988. Falls by elderly people at home: prevalence and associated factors. Age and Ageing 17(6), 365-372.

Bosco C. \& Komi P.V. 1980. Influence of aging on the mechanical behavior of leg extensor muscles. European Journal of Applied Physiology and Occupational Physiology 45(2-3), 209-219.

Buchner D.M., Larson E.B., Wagner E.H., Koepsell T.D. \& de Lateur B.J. 1996. Evidence for a non-linear relationship between leg strength and gait speed. Age and Ageing 25(5), 386-391.

Buchthal F. \& Schmalbruch H. 1970. Contraction times of twitches evoked by Hreflexes. Acta Physiologica Scandinavica 80(3), 378-382.

Burke D. \& Pierrot-Deseilligny E. 2005. The circuitry of the human spinal cord: Its role in motor control and movement disorders. Cambridge University Press, New York.

Burke J.R. \& Kamen G. 1996. Changes in spinal reflexes preceding a voluntary movement in young and old adults. The Journals of Gerontology Series A, Biological Sciences and Medical Sciences 51(1), 17-22.

Burke R.E. 1967. Motor unit types of cat triceps surae muscle. Journal of Physiology 193(1), 141-160.

Burke R.E., Levine D.N., Tsairis P. \& Zajac F.E., 3rd 1973. Physiological types and histochemical profiles in motor units of the cat gastrocnemius. Journal of Physiology 234(3), 723-748.

Burke R.E. \& Tsairis P. 1973. Anatomy and innervation ratios in motor units of cat gastrocnemius. Journal of Physiology 234(3), 749-765.

Butchart P., Farquhar R., Part N.J. \& Roberts R.C. 1993. The effect of age and voluntary contraction on presynaptic inhibition of soleus muscle Ia afferent terminals in man. Experimental Physiology 78(2), 235-242.

Capaday C. 1997. Neurophysiological methods for studies of the motor system in freely moving human subjects. Journal of Neuroscience Methods 74(2), 201-218.

Carroll T.J., Barry B., Riek S. \& Carson R.G. 2001. Resistance training enhances the stability of sensorimotor coordination. Proceedings Biological Sciences 268(1464), 221-227.

Carty C.P., Barrett R.S., Cronin N.J., Lichtwark G.A. \& Mills P.M. 2012. Lower limb muscle weakness predicts use of a multiple- versus single-step strategy to recover from forward loss of balance in older adults. The Journals of Gerontology Series A, Biological Sciences and Medical Sciences 67(11), 1246-1252.

Caserotti P., Aagaard P., Larsen J.B. \& Puggaard L. 2008. Explosive heavyresistance training in old and very old adults: changes in rapid muscle force, strength and power. Scandinavian Journal of Medicine \& Science in Sports 18(6), 773-782.

Cavallari P. \& Lalli S. 1998. Changes in excitability of the flexor carpi radialis Hreflex following tactile stimulation of the index fingertip. Experimental Brain Research 120(3), 345-351. 
Chalmers G.R. \& Knutzen K.M. 2000. Soleus Hoffmann-reflex modulation during walking in healthy elderly and young adults. The Journals of Gerontology Series A, Biological Sciences and Medical Sciences 55(12), B570-579.

Chalmers G.R. \& Knutzen K.M. 2002. Soleus H-reflex gain in healthy elderly and young adults when lying, standing, and balancing. The Journals of Gerontology Series A, Biological Sciences and Medical Sciences 57(8), B321-329.

Chimera N.J., Swanik K.A., Swanik C.B. \& Straub S.J. 2004. Effects of Plyometric Training on Muscle-Activation Strategies and Performance in Female Athletes. Journal of Athletic Training 39(1), 24-31.

Christie A. \& Kamen G. 2006. Doublet discharges in motoneurons of young and older adults. Journal of Neurophysiology 95(5), 2787-2795.

Connelly D.M., Rice C.L., Roos M.R. \& Vandervoort A.A. 1999. Motor unit firing rates and contractile properties in tibialis anterior of young and old men. Journal of Applied Physiology 87(2), 843-852.

Crone C., Hultborn H., Jespersen B. \& Nielsen J. 1987. Reciprocal Ia inhibition between ankle flexors and extensors in man. Journal of Physiology 389,163-185.

Cronin J.B., McNair P.J. \& Marshall R.N. 2002. Is velocity-specific strength training important in improving functional performance? Journal of Sports Medicine and Physical Fitness 42(3), 267-273.

Cronin N.J., Barrett R.S., Lichtwark G., Mills P.M. \& Carty C.P. 2013. Decreased lower limb muscle recruitment contributes to the inability of older adults to recover with a single step following a forward loss of balance. Journal of Electromyography and Kinesiology 23(5), 1139-1144.

Cronin N.J., Carty C.P. \& Barrett R.S. 2011. Triceps surae short latency stretch reflexes contribute to ankle stiffness regulation during human running. PLoS One 6(8), e23917.

Day B.L., Marsden C.D., Obeso J.A. \& Rothwell J.C. 1984. Reciprocal inhibition between the muscles of the human forearm. Journal of Physiology 349,519534.

De Luca C.J., LeFever R.S., McCue M.P. \& Xenakis A.P. 1982. Behaviour of human motor units in different muscles during linearly varying contractions. Journal of Physiology 329,113-128.

De Luca C.J. \& Mambrito B. 1987. Voluntary control of motor units in human antagonist muscles: coactivation and reciprocal activation. Journal of Neurophysiology 58(3), 525-542.

de Salles B.F., Simao R., Miranda F., Novaes Jda S., Lemos A. \& Willardson J.M. 2009. Rest interval between sets in strength training. Sports Medicine 39(9), 765-777.

de Vos N.J., Singh N.A., Ross D.A., Stavrinos T.M., Orr R. \& Fiatarone Singh M.A. 2005. Optimal load for increasing muscle power during explosive resistance training in older adults. The Journals of Gerontology Series A, Biological Sciences and Medical Sciences 60(5), 638-647. 
Delbono O., O'Rourke K.S. \& Ettinger W.H. 1995. Excitation-calcium release uncoupling in aged single human skeletal muscle fibers. Journal of Membrane Biology 148(3), 211-222.

Devanne H., Lavoie B.A. \& Capaday C. 1997. Input-output properties and gain changes in the human corticospinal pathway. Experimental Brain Research 114(2), 329-338.

Dietz V. 1998. Evidence for a load receptor contribution to the control of posture and locomotion. Neuroscience and Biobehavioral Reviews 22(4), 495-499.

Doherty T.J., Komori T., Stashuk D.W., Kassam A. \& Brown W.F. 1994. Physiological properties of single thenar motor units in the F-response of younger and older adults. Muscle \& Nerve 17(8), 860-872.

Doherty T.J., Vandervoort A.A. \& Brown W.F. 1993a. Effects of ageing on the motor unit: a brief review. Canadian Journal of Applied Physiology 18(4), 331-358.

Doherty T.J., Vandervoort A.A., Taylor A.W. \& Brown W.F. 1993b. Effects of motor unit losses on strength in older men and women. Journal of Applied Physiology 74(2), 868-874.

Duysens J., Beerepoot V.P., Veltink P.H., Weerdesteyn V. \& Smits-Engelsman B.C. 2008. Proprioceptive perturbations of stability during gait. Clinical Neurophysiology 38(6), 399-410.

Dyhre-Poulsen P., Simonsen E.B. \& Voigt M. 1991. Dynamic control of muscle stiffness and $\mathrm{H}$ reflex modulation during hopping and jumping in man. Journal of Physiology 437,287-304.

Dykes R.W., Rasmusson D.D. \& Hoeltzell P.B. 1980. Organization of primary somatosensory cortex in the cat. Journal of Neurophysiology 43(6), 15271546.

Eccles J.C., Eccles R.M. \& Magni F. 1961. Central inhibitory action attributable to presynaptic depolarization produced by muscle afferent volleys. Journal of Physiology 159,147-166.

Eccles J.C., Kostyuk P.G. \& Schmidt R.F. 1962. Presynaptic inhibition of the central actions of flexor reflex afferents. Journal of Physiology 161,258-281.

Edgerton V.R., Smith J.L. \& Simpson D.R. 1975. Muscle fibre type populations of human leg muscles. The Histochemical Journal 7(3), 259-266.

Edwen C.E., Thorlund J.B., Magnusson S.P., Slinde F., Svantesson U., Hulthen L. \& Aagaard P. 2013. Stretch-shortening cycle muscle power in women and men aged 18-81 years: Influence of age and gender. Scandinavian Journal of Medicine \& Science in Sports

English A.W. \& Wolf S.L. 1982. The motor unit. Anatomy and physiology. Physical Therapy 62(12), 1763-1772.

Enoka R.M. 2001. Neuromechanics of human movement. Human Kinetics, Champaign, IL.

Fellows S.J., Domges F., Topper R., Thilmann A.F. \& Noth J. 1993. Changes in the short- and long-latency stretch reflex components of the triceps surae muscle during ischaemia in man. Journal of Physiology 472,737-748. 
Fiatarone M.A., Marks E.C., Ryan N.D., Meredith C.N., Lipsitz L.A. \& Evans W.J. 1990. High-intensity strength training in nonagenarians. Effects on skeletal muscle. Journal of the American Medicine Association 263(22), 3029-3034.

Fiatarone M.A., O'Neill E.F., Ryan N.D., Clements K.M., Solares G.R., Nelson M.E., Roberts S.B., Kehayias J.J., Lipsitz L.A. \& Evans W.J. 1994. Exercise training and nutritional supplementation for physical frailty in very elderly people. New England Journal of Medicine 330(25), 1769-1775.

Fitzpatrick R.C., Taylor J.L. \& McCloskey D.I. 1992. Ankle stiffness of standing humans in response to imperceptible perturbation: reflex and taskdependent components. Journal of Physiology 454,533-547.

Fleck S.J. \& Kraemer W.J. 2004. Designing resistance training programs. Human Kinetics, Champaign, Ill. ; Leeds.

Franklin D.W., So U., Burdet E. \& Kawato M. 2007. Visual feedback is not necessary for the learning of novel dynamics. PLoS One 2(12), e1336.

Gajdosik R.L., Vander Linden D.W. \& Williams A.K. 1999. Influence of age on length and passive elastic stiffness characteristics of the calf muscletendon unit of women. Physical Therapy 79(9), 827-838.

Gallagher D., Visser M., De Meersman R.E., Sepulveda D., Baumgartner R.N., Pierson R.N., Harris T. \& Heymsfield S.B. 1997. Appendicular skeletal muscle mass: effects of age, gender, and ethnicity. Journal of Applied Physiology 83(1), 229-239.

Ghez C., Hening W. \& Gordon J. 1991. Organization of voluntary movement. Current Opinion in Neurobiology 1(4), 664-671.

Grace Gaerlan M., Alpert P.T., Cross C., Louis M. \& Kowalski S. 2012. Postural balance in young adults: the role of visual, vestibular and somatosensory systems. Journal of the American Academy of Nurse Practitioners 24(6), 375-381.

Granacher U., Gollhofer A. \& Strass D. 2006. Training induced adaptations in characteristics of postural reflexes in elderly men. Gait Posture 24(4), 459466.

Granacher U., Muehlbauer T. \& Gruber M. 2012. A qualitative review of balance and strength performance in healthy older adults: impact for testing and training. Journal Of Aging Research 2012708905.

Granacher U., Muehlbauer T., Zahner L., Gollhofer A. \& Kressig R.W. 2011. Comparison of traditional and recent approaches in the promotion of balance and strength in older adults. Sports Medicine 41(5), 377-400.

Grey M.J., Ladouceur M., Andersen J.B., Nielsen J.B. \& Sinkjaer T. 2001. Group II muscle afferents probably contribute to the medium latency soleus stretch reflex during walking in humans. Journal of Physiology 534(Pt 3), 925-933.

Hall C.D., Woollacott M.H. \& Jensen J.L. 1999. Age-related changes in rate and magnitude of ankle torque development: implications for balance control. The Journals of Gerontology Series A, Biological Sciences and Medical Sciences 54(10), M507-513. 
Harridge S.D., Kryger A. \& Stensgaard A. 1999. Knee extensor strength, activation, and size in very elderly people following strength training. Muscle \& Nerve 22(7), 831-839.

Harris-Love M.L., Perez M.A., Chen R. \& Cohen L.G. 2007. Interhemispheric inhibition in distal and proximal arm representations in the primary motor cortex. Journal of Neurophysiology 97(3), 2511-2515.

Harris C., DeBeliso M., Adams K.J., Irmischer B.S. \& Spitzer Gibson T.A. 2007. Detraining in the older adult: effects of prior training intensity on strength retention. Journal of Strength and Conditioning Research 21(3), 813-818.

Hasson C.J., Kent-Braun J.A. \& Caldwell G.E. 2011. Contractile and noncontractile tissue volume and distribution in ankle muscles of young and older adults. Journal of Biomechanics 44(12), 2299-2306.

Henneman E., Somjen G. \& Carpenter D.O. 1965. Excitability and inhibitability of motoneurons of different sizes. Journal of Neurophysiology 28(3), 599620 .

Henwood T.R., Riek S. \& Taaffe D.R. 2008. Strength versus muscle powerspecific resistance training in community-dwelling older adults. The Journals of Gerontology Series A, Biological Sciences and Medical Sciences 63(1), 83-91.

Hermens H.J., Freriks B., Merletti R., Stegeman D., Blok J., Rau G., DisselhorstKlug C. \& Hägg G. 1999. European recommendations for surface electromyography : results of the SENIAM project. Roessingh Research and Development, Enschede.

Hicks A.L., Cupido C.M., Martin J. \& Dent J. 1992. Muscle excitation in elderly adults: the effects of training. Muscle \& Nerve 15(1), 87-93.

Hoffren M., Ishikawa M. \& Komi P.V. 2007. Age-related neuromuscular function during drop jumps. Journal of Applied Physiology 103(4), 12761283.

Holsgaard-Larsen A., Caserotti P., Puggaard L. \& Aagaard P. 2011. Stair-ascent performance in elderly women: effect of explosive strength training. Journal of Aging and Physical Activity 19(2), 117-136.

Horak F.B., Nashner L.M. \& Diener H.C. 1990. Postural strategies associated with somatosensory and vestibular loss. Experimental Brain Research 82(1), 167-177.

Horak F.B., Shupert C.L., Dietz V. \& Horstmann G. 1994. Vestibular and somatosensory contributions to responses to head and body displacements in stance. Experimental Brain Research 100(1), 93-106.

Horita T., Komi P.V., Nicol C. \& Kyrolainen H. 1996. Stretch shortening cycle fatigue: interactions among joint stiffness, reflex, and muscle mechanical performance in the drop jump [corrected]. European Journal of Applied Physiology and Occupational Physiology 73(5), 393-403.

Hortobagyi T. \& Devita P. 2006. Mechanisms responsible for the age-associated increase in coactivation of antagonist muscles. Exercise and Sport Sciences Reviews 34(1), 29-35. 
Hultborn H., Meunier S., Morin C. \& Pierrot-Deseilligny E. 1987. Assessing changes in presynaptic inhibition of I a fibres: a study in man and the cat. Journal of Physiology 389,729-756.

Hultborn H. \& Pierrot-Deseilligny E. 1979. Changes in recurrent inhibition during voluntary soleus contractions in man studied by an H-reflex technique. Journal of Physiology 297(0), 229-251.

Häkkinen K. 2002. Training-specific characteristics of neuromuscular performance. In: Kraemer W.J., Häkkinen K. (eds) Strength training for sport. Blackwell Science, pp. 20-36.

Häkkinen K. \& Häkkinen A. 1991. Muscle cross-sectional area, force production and relaxation characteristics in women at different ages. European Journal of Applied Physiology and Occupational Physiology 62(6), 410-414.

Häkkinen K. \& Häkkinen A. 1995. Neuromuscular adaptations during intensive strength training in middle-aged and elderly males and females. Electromyography and Clinical Neurophysiology 35(3), 137-147.

Häkkinen K., Kallinen M., Izquierdo M., Jokelainen K., Lassila H., Malkia E., Kraemer W.J., Newton R.U. \& Alen M. 1998. Changes in agonistantagonist EMG, muscle CSA, and force during strength training in middle-aged and older people. Journal of Applied Physiology 84(4), 13411349.

Häkkinen K. \& Komi P.V. 1986. Training-induced changes in neuromuscular performance under voluntary and reflex conditions. European Journal of Applied Physiology and Occupational Physiology 55(2), 147-155.

Häkkinen K., Komi P.V. \& Alen M. 1985. Effect of explosive type strength training on isometric force- and relaxation-time, electromyographic and muscle fibre characteristics of leg extensor muscles. Acta Physiologica Scandinavica 125(4), 587-600.

Häkkinen K., Kraemer W.J., Newton R.U. \& Alen M. 2001. Changes in electromyographic activity, muscle fibre and force production characteristics during heavy resistance/power strength training in middle-aged and older men and women. Acta Physiologica Scandinavica 171(1), 51-62.

Häkkinen K., Pakarinen A. \& Kallinen M. 1992. Neuromuscular adaptations and serum hormones in women during short-term intensive strength training. European Journal of Applied Physiology and Occupational Physiology 64(2), 106-111.

Häkkinen K., Pastinen U.M., Karsikas R. \& Linnamo V. 1995. Neuromuscular performance in voluntary bilateral and unilateral contraction and during electrical stimulation in men at different ages. European Journal of Applied Physiology and Occupational Physiology 70(6), 518-527.

Höök P., Sriramoju V. \& Larsson L. 2001. Effects of aging on actin sliding speed on myosin from single skeletal muscle cells of mice, rats, and humans. American Journal of Physiology: Cell Physiology 280(4), C782-788. 
Iwamura Y., Tanaka M. \& Hikosaka O. 1980. Overlapping representation of fingers in the somatosensory cortex (area 2) of the conscious monkey. Brain Research 197(2), 516-520.

Izquierdo M., Aguado X., Gonzalez R., Lopez J.L. \& Häkkinen K. 1999a. Maximal and explosive force production capacity and balance performance in men of different ages. European Journal of Applied Physiology and Occupational Physiology 79(3), 260-267.

Izquierdo M., Ibanez J., Gorostiaga E., Garrues M., Zuniga A., Anton A., Larrion J.L. \& Häkkinen K. 1999b. Maximal strength and power characteristics in isometric and dynamic actions of the upper and lower extremities in middle-aged and older men. Acta Physiologica Scandinavica 167(1), 57-68.

Jankowska E. \& Edgley S.A. 2006. How can corticospinal tract neurons contribute to ipsilateral movements? A question with implications for recovery of motor functions. Neuroscientist 12(1), 67-79.

Kallio J., Avela J., Moritani T., Kanervo M., Selänne H., Komi P. \& Linnamo V. 2010. Effects of ageing on motor unit activation patterns and reflex sensitivity in dynamic movements. Journal of Electromyography and Kinesiology 20(4), 590-598.

Kallio J., Sogaard K., Avela J., Komi P., Selänne H. \& Linnamo V. 2012. Agerelated decreases in motor unit discharge rate and force control during isometric plantar flexion. Journal of Electromyography and Kinesiology 22(6), 983-989.

Kamen G. \& Knight C.A. 2004. Training-related adaptations in motor unit discharge rate in young and older adults. The Journals of Gerontology Series A, Biological Sciences and Medical Sciences 59(12), 1334-1338.

Kamen G. \& Roy A. 2000. Motor unit synchronization in young and elderly adults. European Journal of Applied Physiology 81(5), 403-410.

Kannus P. 1999. [Prevention of osteoporotic fractures]. Duodecim 115(7), 759764.

Kannus P., Jarvinen M. \& Vuori I. 2000. [Fall-induced injuries among the elderly are a big challenge of the 21st century]. Duodecim 116(5), 469-471.

Kannus P. \& Parkkari J. 2006. Prevention of hip fracture with hip protectors. Age and Ageing 35 Suppl 2ii51-ii54.

Katz R. \& Pierrot-Deseilligny E. 1999. Recurrent inhibition in humans. Progress in Neurobiology 57(3), 325-355.

Kawashima N., Nakazawa K., Yamamoto S.I., Nozaki D., Akai M. \& Yano H. 2004. Stretch reflex excitability of the anti-gravity ankle extensor muscle in elderly humans. Acta Physiologica Scandinavica 180(1), 99-105.

Kidgell D.J., Sale M.V. \& Semmler J.G. 2006. Motor unit synchronization measured by cross-correlation is not influenced by short-term strength training of a hand muscle. Experimental Brain Research 175(4), 745-753.

Kido A., Tanaka N. \& Stein R.B. 2004. Spinal excitation and inhibition decrease as humans age. Canadian Journal Physiology and Pharmacology 82(4), 238-248. 
Kim B.J. \& Robinson C.J. 2005. Postural control and detection of slip/fall initiation in the elderly population. Ergonomics 48(9), 1065-1085.

Klass M., Baudry S. \& Duchateau J. 2005. Aging does not affect voluntary activation of the ankle dorsiflexors during isometric, concentric, and eccentric contractions. Journal of Applied Physiology 99(1), 31-38.

Klass M., Baudry S. \& Duchateau J. 2011. Modulation of reflex responses in activated ankle dorsiflexors differs in healthy young and elderly subjects. European Journal of Applied Physiology 111(8), 1909-1916.

Koceja D.M. \& Kamen G. 1988. Conditioned patellar tendon reflexes in sprintand endurance-trained athletes. Medicine and Science in Sports and Exercise 20(2), 172-177.

Koceja D.M., Markus C.A. \& Trimble M.H. 1995. Postural modulation of the soleus $\mathrm{H}$ reflex in young and old subjects. Electroencephalography and Clinical Neurophysiology 97(6), 387-393.

Komi P.V. 2000. Stretch-shortening cycle: a powerful model to study normal and fatigued muscle. Journal of Biomechanics 33(10), 1197-1206.

Kubo K., Morimoto M., Komuro T., Yata H., Tsunoda N., Kanehisa H. \& Fukunaga T. 2007. Effects of plyometric and weight training on muscletendon complex and jump performance. Medicine and Science in Sports and Exercise 39(10), 1801-1810.

Kyröläinen H., Avela J., McBride J.M., Koskinen S., Andersen J.L., Sipilä S., Takala T.E. \& Komi P.V. 2005. Effects of power training on muscle structure and neuromuscular performance. Scandinavian Journal of Medicine \& Science in Sports 15(1), 58-64.

Kyröläinen H., Komi P.V., Oksanen P., Häkkinen K., Cheng S. \& Kim D.H. 1990. Mechanical efficiency of locomotion in females during different kinds of muscle action. European Journal of Applied Physiology and Occupational Physiology 61(5-6), 446-452.

Larsen B. \& Voigt M. 2006. Quadriceps H-reflex modulation during pedaling. Journal of Neurophysiology 96(1), 197-208.

Larsson L. 1982. Physical training effects on muscle morphology in sedentary males at different ages. Medicine and Science in Sports and Exercise 14(3), 203-206.

Latham N.K., Bennett D.A., Stretton C.M. \& Anderson C.S. 2004. Systematic review of progressive resistance strength training in older adults. The Journals of Gerontology Series A, Biological Sciences and Medical Sciences 59(1), 48-61.

Leonard C.T., Matsumoto T., Diedrich P.M. \& McMillan J.A. 1997. Changes in neural modulation and motor control during voluntary movement of older individuals. The Journals of Gerontology Series A, Biological Sciences and Medical Sciences 52(5), M320-325.

Leukel C., Taube W., Gruber M., Hodapp M. \& Gollhofer A. 2008. Influence of falling height on the excitability of the soleus H-reflex during drop-jumps. Acta Physiologica (Oxford, England) 192(4), 569-576. 
Lexell J., Taylor C.C. \& Sjostrom M. 1988. What is the cause of the ageing atrophy? Total number, size and proportion of different fiber types studied in whole vastus lateralis muscle from 15- to 83-year-old men. Journal of Neurological Sciences 84(2-3), 275-294.

Light N. \& Champion A.E. 1984. Characterization of muscle epimysium, perimysium and endomysium collagens. Biochemical Journal 219(3), 10171026.

Lin S.I. \& Woollacott M.H. 2002. Postural muscle responses following changing balance threats in young, stable older, and unstable older adults. Journal of Motor Behavior 34(1), 37-44.

Linnamo V., Moritani T., Nicol C. \& Komi P.V. 2003. Motor unit activation patterns during isometric, concentric and eccentric actions at different force levels. Journal of Electromyography and Kinesiology 13(1), 93-101.

Linnamo V., Newton R.U., Häkkinen K., Komi P.V., Davie A., McGuigan M. \& Triplett-McBride T. 2000. Neuromuscular responses to explosive and heavy resistance loading. Journal of Electromyography and Kinesiology 10(6), 417-424.

Lovell D.I., Cuneo R. \& Gass G.C. 2010. The effect of strength training and short-term detraining on maximum force and the rate of force development of older men. European Journal of Applied Physiology 109(3), 429-435.

Macaluso A. \& De Vito G. 2004. Muscle strength, power and adaptations to resistance training in older people. European Journal of Applied Physiology 91(4), 450-472.

Maffiuletti N.A., Martin A., Babault N., Pensini M., Lucas B. \& Schieppati M. 2001. Electrical and mechanical $\mathrm{H}(\max )$-to- $\mathrm{M}(\max )$ ratio in power- and endurance-trained athletes. Journal of Applied Physiology 90(1), 3-9.

Martel G.F., Roth S.M., Ivey F.M., Lemmer J.T., Tracy B.L., Hurlbut D.E., Metter E.J., Hurley B.F. \& Rogers M.A. 2006. Age and sex affect human muscle fibre adaptations to heavy-resistance strength training. Experimental Physiology 91(2), 457-464.

McComas A.J., Galea V. \& de Bruin H. 1993. Motor unit populations in healthy and diseased muscles. Physical Therapy 73(12), 868-877.

Mero A.A., Hulmi J.J., Salmijarvi H., Katajavuori M., Haverinen M., Holviala J., Ridanpaa T., Hakkinen K., Kovanen V., Ahtiainen J.P. \& Selanne H. 2013. Resistance training induced increase in muscle fiber size in young and older men. European Journal of Applied Physiology 113(3), 641-650.

Merton P.A. 1954. Voluntary strength and fatigue. Journal of Physiology 123(3), 553-564.

Milner-Brown H.S., Stein R.B. \& Yemm R. 1973. The orderly recruitment of human motor units during voluntary isometric contractions. Journal of Physiology 230(2), 359-370.

Misiaszek J.E. 2003. The H-reflex as a tool in neurophysiology: its limitations and uses in understanding nervous system function. Muscle \& Nerve 28(2), 144-160. 
Miszko T.A., Cress M.E., Slade J.M., Covey C.J., Agrawal S.K. \& Doerr C.E. 2003. Effect of strength and power training on physical function in communitydwelling older adults. The Journals of Gerontology Series A, Biological Sciences and Medical Sciences 58(2), 171-175.

Miwa T., Miwa Y. \& Kanda K. 1995. Dynamic and static sensitivities of muscle spindle primary endings in aged rats to ramp stretch. Neuroscience Letters 201(2), 179-182.

Morita H., Shindo M., Yanagawa S., Yoshida T., Momoi H. \& Yanagisawa N. 1995. Progressive decrease in heteronymous monosynaptic Ia facilitation with human ageing. Experimental Brain Research 104(1), 167-170.

Moritani T. \& deVries H.A. 1979. Neural factors versus hypertrophy in the time course of muscle strength gain. American Journal of Physical Medicine 58(3), 115-130.

Morse C.I., Thom J.M., Davis M.G., Fox K.R., Birch K.M. \& Narici M.V. 2004. Reduced plantarflexor specific torque in the elderly is associated with a lower activation capacity. European Journal of Applied Physiology 92(1-2), 219-226.

Moxley Scarborough D., Krebs D.E. \& Harris B.A. 1999. Quadriceps muscle strength and dynamic stability in elderly persons. Gait Posture 10(1), 10-20.

Muehlbauer T., Besemer C., Wehrle A., Gollhofer A. \& Granacher U. 2012. Relationship between strength, power and balance performance in seniors. Gerontology 58(6), 504-512.

Mynark R.G. \& Koceja D.M. 2001. Effects of age on the spinal stretch reflex. Journal of Applied Biomechanics 17188-203.

Mynark R.G. \& Koceja D.M. 2002. Down training of the elderly soleus H reflex with the use of a spinally induced balance perturbation. Journal of Applied Physiology 93(1), 127-133.

Nakazawa K., Kawashima N., Obata H., Yamanaka K., Nozaki D. \& Akai M. 2003. Facilitation of both stretch reflex and corticospinal pathways of the tibialis anterior muscle during standing in humans. Neuroscience Letters 338(1), 53-56.

Nardone A., Corra T. \& Schieppati M. 1990. Different activations of the soleus and gastrocnemii muscles in response to various types of stance perturbation in man. Experimental Brain Research 80(2), 323-332.

Nardone A., Romano C. \& Schieppati M. 1989. Selective recruitment of highthreshold human motor units during voluntary isotonic lengthening of active muscles. Journal of Physiology 409451-471.

Nardone A. \& Schieppati M. 1988. Shift of activity from slow to fast muscle during voluntary lengthening contractions of the triceps surae muscles in humans. Journal of Physiology 395,363-381.

Nardone A., Siliotto R., Grasso M. \& Schieppati M. 1995. Influence of aging on leg muscle reflex responses to stance perturbation. Archives of Physical Medicine and Rehabilitation 76(2), 158-165.

Narici M.V., Bordini M. \& Cerretelli P. 1991. Effect of aging on human adductor pollicis muscle function. Journal of Applied Physiology 71(4), 1277-1281. 
Narici M.V. \& Maffulli N. 2010. Sarcopenia: characteristics, mechanisms and functional significance. British Medical Bulletin 95139-159.

Nielsen J. \& Kagamihara Y. 1992. The regulation of disynaptic reciprocal Ia inhibition during co-contraction of antagonistic muscles in man. Journal of Physiology 456,373-391.

Obata H., Kawashima N., Akai M., Nakazawa K. \& Ohtsuki T. 2010. Agerelated changes of the stretch reflex excitability in human ankle muscles. Journal of Electromyography and Kinesiology 20(1), 55-60.

Ochala J., Lambertz D., Pousson M., Goubel F. \& Hoecke J.V. 2004. Changes in mechanical properties of human plantar flexor muscles in ageing. Experimental Gerontology 39(3), 349-358.

Orr R., de Vos N.J., Singh N.A., Ross D.A., Stavrinos T.M. \& Fiatarone-Singh M.A. 2006. Power training improves balance in healthy older adults. The Journals of Gerontology Series A, Biological Sciences and Medical Sciences 61(1), 78-85.

Oya T., Riek S. \& Cresswell A.G. 2009. Recruitment and rate coding organisation for soleus motor units across entire range of voluntary isometric plantar flexions. Journal of Physiology 587(Pt 19), 4737-4748.

Palmieri R.M., Ingersoll C.D. \& Hoffman M.A. 2004. The Hoffmann Reflex: Methodologic Considerations and Applications for Use in Sports Medicine and Athletic Training Research. Journal of Athletic Training 39(3), 268-277.

Paterson D.H., Jones G.R. \& Rice C.L. 2007. Ageing and physical activity: evidence to develop exercise recommendations for older adults. Canadian Journal of Public Health 98 Suppl 2S69-108.

Peinemann A., Lehner C., Conrad B. \& Siebner H.R. 2001. Age-related decrease in paired-pulse intracortical inhibition in the human primary motor cortex. Neuroscience Letters 313(1-2), 33-36.

Perot C., Goubel F. \& Mora I. 1991. Quantification of T- and H-responses before and after a period of endurance training. European Journal of Applied Physiology and Occupational Physiology 63(5), 368-375.

Petersen N., Christensen L.O., Morita H., Sinkjaer T. \& Nielsen J. 1998. Evidence that a transcortical pathway contributes to stretch reflexes in the tibialis anterior muscle in man. Journal of Physiology 512 ( Pt 1)267-276.

Pierrot-Deseilligny E. \& Mazevet D. 2000. The monosynaptic reflex: a tool to investigate motor control in humans. Interest and limits. Clinical Neurophysiology 30(2), 67-80.

Piirainen J.M., Tanskanen M., Nissila J., Kaarela J., Vaarala A., Sippola N. \& Linnamo V. 2011. Effects of a heart rate-based recovery period on hormonal, neuromuscular, and aerobic performance responses during 7 weeks of strength training in men. Journal of Strength and Conditioning Research 25(8), 2265-2273.

Place N., Casartelli N., Glatthorn J.F. \& Maffiuletti N.A. 2010. Comparison of quadriceps inactivation between nerve and muscle stimulation. Muscle \& Nerve 42(6), 894-900. 
Renshaw B. 1946. Central effects of centripetal impulses in axons of spinal ventral roots. Journal of Neurophysiology 9191-204.

Roos M.R., Rice C.L., Connelly D.M. \& Vandervoort A.A. 1999. Quadriceps muscle strength, contractile properties, and motor unit firing rates in young and old men. Muscle \& Nerve 22(8), 1094-1103.

Roos M.R., Rice C.L. \& Vandervoort A.A. 1997. Age-related changes in motor unit function. Muscle \& Nerve 20(6), 679-690.

Runge M., Rittweger J., Russo C.R., Schiessl H. \& Felsenberg D. 2004. Is muscle power output a key factor in the age-related decline in physical performance? A comparison of muscle cross section, chair-rising test and jumping power. Clinical Physiology and Functional Imaging 24(6), 335340.

Sabbahi M.A. \& Sedgwick E.M. 1982. Age-related changes in monosynaptic reflex excitability. Journal of Gerontology 37(1), 24-32.

Sale D.G. 2003. Neural adaptation to strength training. In: Komi P.V. (ed) Strength and power in sport. Blackwell Science, Oxford, pp. 281-314.

Sargeant A.J. 2007. Structural and functional determinants of human muscle power. Experimental Physiology 92(2), 323-331.

Scaglioni G., Ferri A., Minetti A.E., Martin A., Van Hoecke J., Capodaglio P., Sartorio A. \& Narici M.V. 2002. Plantar flexor activation capacity and H reflex in older adults: adaptations to strength training. Journal of Applied Physiology 92(6), 2292-2302.

Scaglioni G., Narici M.V., Maffiuletti N.A., Pensini M. \& Martin A. 2003. Effect of ageing on the electrical and mechanical properties of human soleus motor units activated by the $\mathrm{H}$ reflex and $\mathrm{M}$ wave. Journal of Physiology 548(Pt 2), 649-661.

Schieppati M. 1987. The Hoffmann reflex: a means of assessing spinal reflex excitability and its descending control in man. Progress in Neurobiology 28(4), 345-376.

Schieppati M. \& Nardone A. 1997. Medium-latency stretch reflexes of foot and leg muscles analysed by cooling the lower limb in standing humans. Journal of Physiology 503 ( Pt 3)691-698.

Semmler J.G., Steege J.W., Kornatz K.W. \& Enoka R.M. 2000. Motor-unit synchronization is not responsible for larger motor-unit forces in old adults. Journal of Neurophysiology 84(1), 358-366.

Shah P.K., Stevens J.E., Gregory C.M., Pathare N.C., Jayaraman A., Bickel S.C., Bowden M., Behrman A.L., Walter G.A., Dudley G.A. \& Vandenborne K. 2006. Lower-extremity muscle cross-sectional area after incomplete spinal cord injury. Archives of Physical Medicine and Rehabilitation 87(6), 772778.

Shemmell J., Krutky M.A. \& Perreault E.J. 2010. Stretch sensitive reflexes as an adaptive mechanism for maintaining limb stability. Clinical Neurophysiology 121(10), 1680-1689. 
Shumway-Cook A. \& Woollacott M. 2000. Attentional demands and postural control: the effect of sensory context. The Journals of Gerontology Series A, Biological Sciences and Medical Sciences 55(1), M10-16.

Simoneau E., Martin A. \& Van Hoecke J. 2007. Effects of joint angle and age on ankle dorsi- and plantar-flexor strength. Journal of Electromyography and Kinesiology 17(3), 307-316.

Solomonow M. 1984. External control of the neuromuscular system. IEEE Transactions on Biomedical Engineering 31(12), 752-763.

Stackhouse S.K., Stevens J.E., Lee S.C., Pearce K.M., Snyder-Mackler L. \& Binder-Macleod S.A. 2001. Maximum voluntary activation in nonfatigued and fatigued muscle of young and elderly individuals. Physical Therapy 81(5), 1102-1109.

Staron R.S., Hagerman F.C., Hikida R.S., Murray T.F., Hostler D.P., Crill M.T., Ragg K.E. \& Toma K. 2000. Fiber type composition of the vastus lateralis muscle of young men and women. Journal of Histochemistry and Cytochemistry 48(5), 623-629.

Stein R.B. 1995. Presynaptic inhibition in humans. Progress in Neurobiology 47(6), 533-544.

Stevens J.E., Stackhouse S.K., Binder-Macleod S.A. \& Snyder-Mackler L. 2003. Are voluntary muscle activation deficits in older adults meaningful? Muscle \& Nerve 27(1), 99-101.

Stone M.H., Potteiger J.A., Pierce K.C., Proulx C.M., O’Bryant H.S., Johnson R.L. \& Stone M.E. 2000. Comparison of the effects of three different weighttraining programs on the one repetition maximum squat. Journal of Strength and Conditioning Research 14(3), 332-337.

Strojnik V. \& Komi P.V. 1998. Neuromuscular fatigue after maximal stretchshortening cycle exercise. Journal of Applied Physiology 84(1), 344-350.

Sturnieks D.L., Menant J., Vanrenterghem J., Delbaere K., Fitzpatrick R.C. \& Lord S.R. 2012. Sensorimotor and neuropsychological correlates of force perturbations that induce stepping in older adults. Gait Posture 36(3), 356360.

Suetta C., Aagaard P., Rosted A., Jakobsen A.K., Duus B., Kjaer M. \& Magnusson S.P. 2004. Training-induced changes in muscle CSA, muscle strength, EMG, and rate of force development in elderly subjects after long-term unilateral disuse. Journal of Applied Physiology 97(5), 19541961.

Swash M. \& Fox K.P. 1972. Muscle spindle innervation in man. Journal of Anatomy 112(Pt 1), 61-80.

Tang P.F. \& Woollacott M.H. 1998. Inefficient postural responses to unexpected slips during walking in older adults. The Journals of Gerontology Series A, Biological Sciences and Medical Sciences 53(6), M471-480.

Taube W., Schubert M., Gruber M., Beck S., Faist M. \& Gollhofer A. 2006. Direct corticospinal pathways contribute to neuromuscular control of perturbed stance. Journal of Applied Physiology 101(2), 420-429. 
Tokuno C.D., Carpenter M.G., Thorstensson A. \& Cresswell A.G. 2006. The influence of natural body sway on neuromuscular responses to an unpredictable surface translation. Experimental Brain Research 174(1), 1928.

Tokuno C.D., Cresswell A.G., Thorstensson A. \& Carpenter M.G. 2010. Agerelated changes in postural responses revealed by support-surface translations with a long acceleration-deceleration interval. Clinical Neurophysiology 121(1), 109-117.

Tokuno C.D., Garland S.J., Carpenter M.G., Thorstensson A. \& Cresswell A.G. 2008. Sway-dependent modulation of the triceps surae H-reflex during standing. Journal of Applied Physiology 104(5), 1359-1365.

Topp R., Mikesky A., Wigglesworth J., Holt W., Jr. \& Edwards J.E. 1993. The effect of a 12-week dynamic resistance strength training program on gait velocity and balance of older adults. Gerontologist 33(4), 501-506.

Tracy B.L., Byrnes W.C. \& Enoka R.M. 2004. Strength training reduces force fluctuations during anisometric contractions of the quadriceps femoris muscles in old adults. Journal of Applied Physiology 96(4), 1530-1540.

Tsuruike M., Kitano K., Koceja D.M. \& Riley Z.A. 2012. Differential control of H-reflex amplitude in different weight-bearing conditions in young and elderly subjects. Clinical Neurophysiology 123(10), 2018-2024.

Upton A.R., McComas A.J. \& Sica R.E. 1971. Potentiation of "late" responses evoked in muscles during effort. Journal of Neurology, Neurosurgery and Psychiatry 34(6), 699-711.

Van Cutsem M., Duchateau J. \& Hainaut K. 1998. Changes in single motor unit behaviour contribute to the increase in contraction speed after dynamic training in humans. Journal of Physiology 513 ( Pt 1)295-305.

Vandervoort A.A. 2002. Aging of the human neuromuscular system. Muscle \& Nerve 25(1), 17-25.

Vandervoort A.A. \& Hayes K.C. 1989. Plantarflexor muscle function in young and elderly women. European Journal of Applied Physiology and Occupational Physiology 58(4), 389-394.

Vandervoort A.A. \& McComas A.J. 1986. Contractile changes in opposing muscles of the human ankle joint with aging. Journal of Applied Physiology 61(1), 361-367.

Vaportzis E., Georgiou-Karistianis N. \& Stout J.C. 2013. Dual task performance in normal aging: a comparison of choice reaction time tasks. PLoS One 8(3), e60265.

Weiss L.W., Cureton K.J. \& Thompson F.N. 1983. Comparison of serum testosterone and androstenedione responses to weight lifting in men and women. European Journal of Applied Physiology and Occupational Physiology 50(3), 413-419.

Winter D.A., Patla A.E., Rietdyk S. \& Ishac M.G. 2001. Ankle muscle stiffness in the control of balance during quiet standing. Journal of Neurophysiology 85(6), 2630-2633. 
Voigt M., Chelli F. \& Frigo C. 1998. Changes in the excitability of soleus muscle short latency stretch reflexes during human hopping after 4 weeks of hopping training. European Journal of Applied Physiology and Occupational Physiology 78(6), 522-532.

Wolfson L., Whipple R., Derby C., Judge J., King M., Amerman P., Schmidt J. \& Smyers D. 1996. Balance and strength training in older adults: intervention gains and Tai Chi maintenance. Journal of the American Geriatrics Society 44(5), 498-506.

Woollacott M.H. \& Shumway-Cook A. 1990. Changes in posture control across the life span--a systems approach. Physical Therapy 70(12), 799-807.

Yoon S., Tauchi K. \& Takamatsu K. 2007. Effect of ankle joint stiffness during eccentric phase in rebound jumps on ankle joint torque at midpoint. International Journal of Sports Medicine 28(1), 66-71.

Zehr P.E. 2002. Considerations for use of the Hoffmann reflex in exercise studies. European Journal of Applied Physiology 86(6), 455-468.

Zemková E. 2011. Assessment of balance in sport: Science and reality. Serbian Journal of Sports Sciences 5(4), 127-139.

Zemková E. \& Hamar D. 2008. The effect of proprioceptive stimulation of different duration on static and dynamic balance. International Journal of Applied Sport Sciences 20(2), 35-43.

Zemková E. \& Hamar D. 2010. The effect of task - oriented sensorimotor exercise on visual feedback control of body position and body balance. Human Movement 11(2), 119-123. 